\title{
Método directo de diseño basado en desplazamientos (DDBD) aplicado a sistemas mixtos de hormigón armado
}

\section{Direct displacement-based design method (DDBD) applied to reinforced concrete frame-wall systems}

\section{Alejandro Morales}

Escuela de Ingeniería Civil, Universidad de Valparaíso, General Cruz 222, Valparaíso, Chile, alejandro.morales@uv.cl

En este trabajo se presenta una aplicación del método directo de diseño basado en desplazamientos (DDBD) a un sistema mixto (muros y marcos resistiendo acciones sísmicas simultáneamente) de hormigón armado. Se expone el modelo matemático que fundamenta el método; la metodología para asignar esfuerzos a muros y marcos, para determinar el amortiguamiento del sistema y en general todas las herramientas necesarias para reducir la estructura a un sistema de un grado de libertad (SDOF). Con el método DDBD se analiza y diseña una estructura de 12 pisos, determinando: desplazamientos y deformaciones de entrepiso (drifts), cortes basales y esfuerzos en muros y marcos; se entregan las directrices para el diseño de los elementos de hormigón armado, principalmente las referentes a la rigidez considerada para la distribución de esfuerzos y al diseño por capacidad. Finalmente, se presentan los resultados obtenidos del análisis nolineal tiempo historia, desarrollado con el programa RUAUMOKO 2D, usando tres registros del terremoto del Maule consistentes con el espectro de desplazamiento contenido en el Decreto Supremo $N^{\circ} 61$ (zona 3, suelo tipo D). Estos análisis demuestran que el método DDBD proporciona una muy buena estimación de las demandas de deformación esperadas durante un sismo, validando la metodología utilizada.

Palabras clave: diseño basado en desplazamientos, análisis sísmico, estructuras de hormigón armado

\section{Introducción}

El método directo de diseño basado en desplazamientos (DDBD) fue desarrollado (Priestley et al., 2007) como respuesta a las deficiencias del diseño sísmico basado en fuerzas, ampliamente documentadas en la literatura

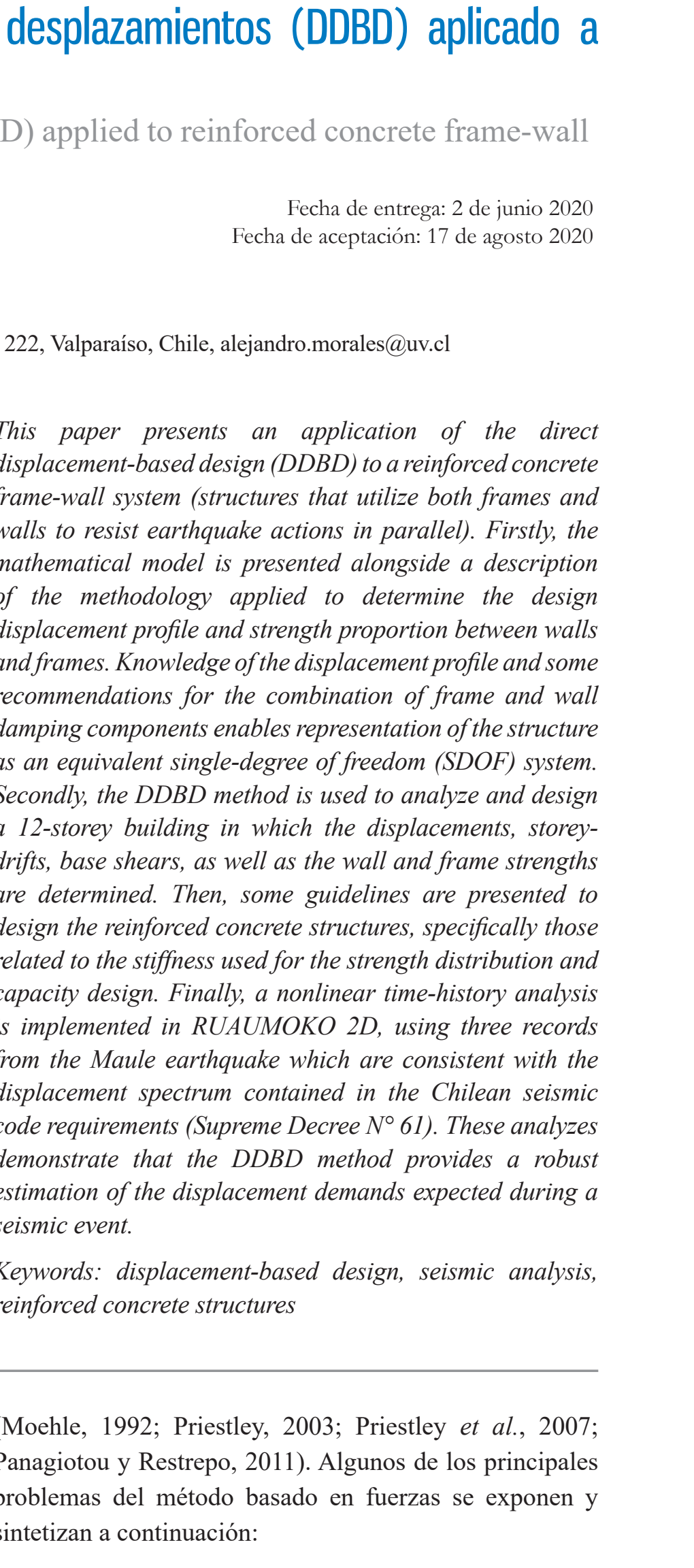

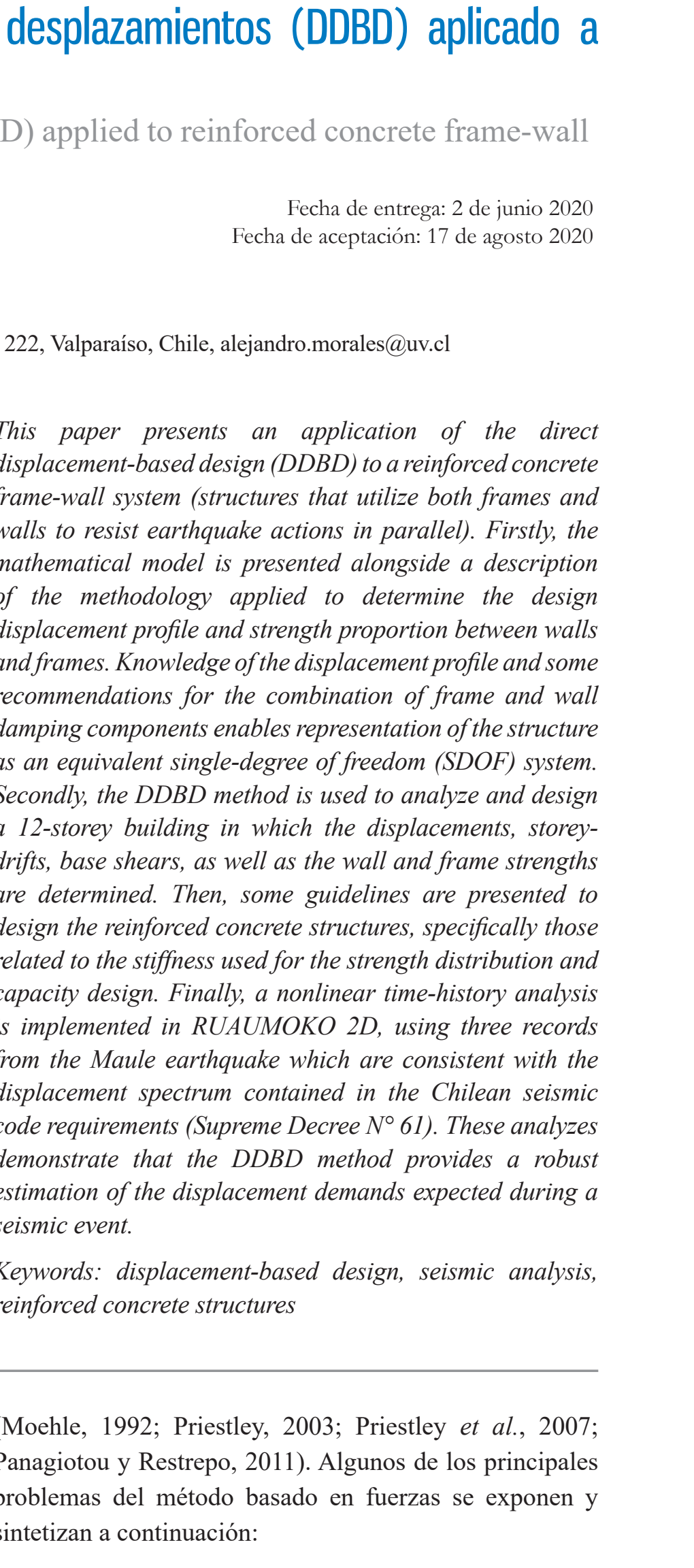

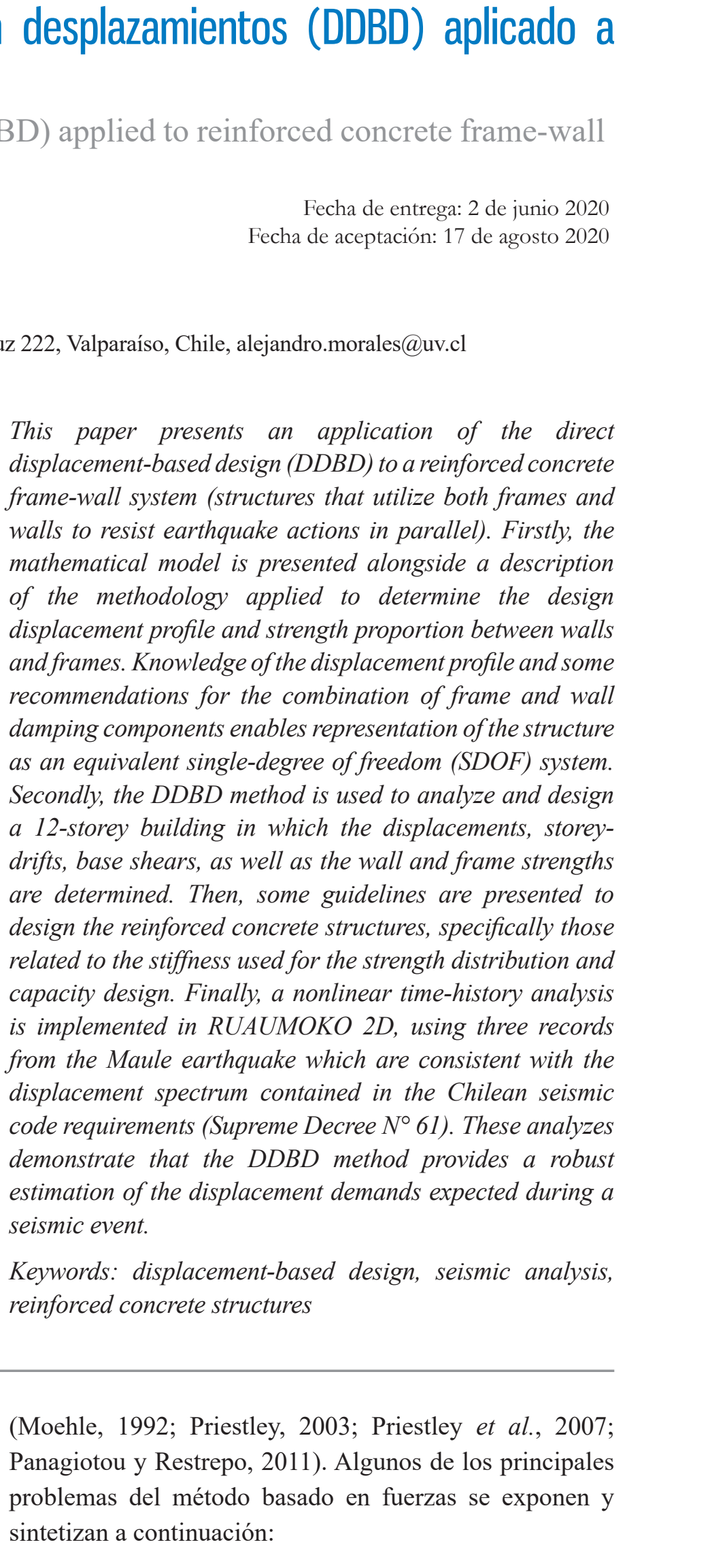

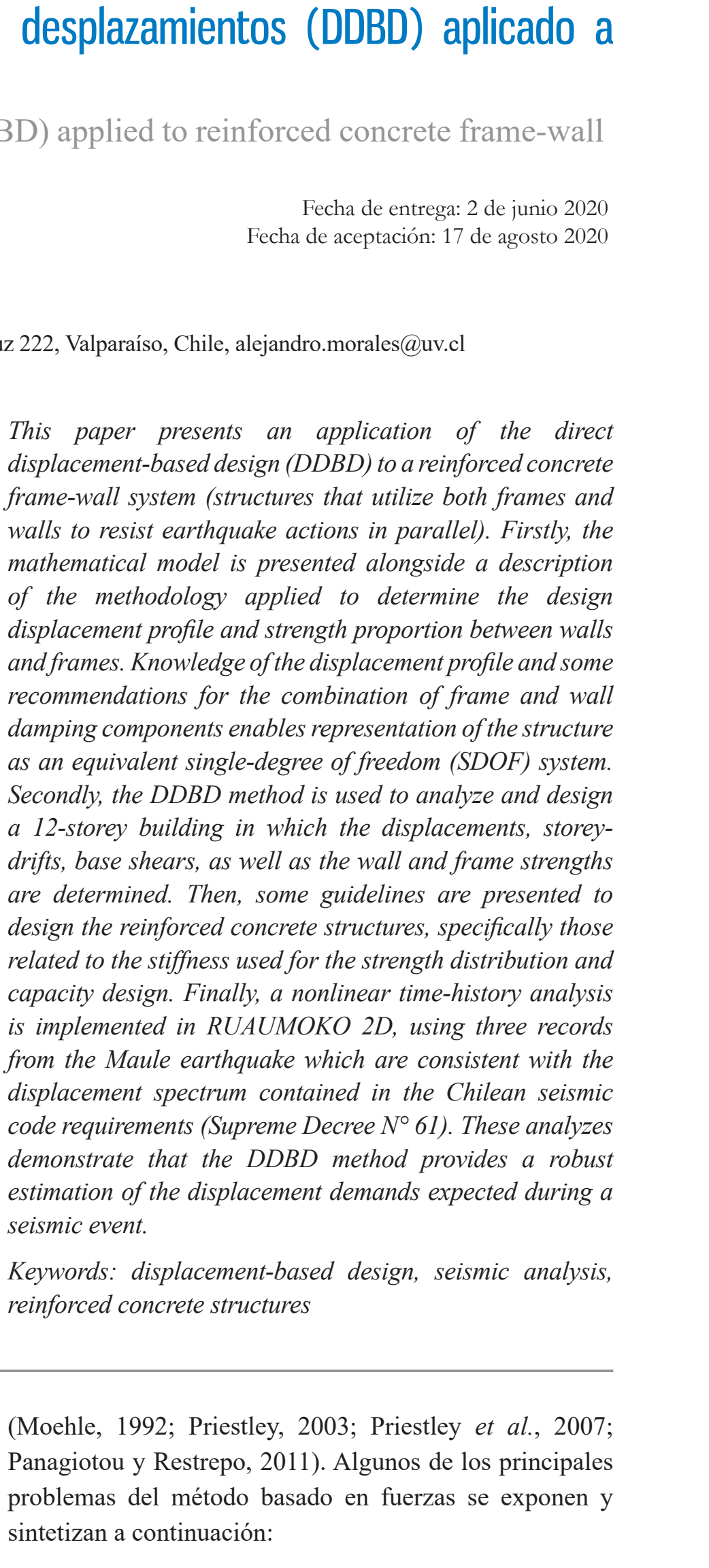

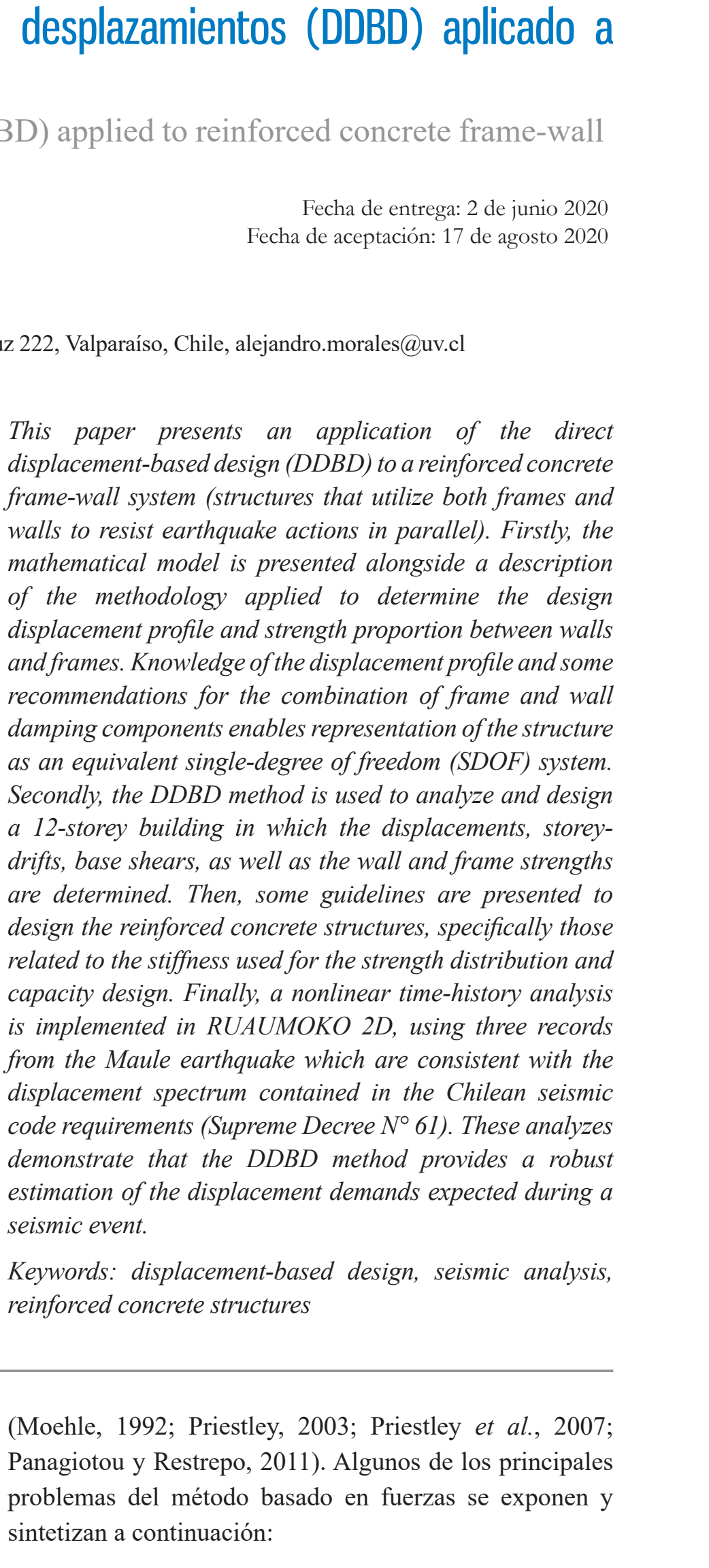

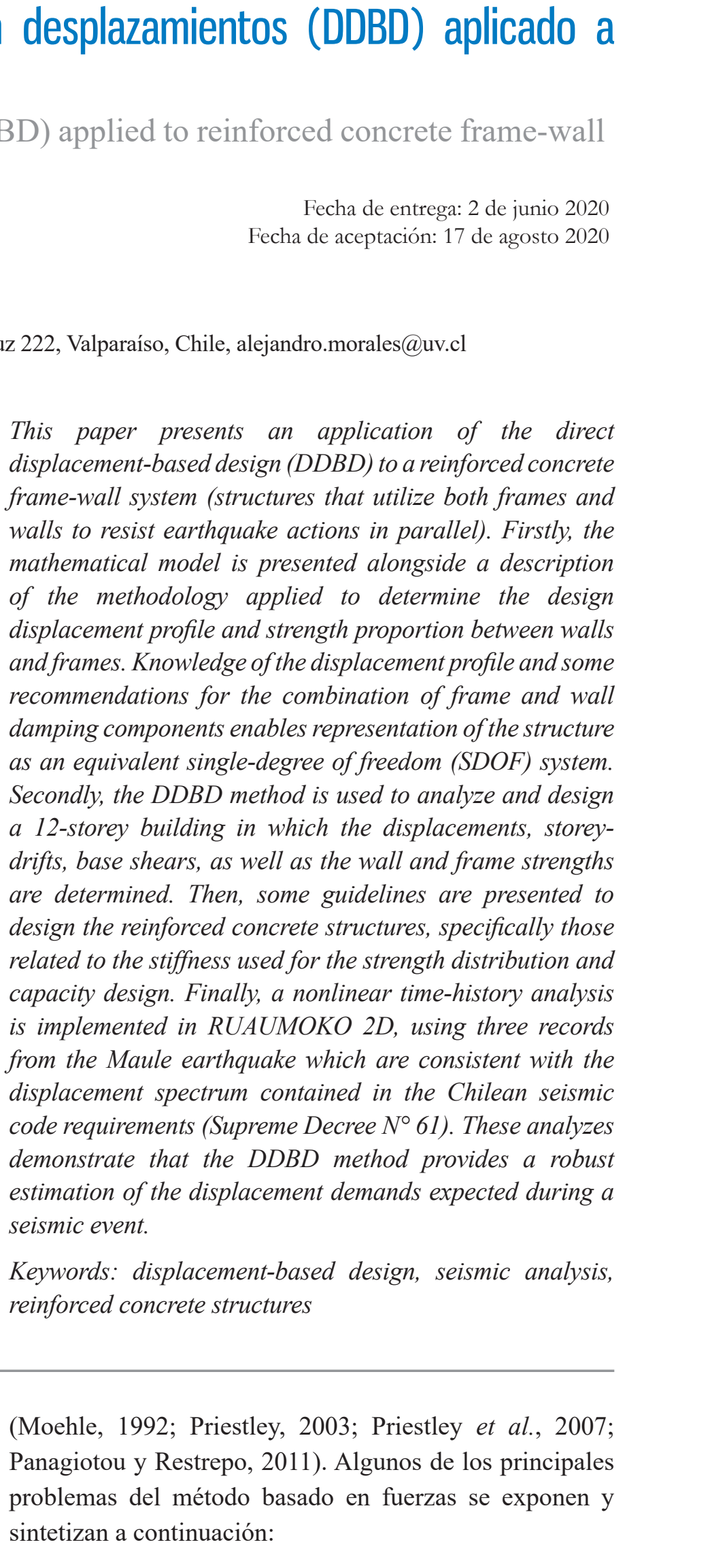

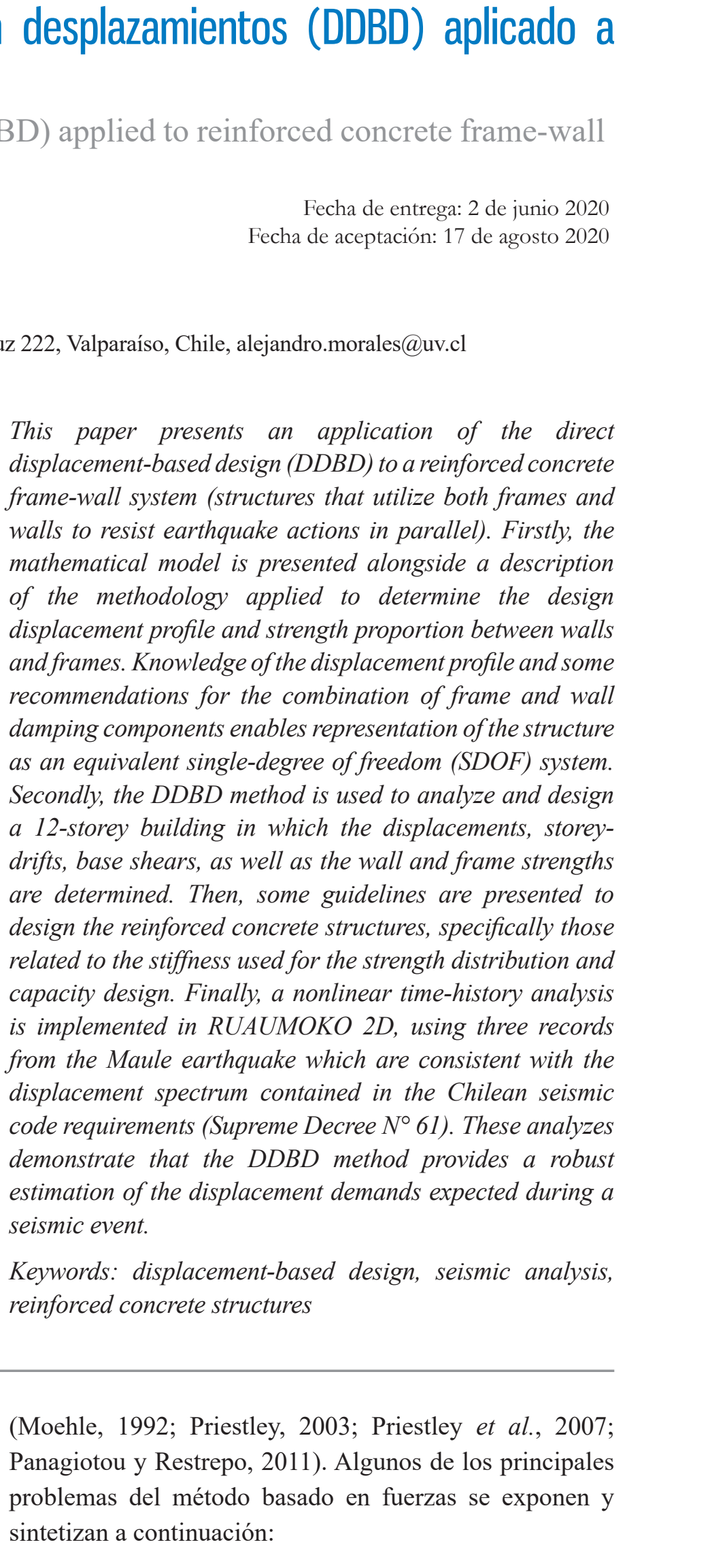

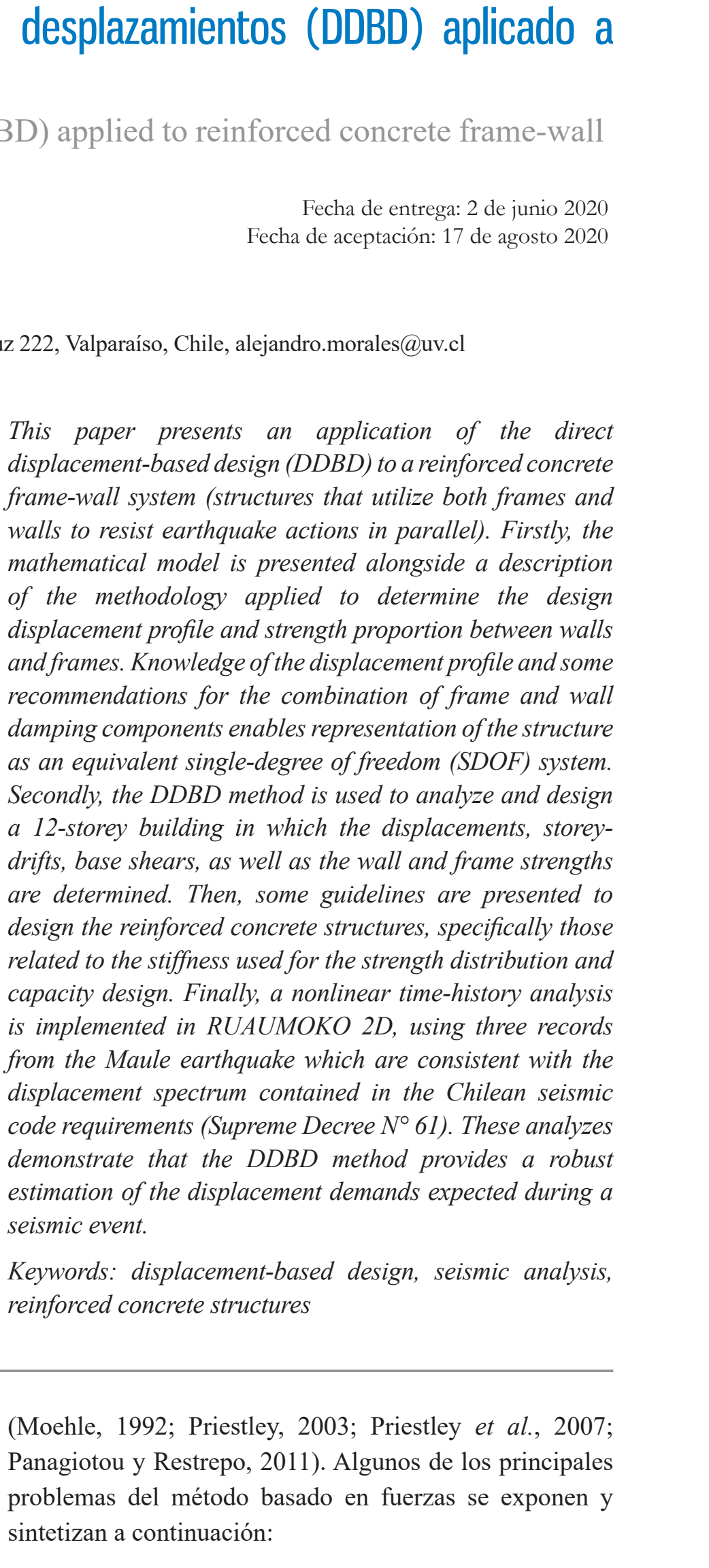

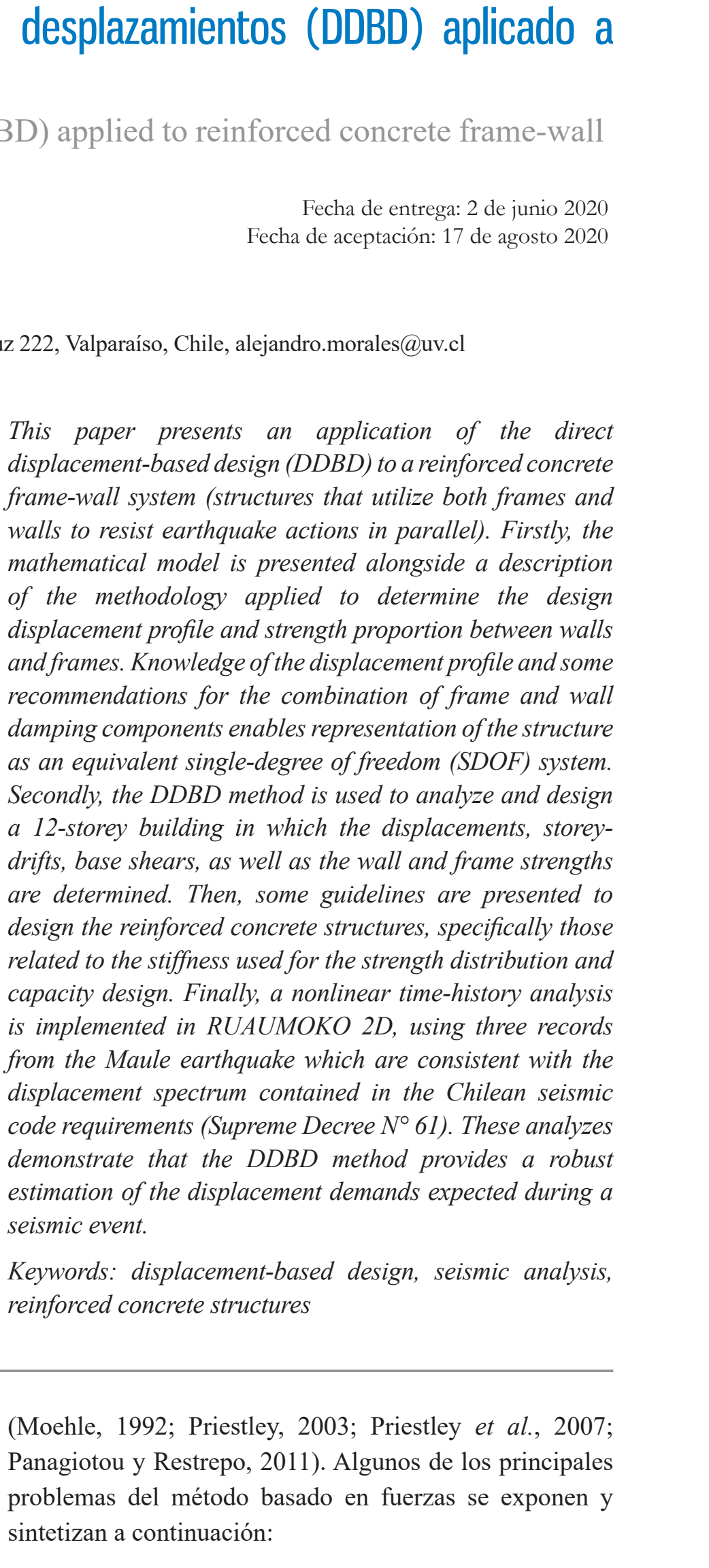

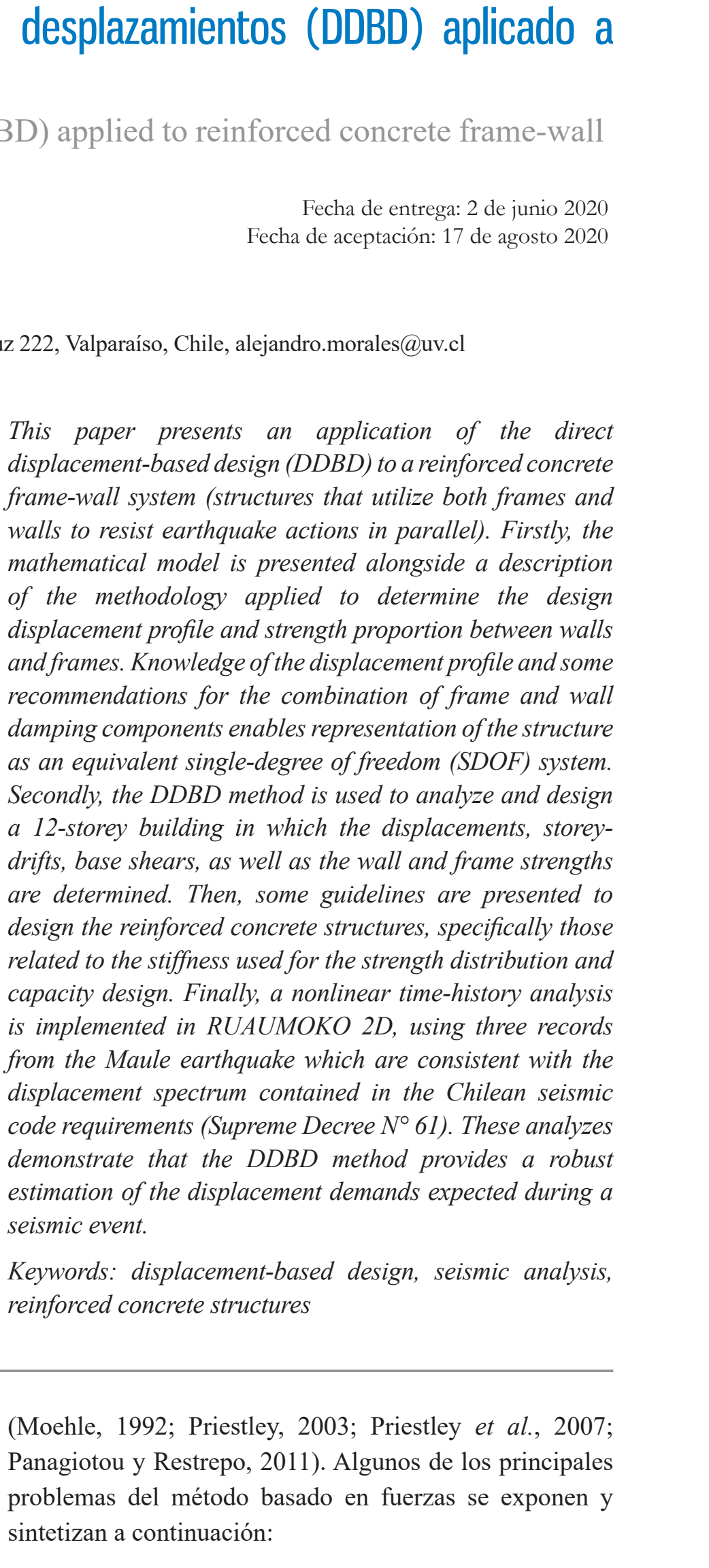

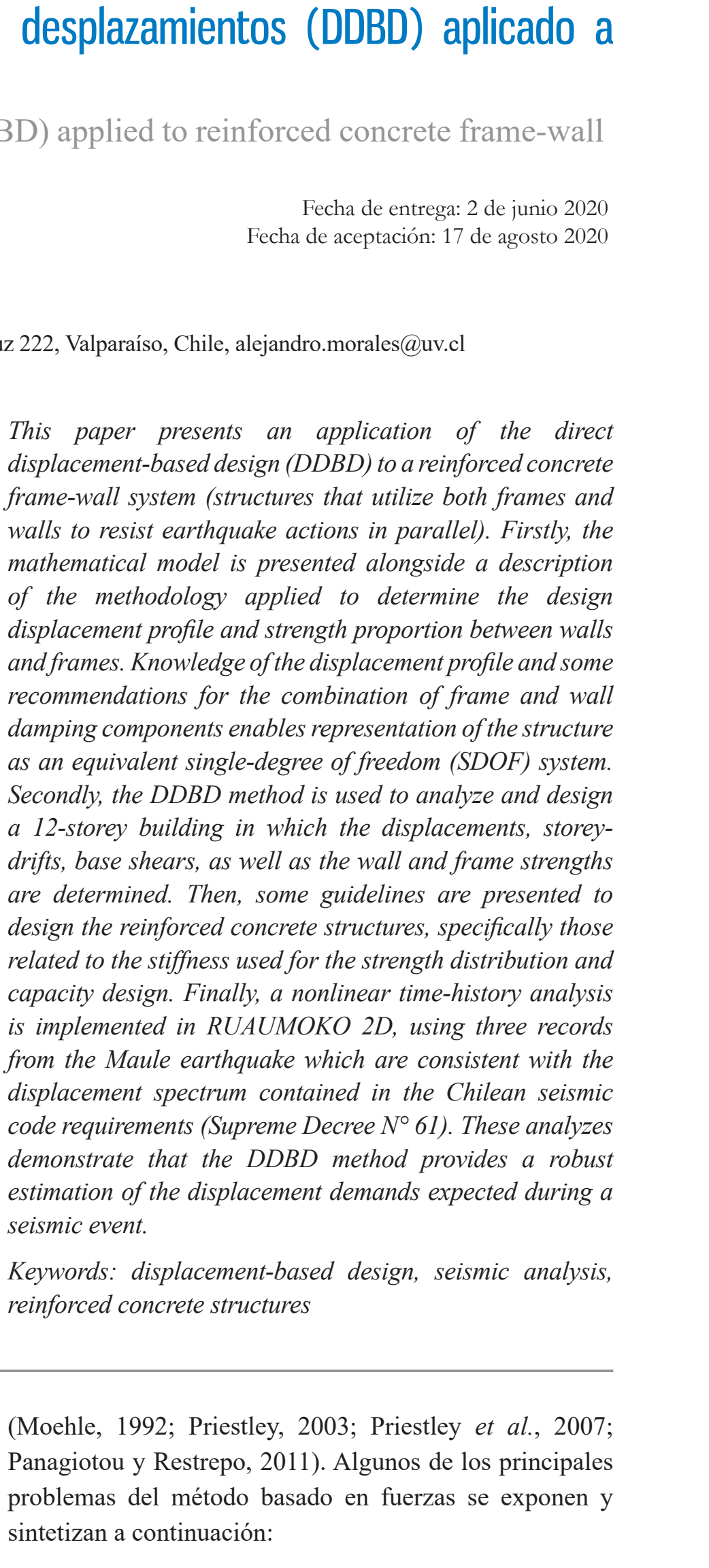

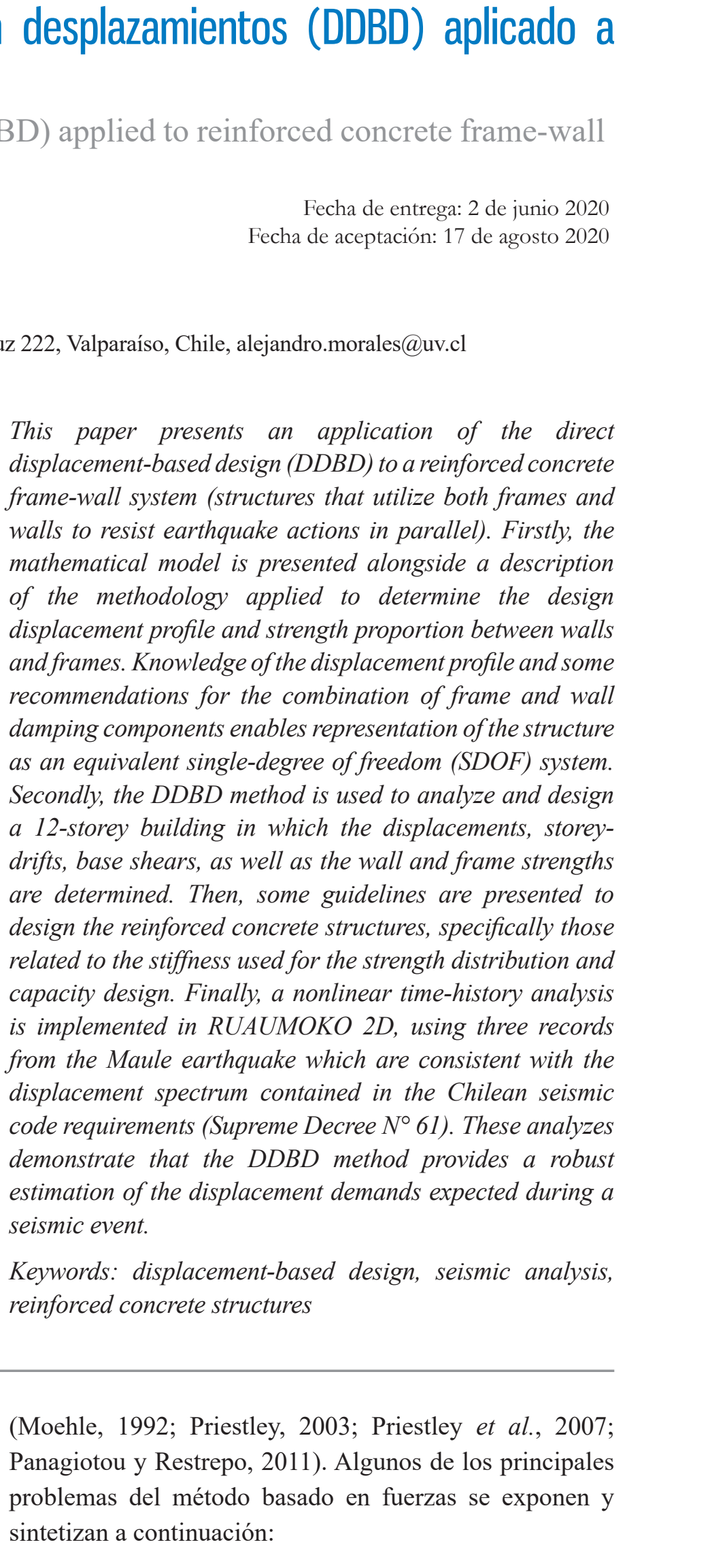

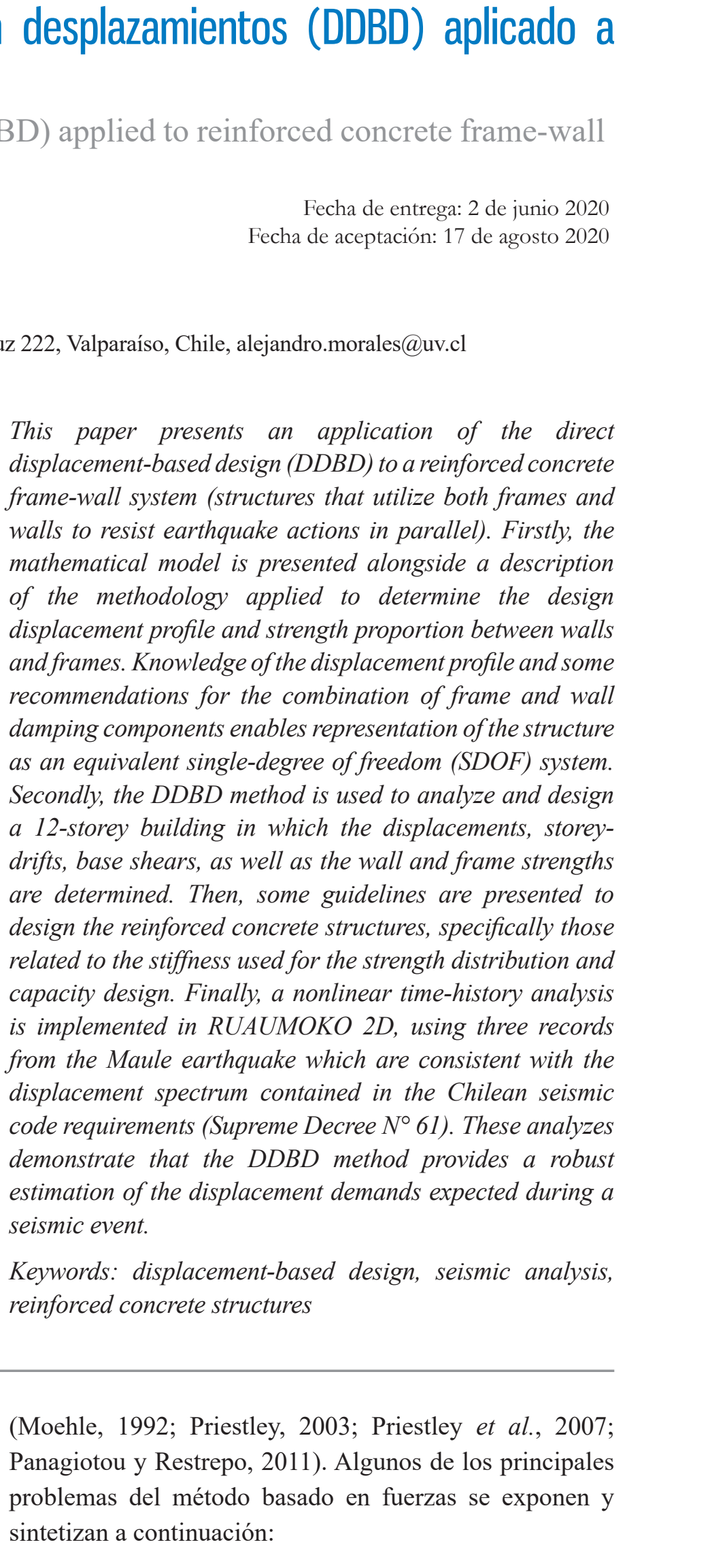

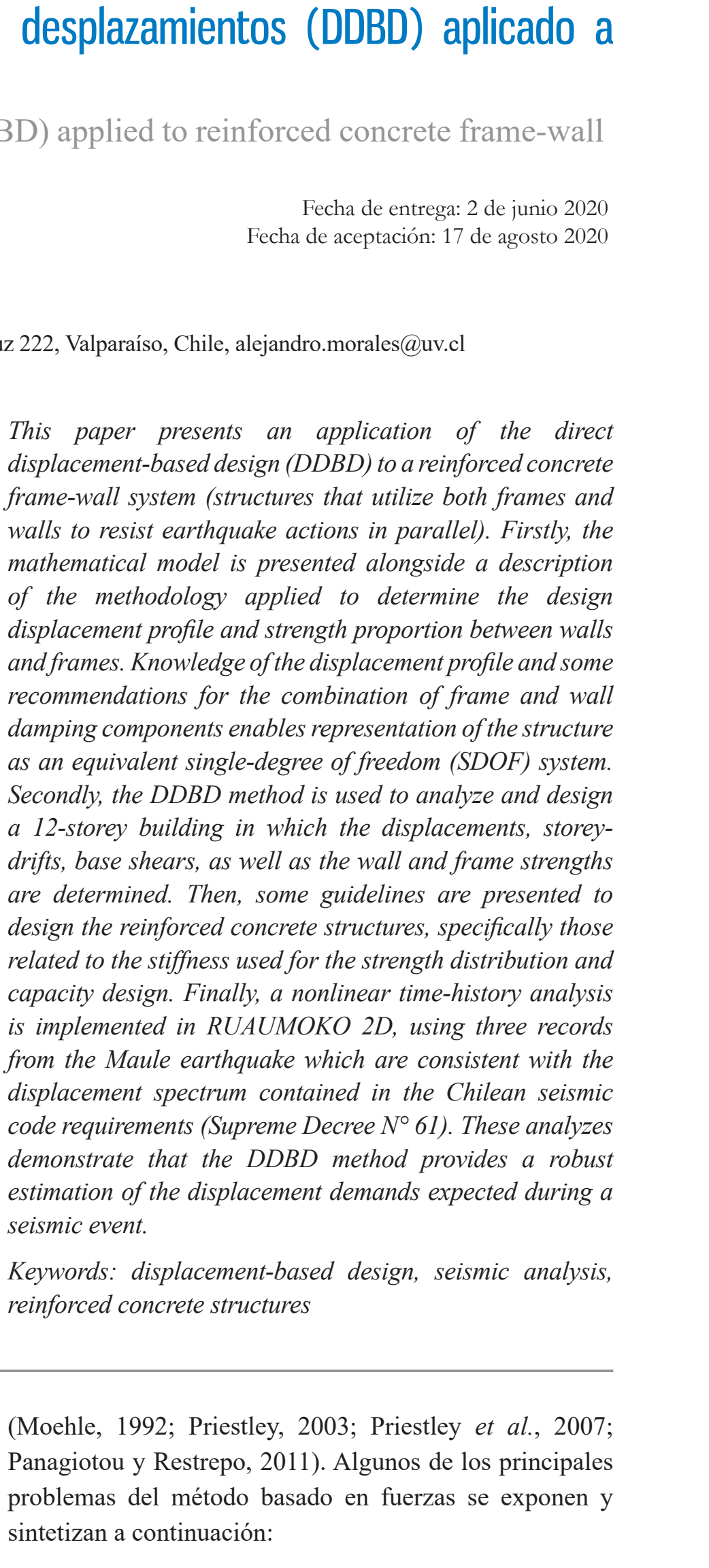

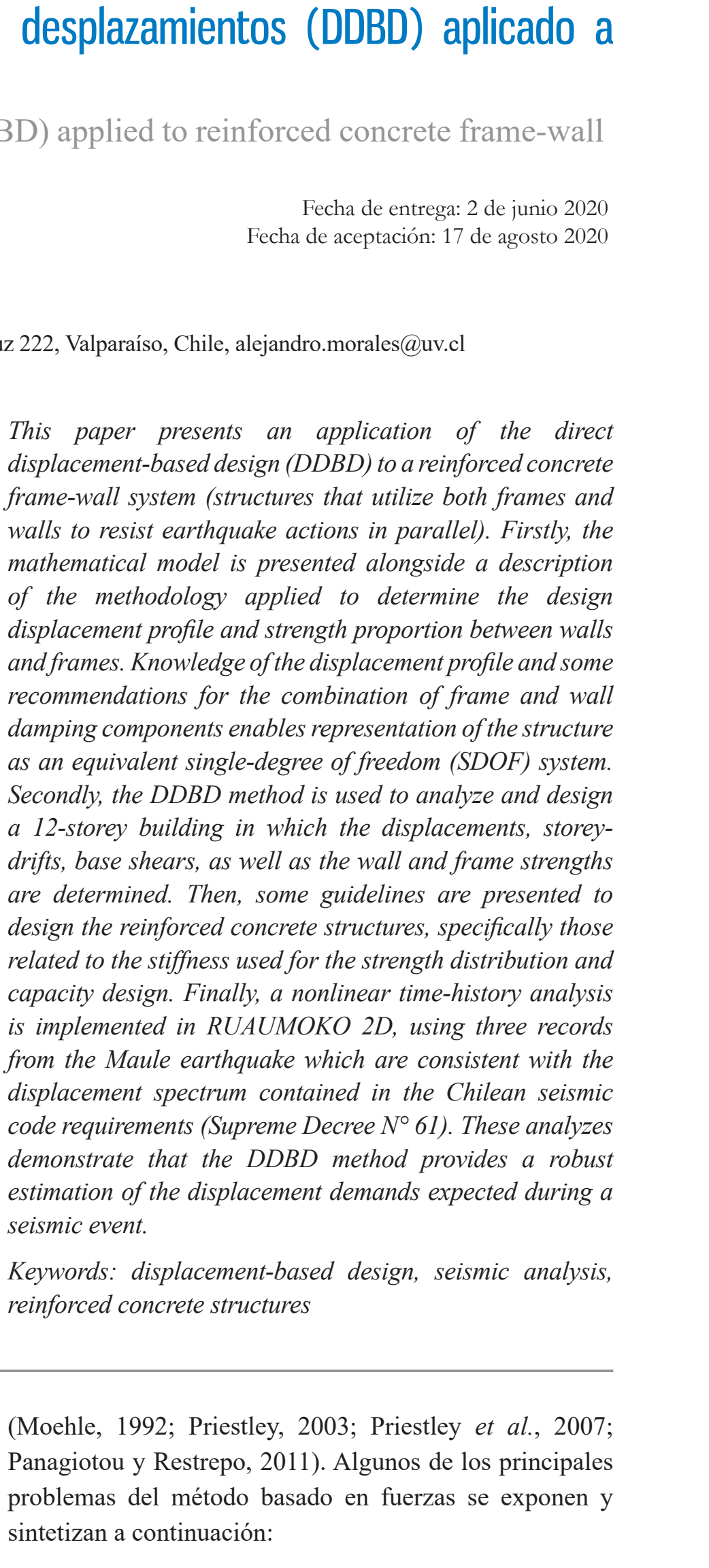

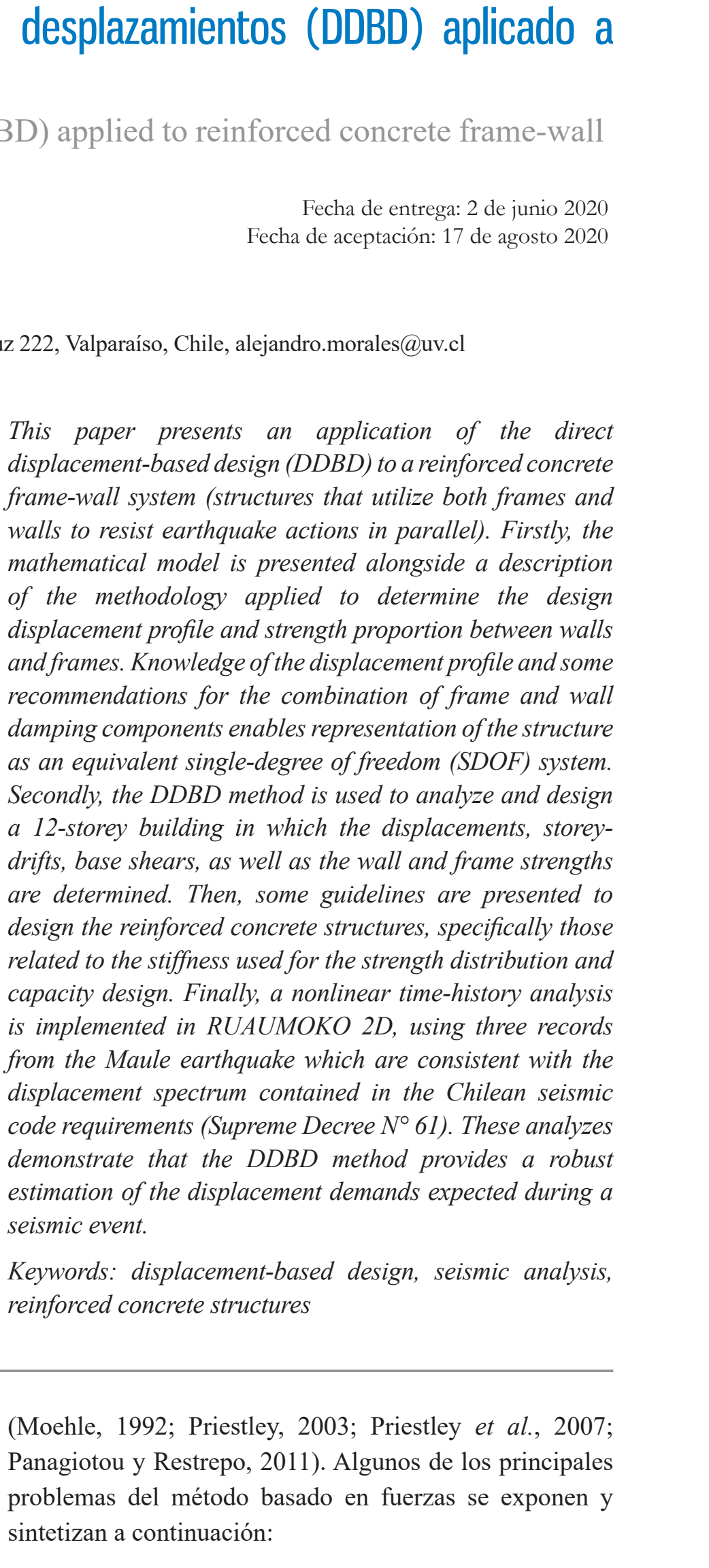

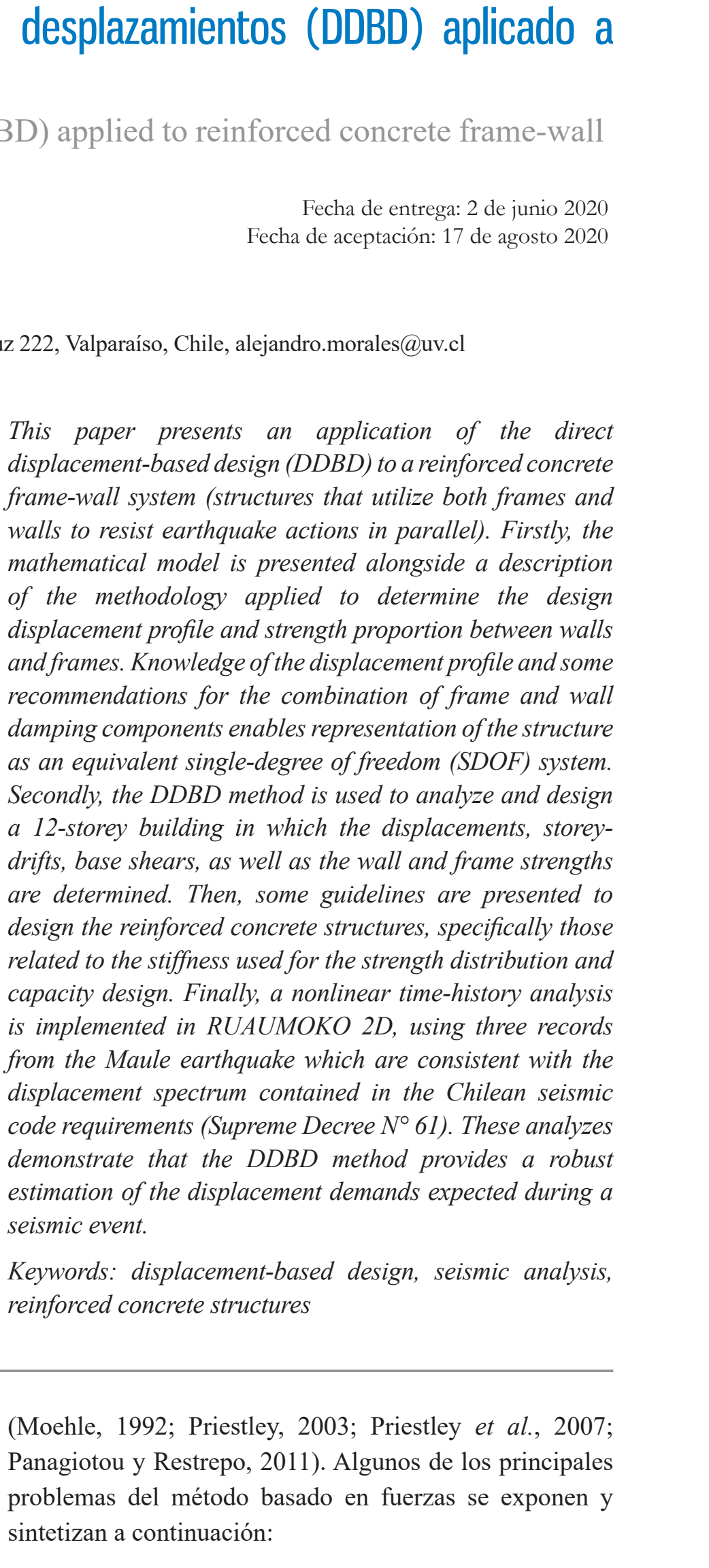

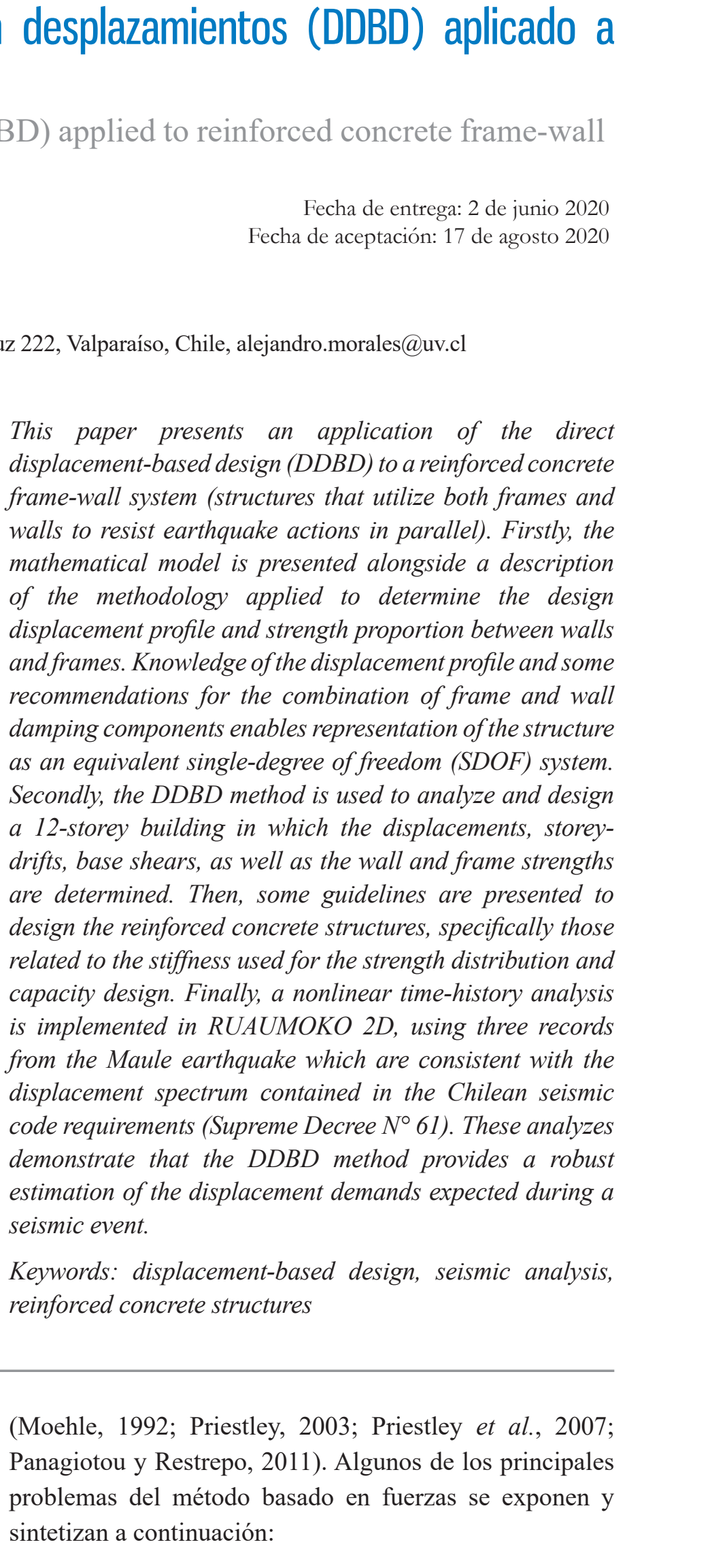

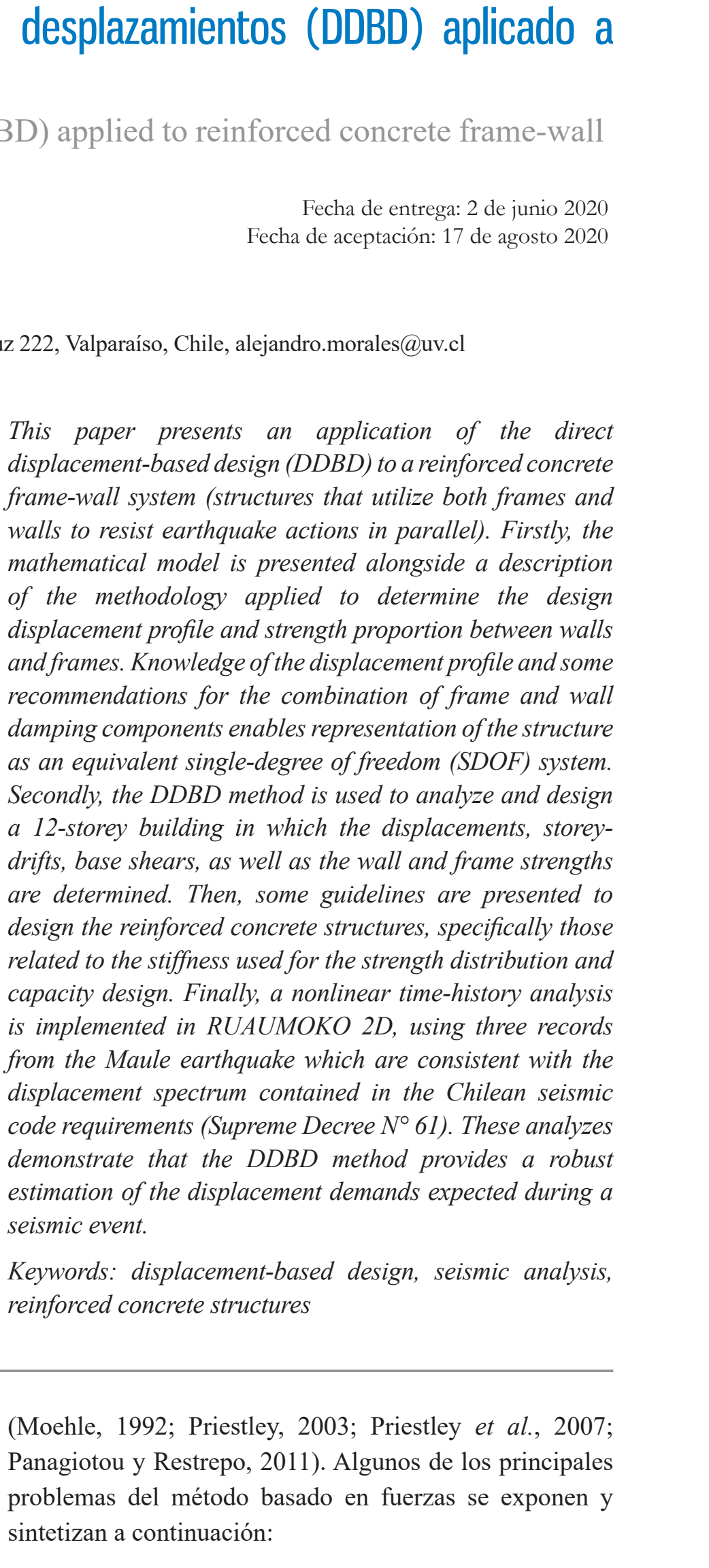

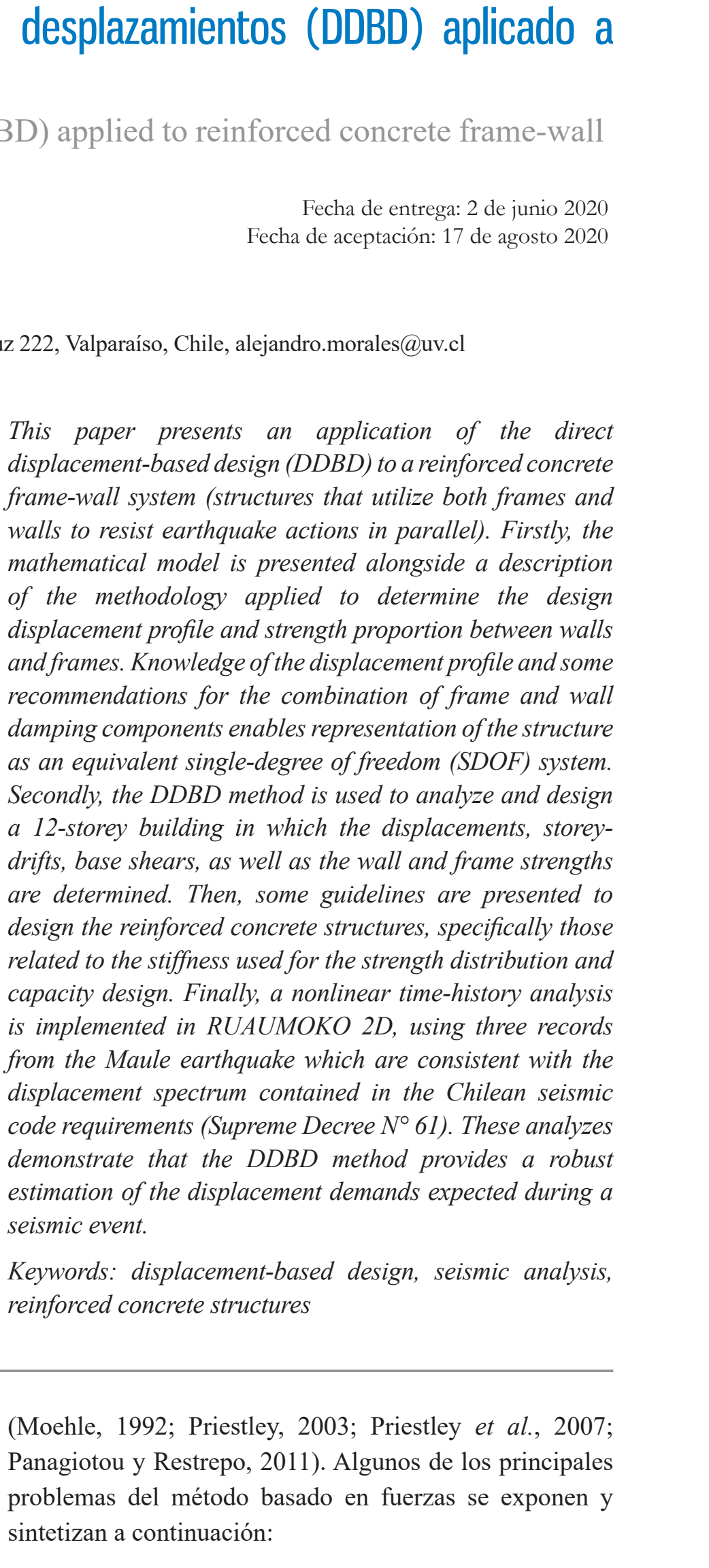

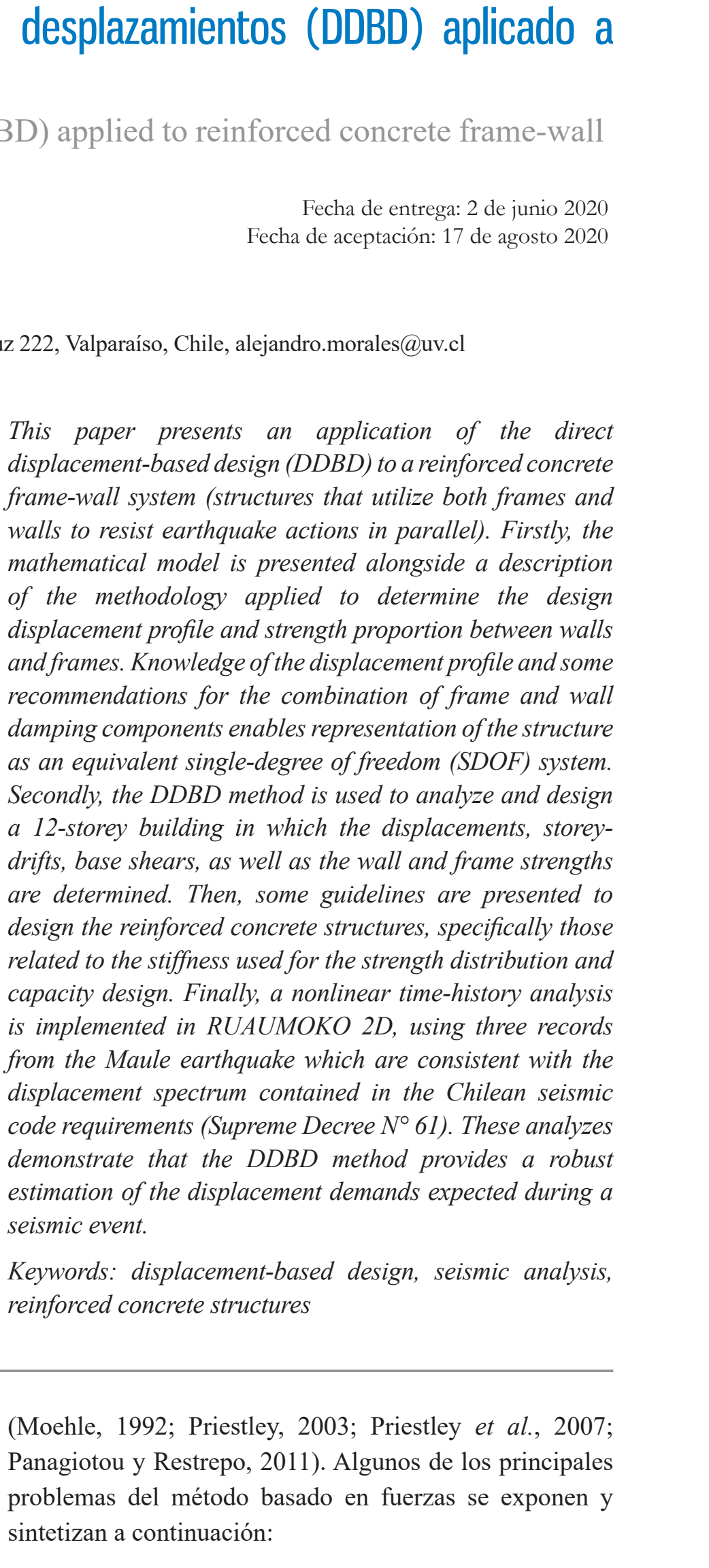

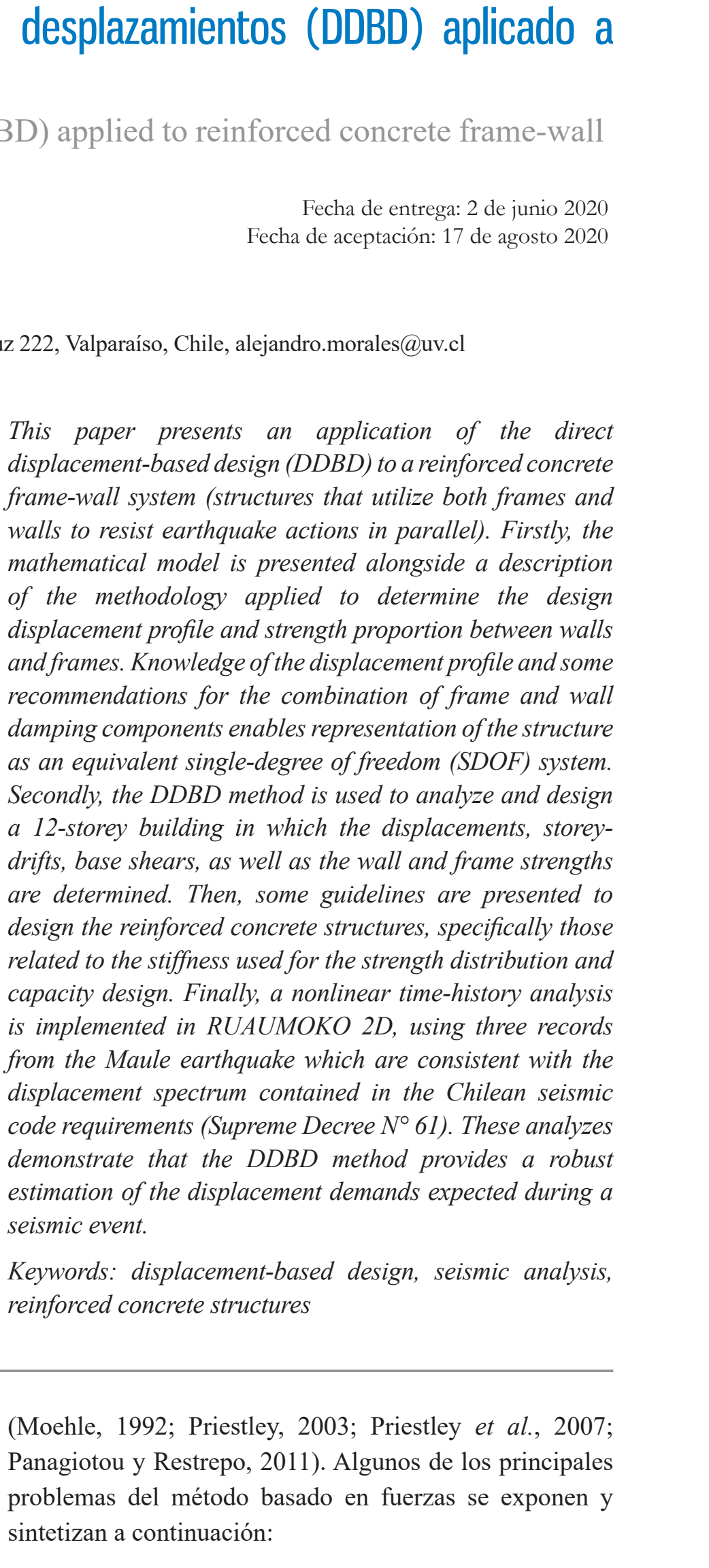

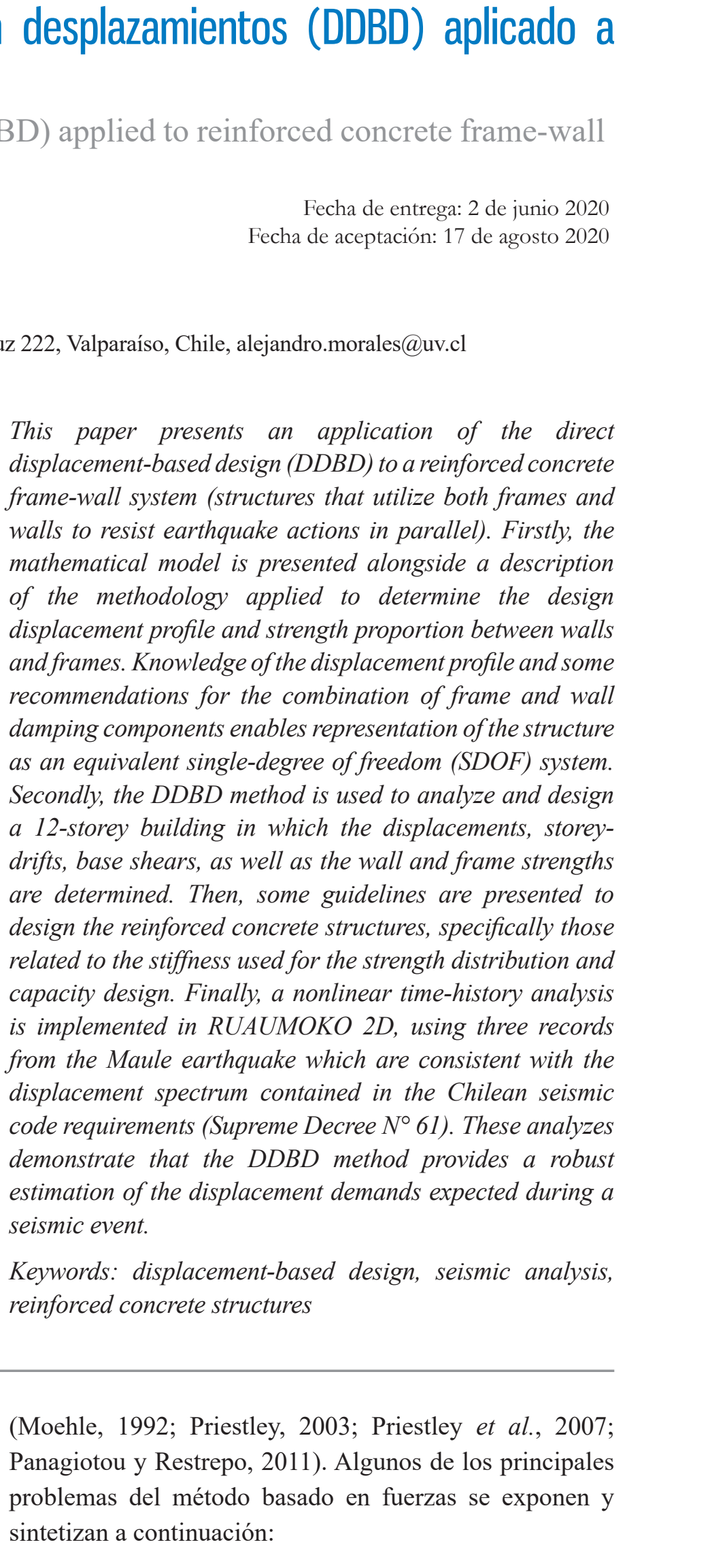

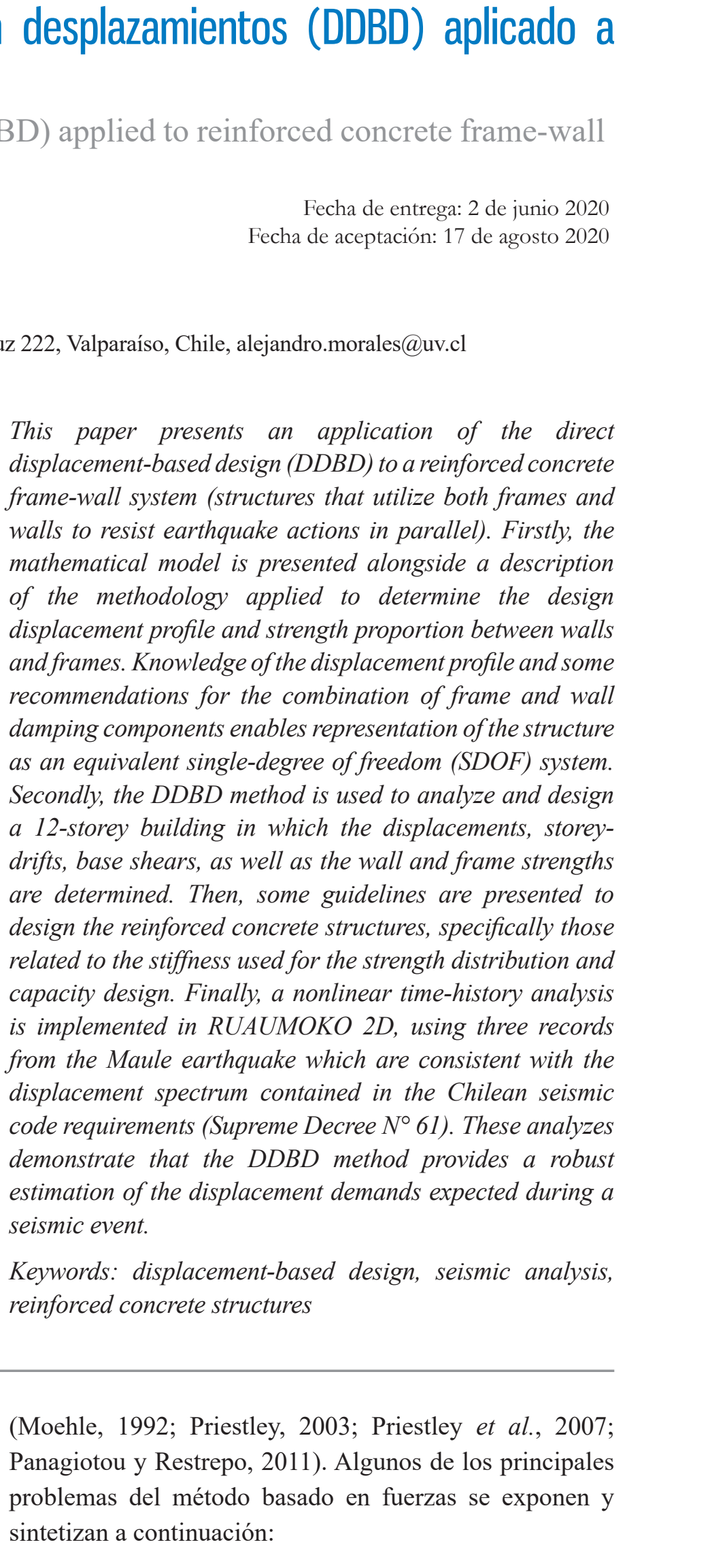

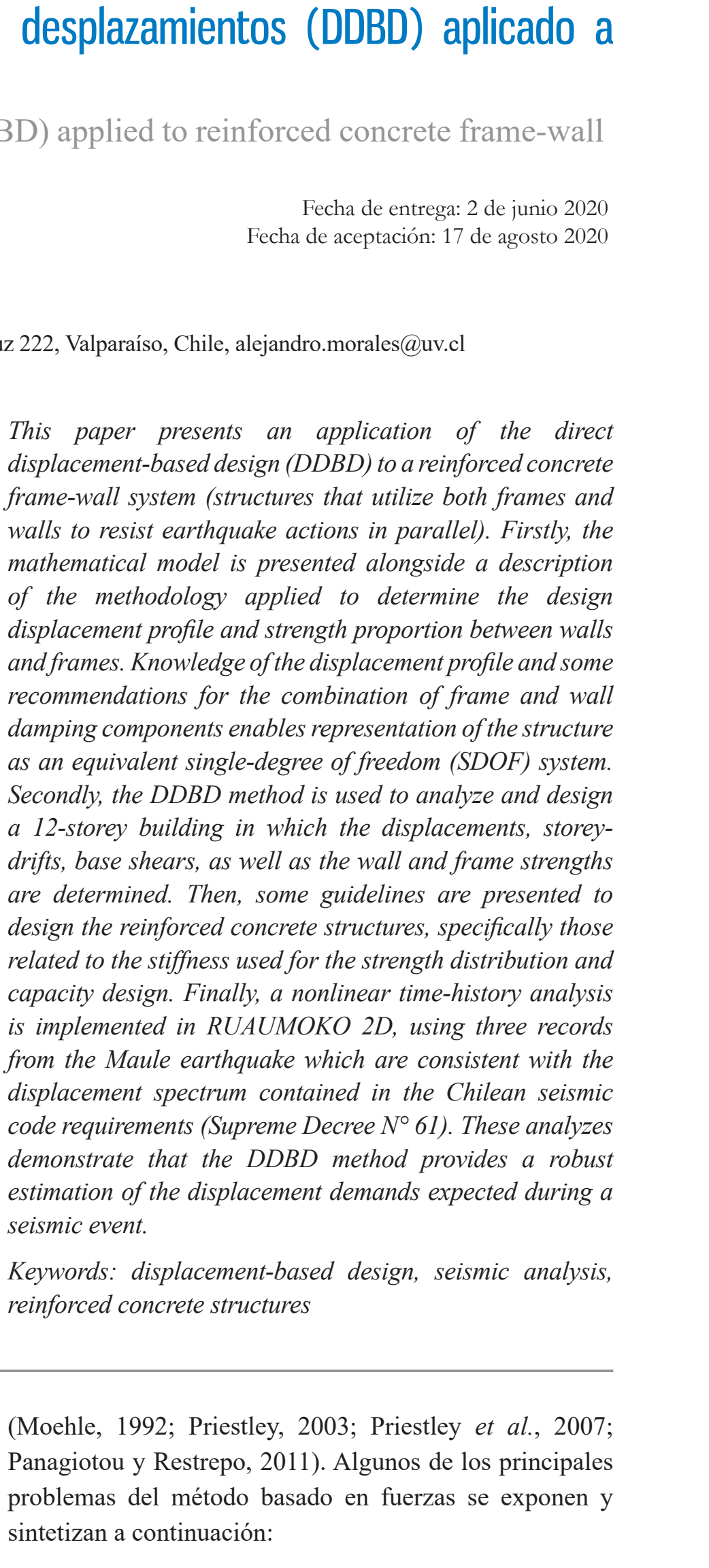

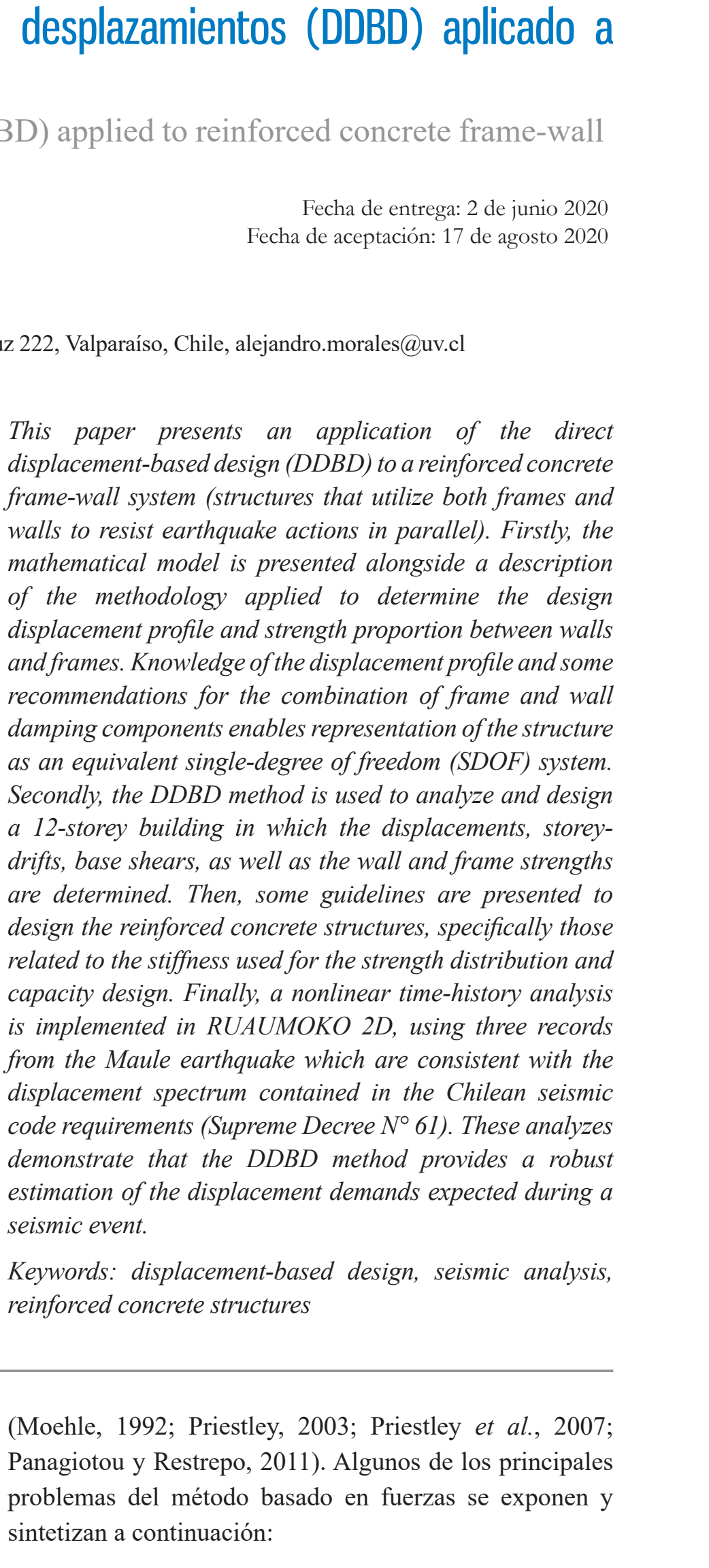

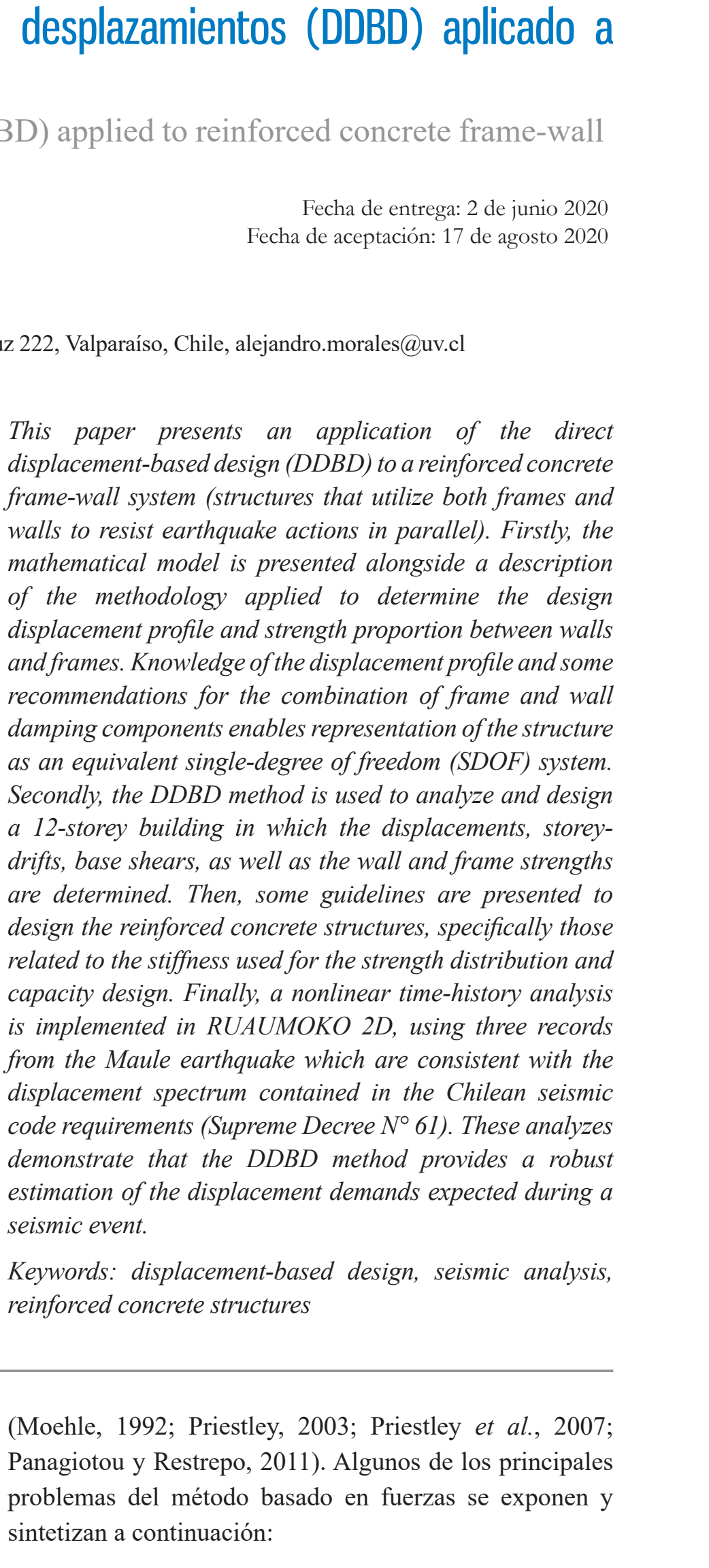

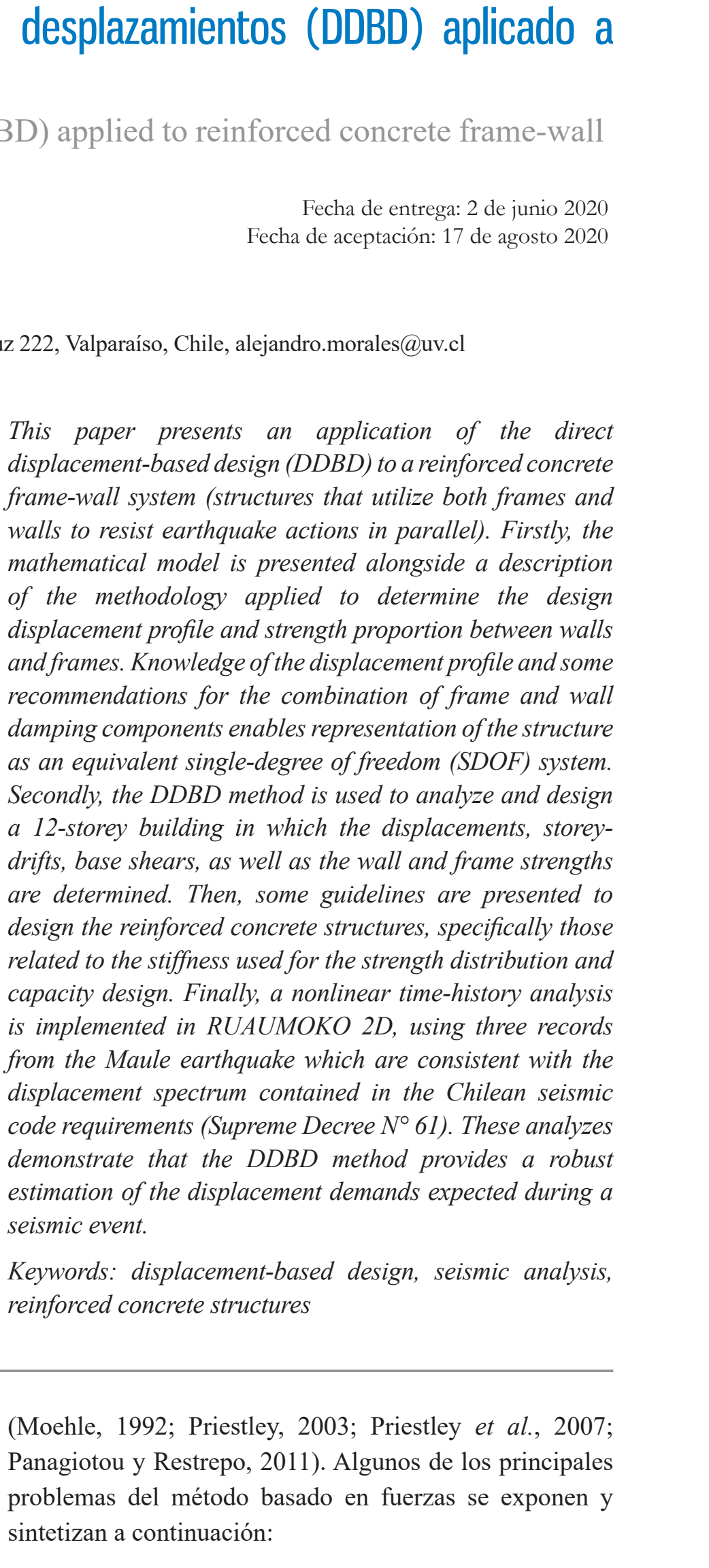

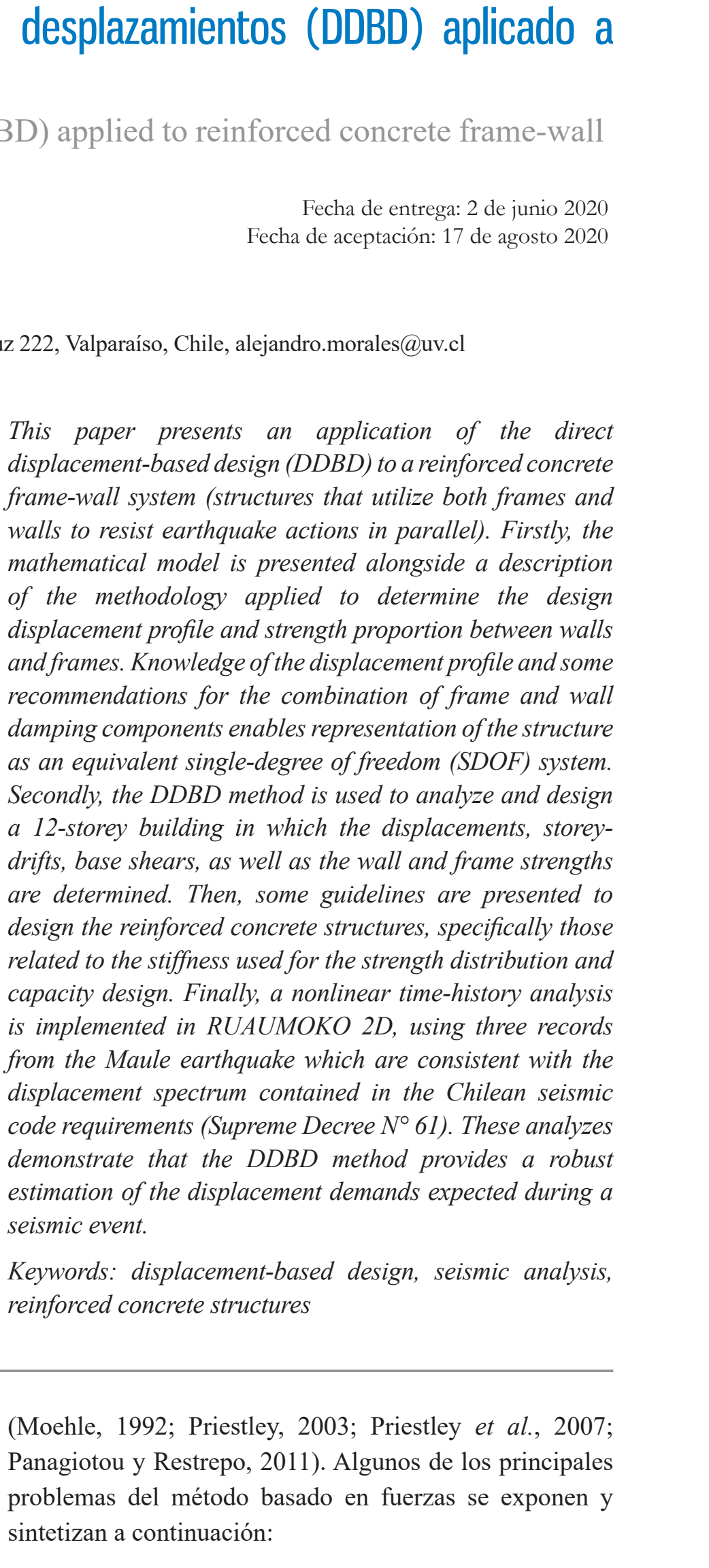

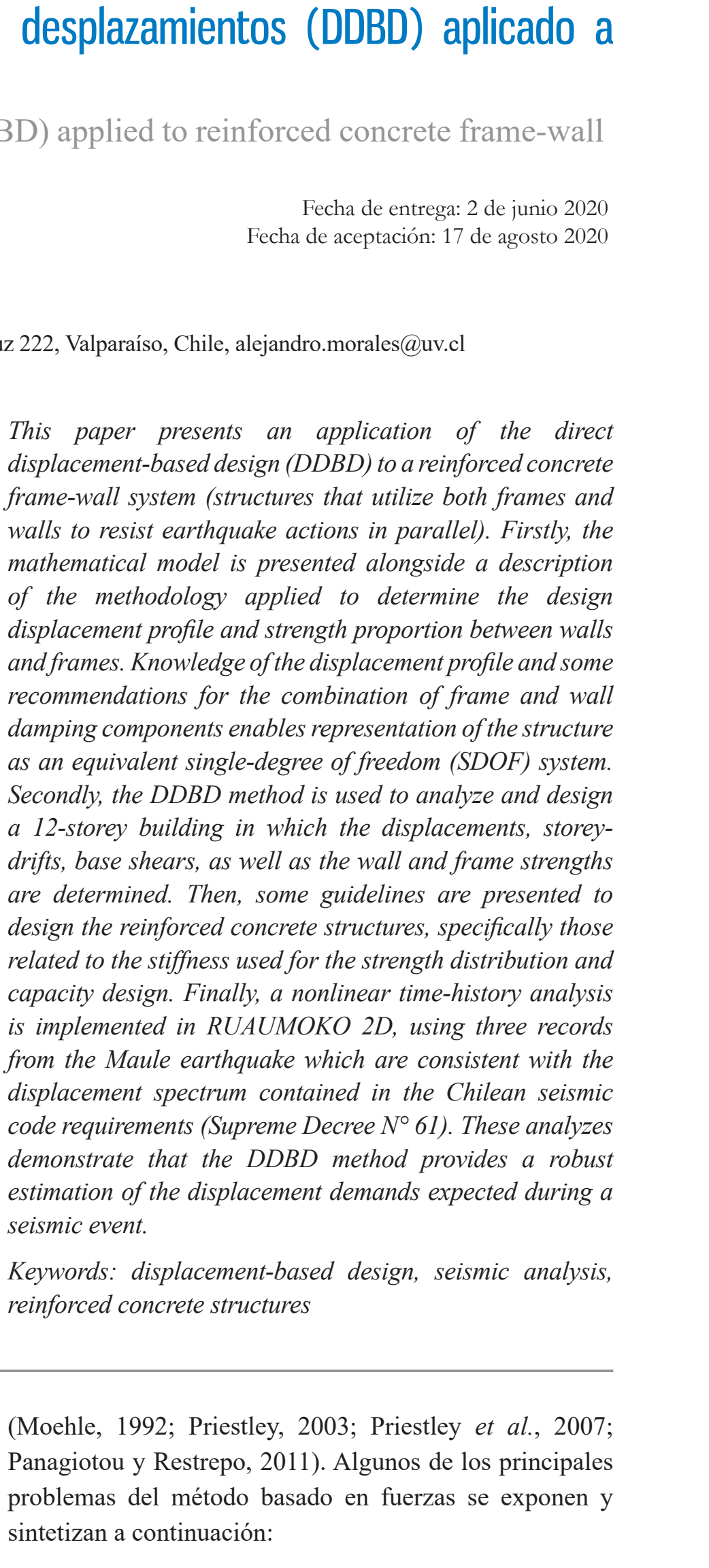

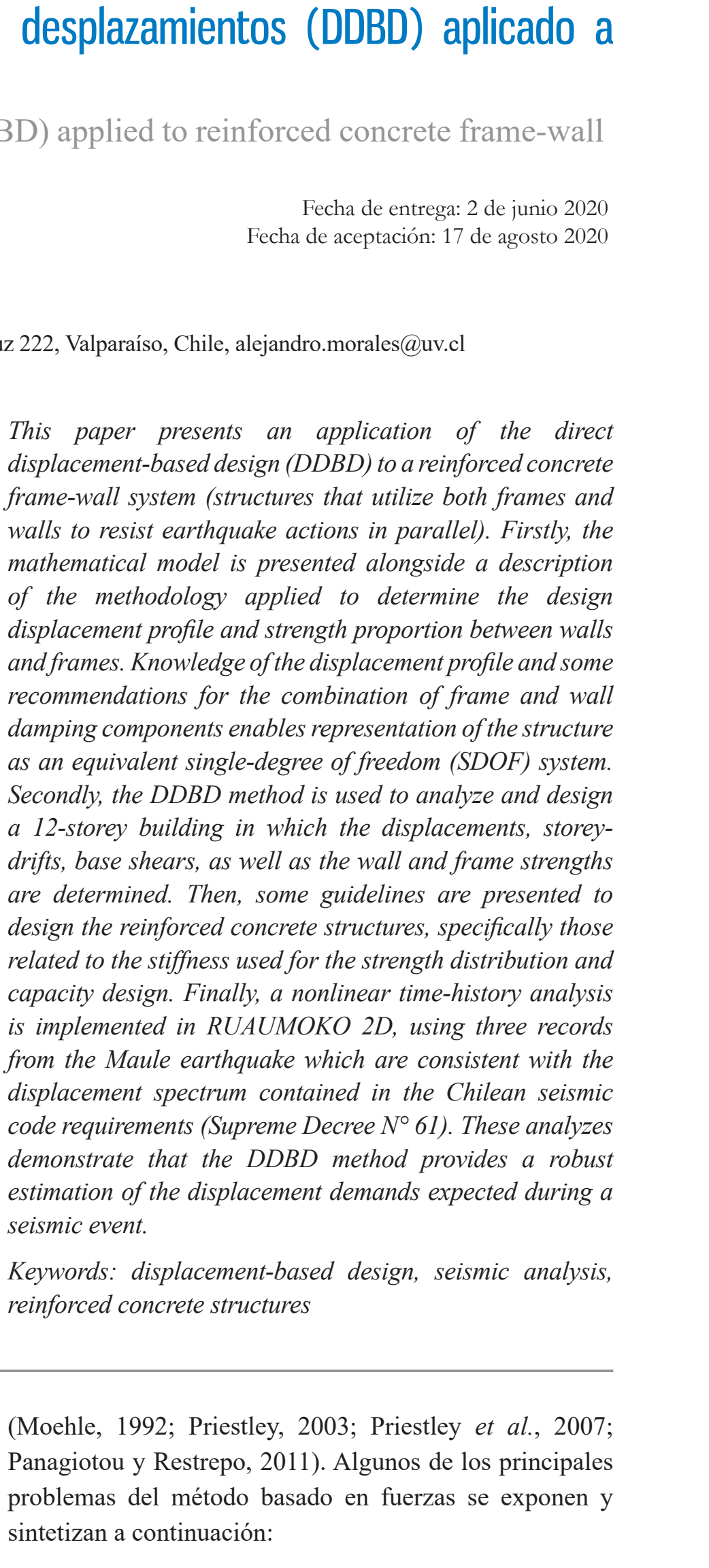

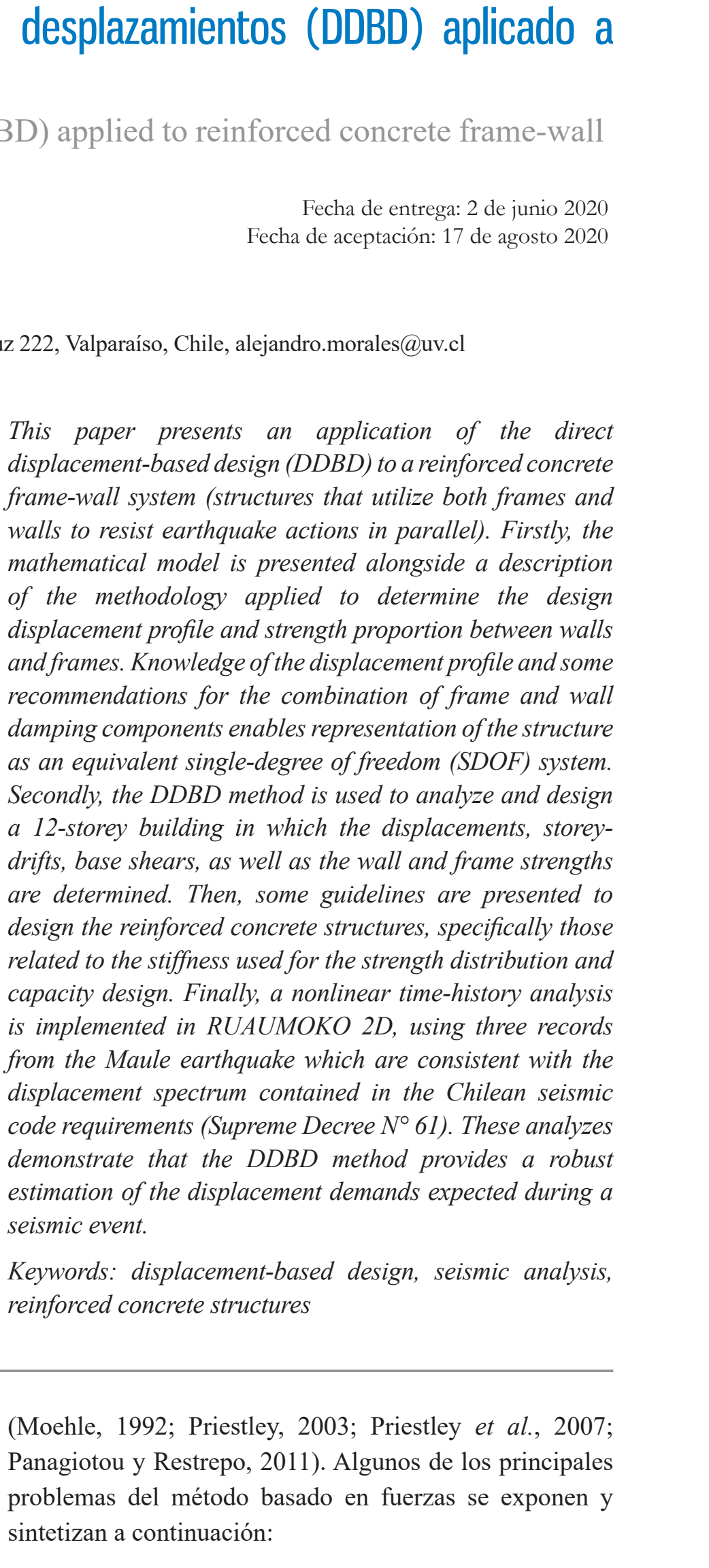

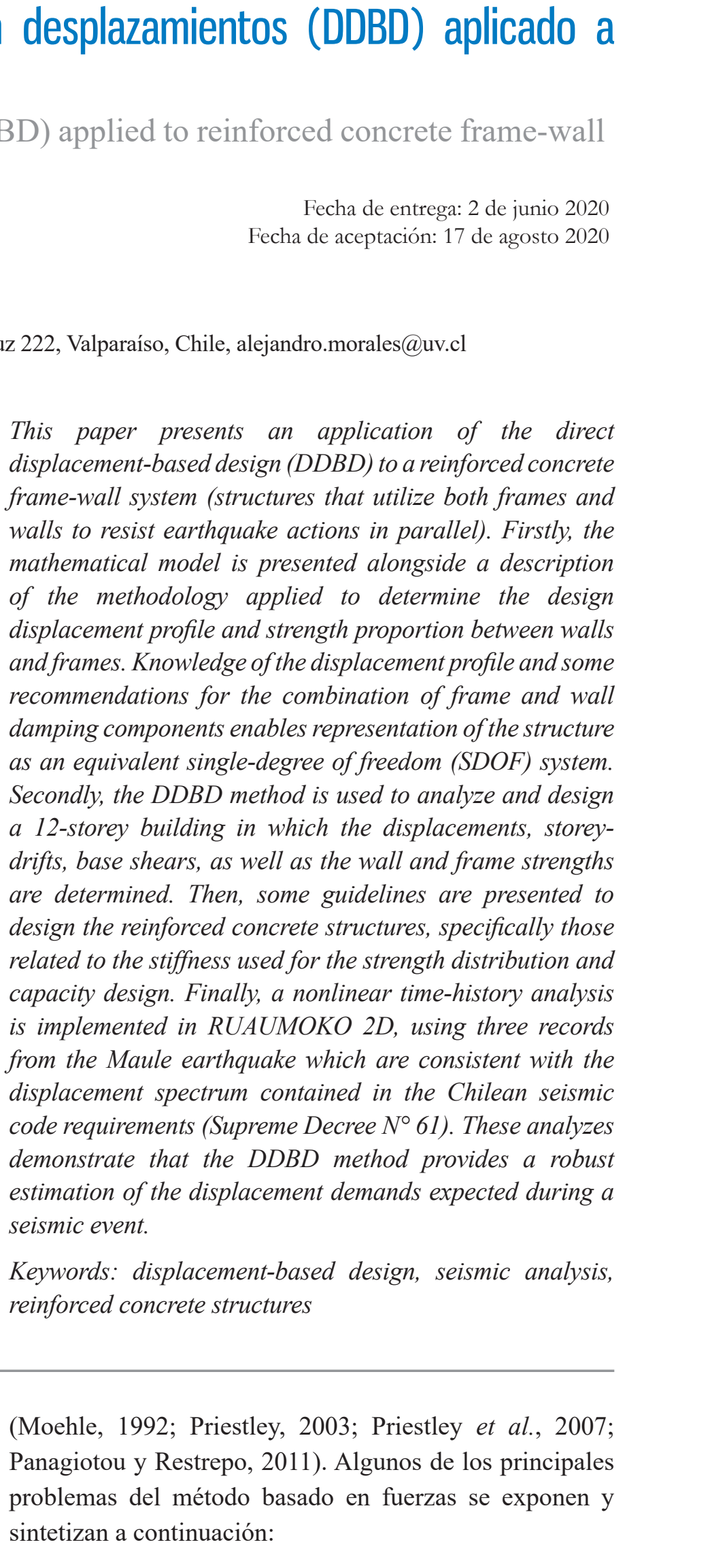

- El diseño basado en fuerzas requiere una estimación 
inicial de la rigidez del sistema estructural, con ésta se determina el período natural de la estructura y la distribución de los esfuerzos entre los distintos elementos estructurales que componen el sistema. Sin embargo, debido a que la rigidez depende de la resistencia de los elementos, ésta no se conoce hasta que el proceso de diseño está completo (Priestley et al., 2007).

- Se asume una rigidez flexural constante. En el caso del hormigón armado, esto implica que la curvatura de fluencia es proporcional a la resistencia a flexión (Figura 1a). La evidencia experimental en cambio muestra que este supuesto es erróneo, ya que la rigidez es proporcional a la resistencia y la curvatura de fluencia no depende de la misma (Priestley, 1998), ver Figura $1 b$. a)

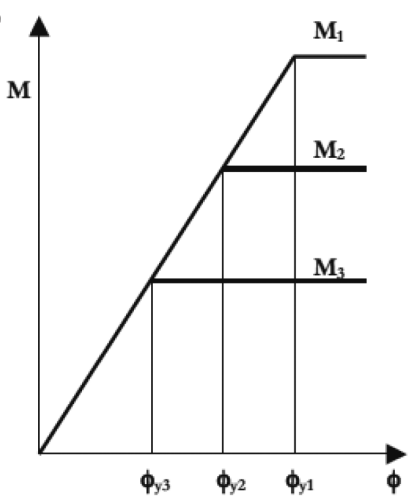

b)

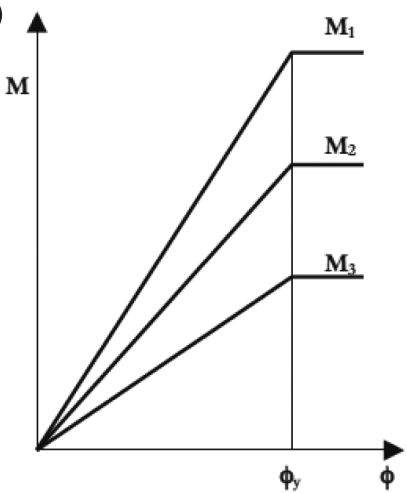

Figura 1: Relación momento-curvatura: (a) supuesto de diseño basado en fuerzas (rigidez constante) y (b) condición realista, curvatura de fluencia constante (Priestley, 2003).

- Los esfuerzos de los distintos elementos estructurales dentro de un sistema se asignan en función de la rigidez inicial. Incluso si se conoce con exactitud, su utilización asume de manera errónea que los distintos elementos pueden ser forzados a fluir al mismo tiempo. La Figura 2 muestra los resultados reportados por Beyer et al. (2014), estos ilustran cómo se distribuyen los esfuerzos entre los elementos estructurales (Figura 2a), de distintas rigideces (o longitudes), dentro de un sistema estructural. Las Figuras $2 b, 2 c$ y $2 d$ muestran la relación corte basal versus deformación lateral para muro corto (menos rígido), muro largo (más rígido) y del sistema completo, respectivamente. Se observa que la fluencia de los distintos elementos estructurales ocurre a niveles distintos de deformación lateral (o en distintos instantes durante la respuesta). (a)

(c)
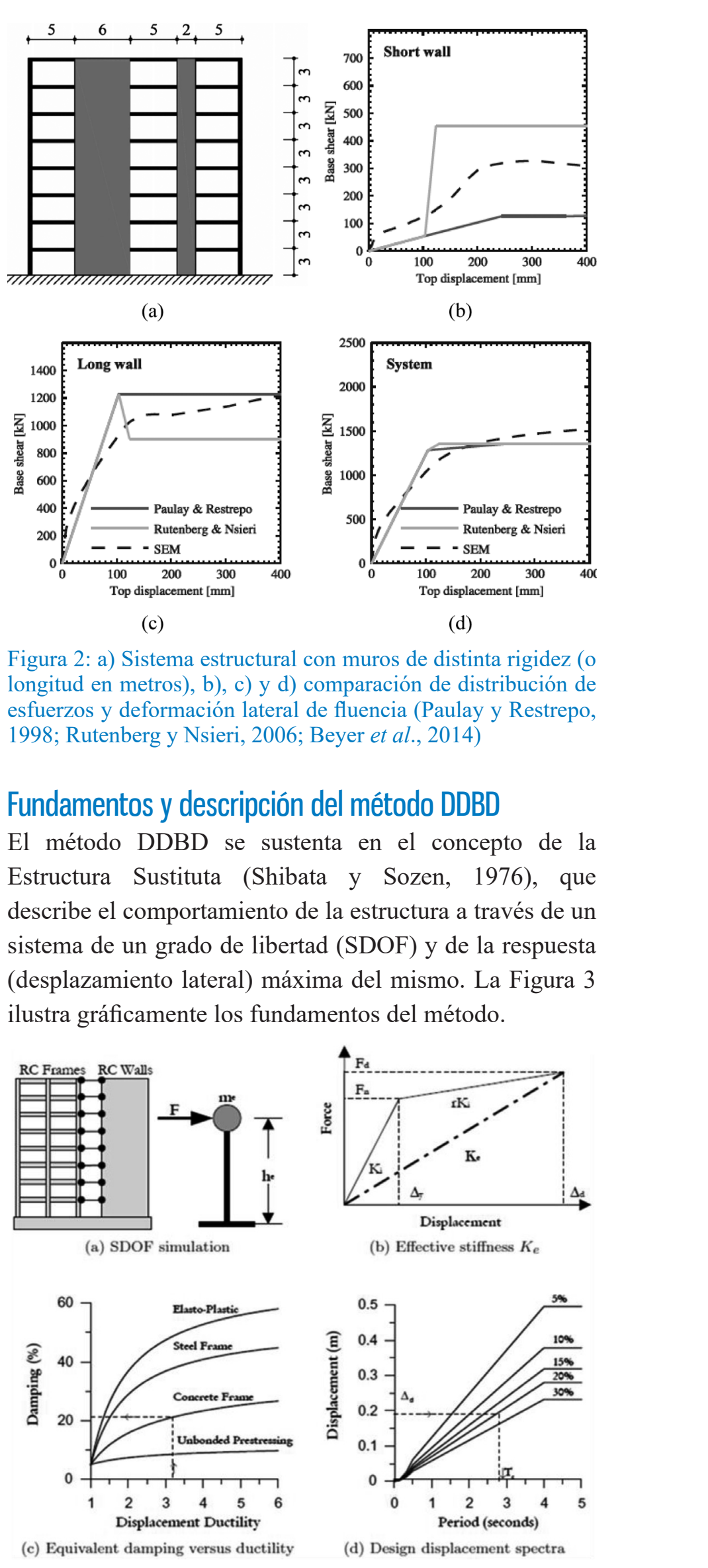

(b)

(d)
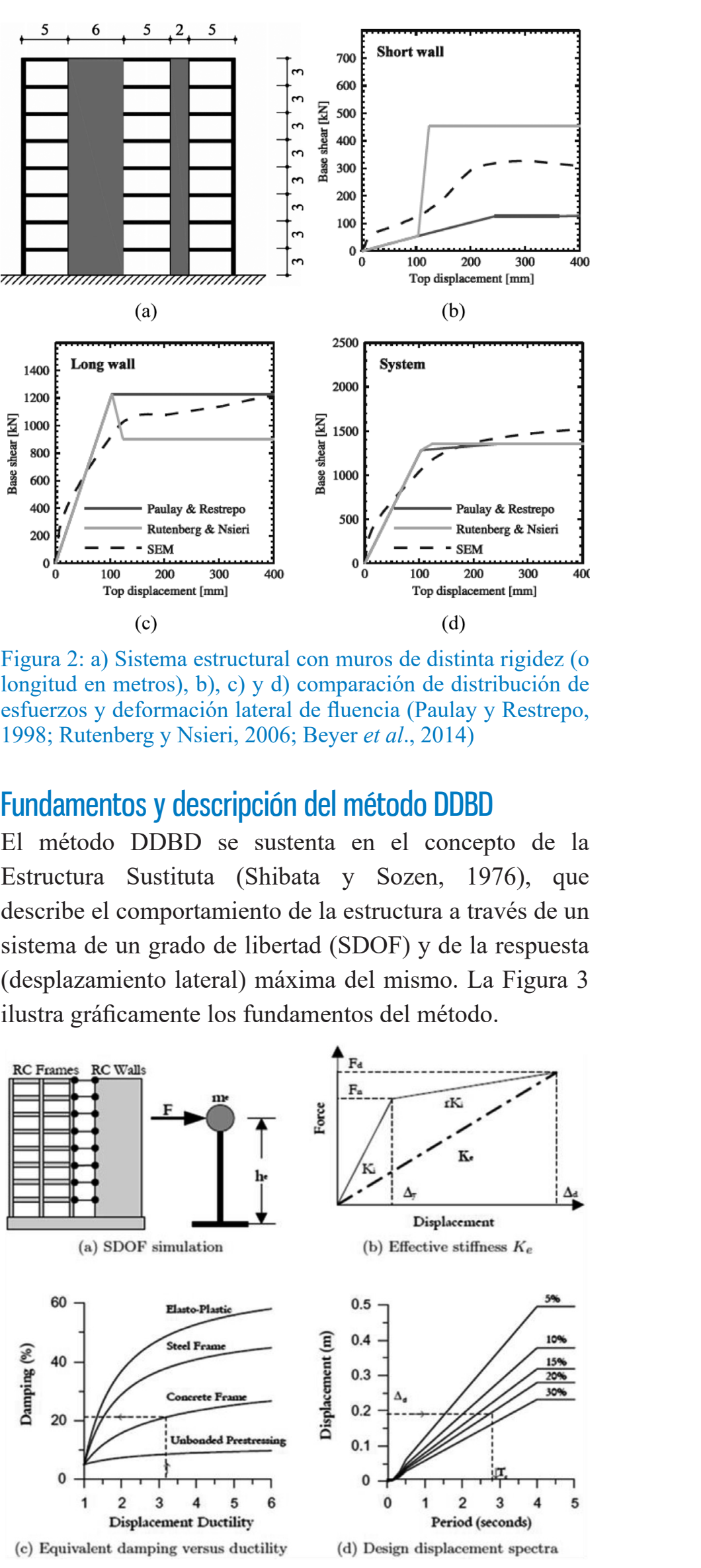

Figura 2: a) Sistema estructural con muros de distinta rigidez (o longitud en metros), b), c) y d) comparación de distribución de esfuerzos y deformación lateral de fluencia (Paulay y Restrepo, 1998; Rutenberg y Nsieri, 2006; Beyer et al., 2014)

\section{Fundamentos y descripción del método DDBD}

El método DDBD se sustenta en el concepto de la Estructura Sustituta (Shibata y Sozen, 1976), que describe el comportamiento de la estructura a través de un sistema de un grado de libertad (SDOF) y de la respuesta (desplazamiento lateral) máxima del mismo. La Figura 3 ilustra gráficamente los fundamentos del método. (a) SDOF simulation

(c) Equivalent damping versus ductility Figura 3: Fundamentos del método DDBD (Sullivan et al., 2012)
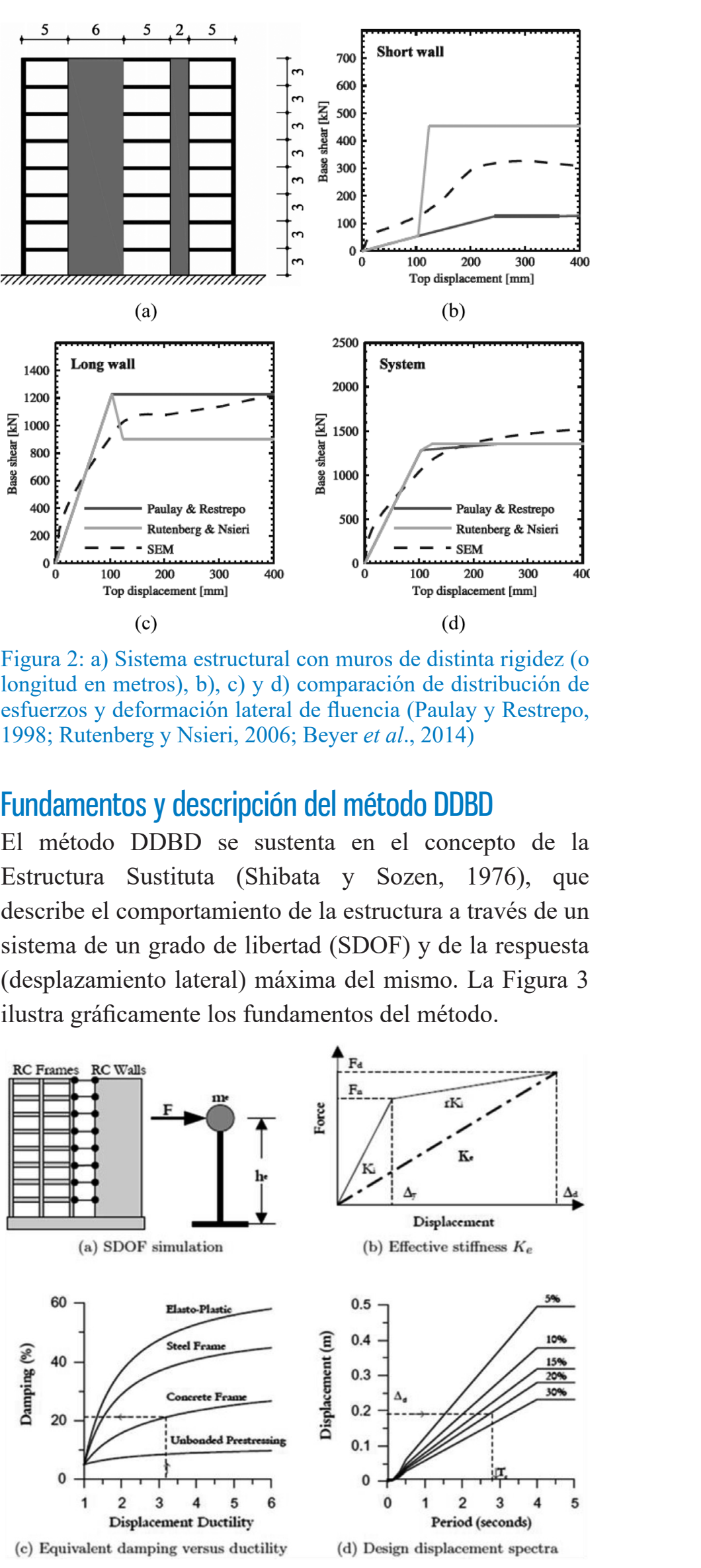

(b) Effective stiffness $K_{e}$

(d) Design displacement spectra
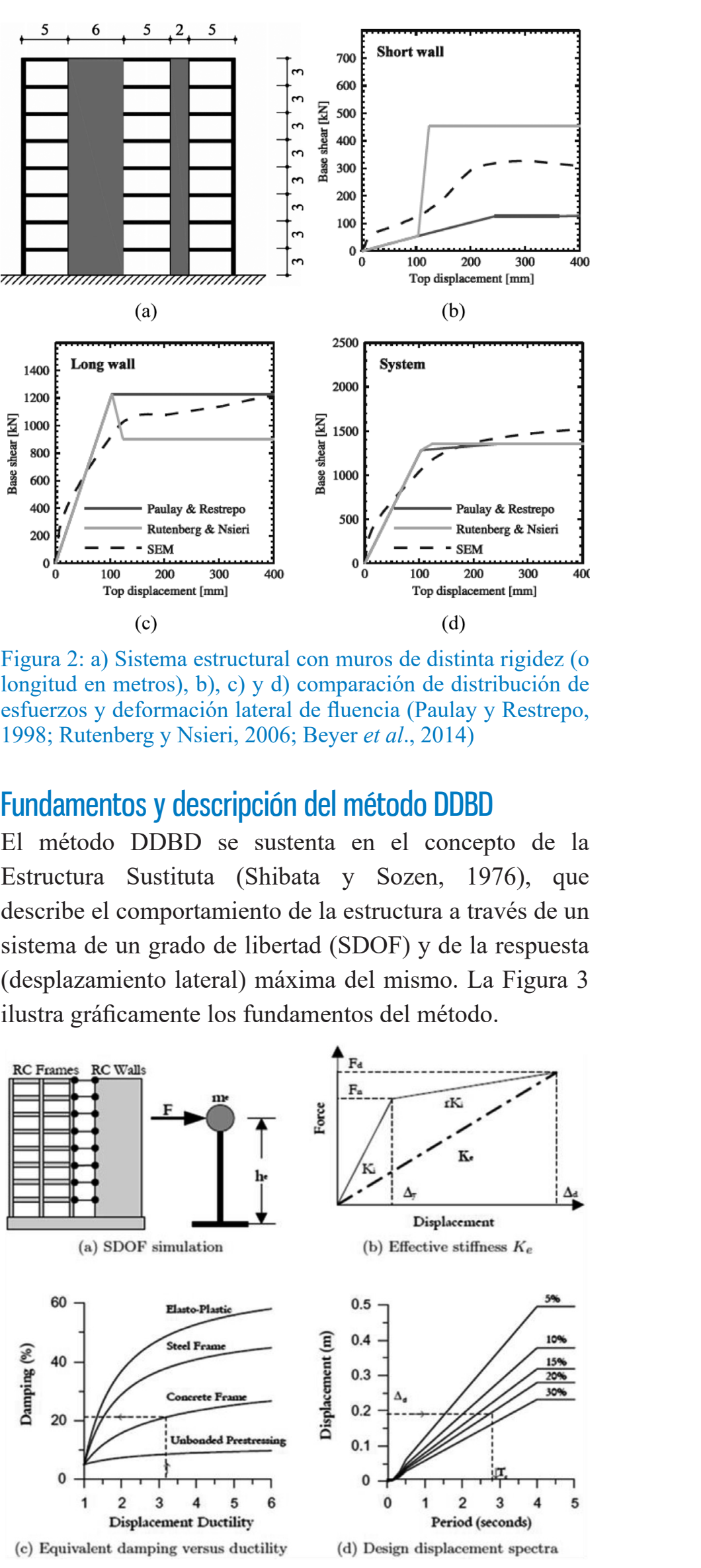
La estructura a analizar es representada por un sistema SDOF equivalente con una masa efectiva $m_{e}$, altura efectiva $h_{e}$ (Figura 3a) y por la rigidez secante $K_{e}$, cuando alcanza el máximo desplazamiento $\Delta_{d}$ (Figura 3b). El desplazamiento máximo o de diseño $\Delta_{d}$, definido por el diseñador, generalmente se obtiene a partir de la deformada (o perfil de desplazamientos) de la estructura para una deformación lateral de entrepiso (o drift) de diseño $\theta_{d}$, este último escogido para tener niveles aceptables de deformación lateral frente a la acción de un sismo dado. Conocida la deformada de la estructura, el desplazamiento de diseño
$\Delta_{d}$, para el sistema SDOF equivalente a una altura efectiva $h_{e}$, se puede calcular con la siguiente expresión:

$$
\Delta_{d}=\frac{\sum_{i=1}^{N} m_{i} \Delta_{i}^{2}}{\sum_{i=1}^{N} m_{i} \Delta_{i}}
$$

donde $N$ es el número total de pisos del edificio, $m_{i}$ es la masa de cada piso y $\Delta_{i}$ es el desplazamiento de diseño del piso $i$-ésimo. La altura efectiva $h_{e}$ también es función de la deformada de la estructura para el máximo desplazamiento $\Delta_{d}$, de las masas $m_{i}$ de cada piso, del desplazamiento $\Delta_{i}$ del

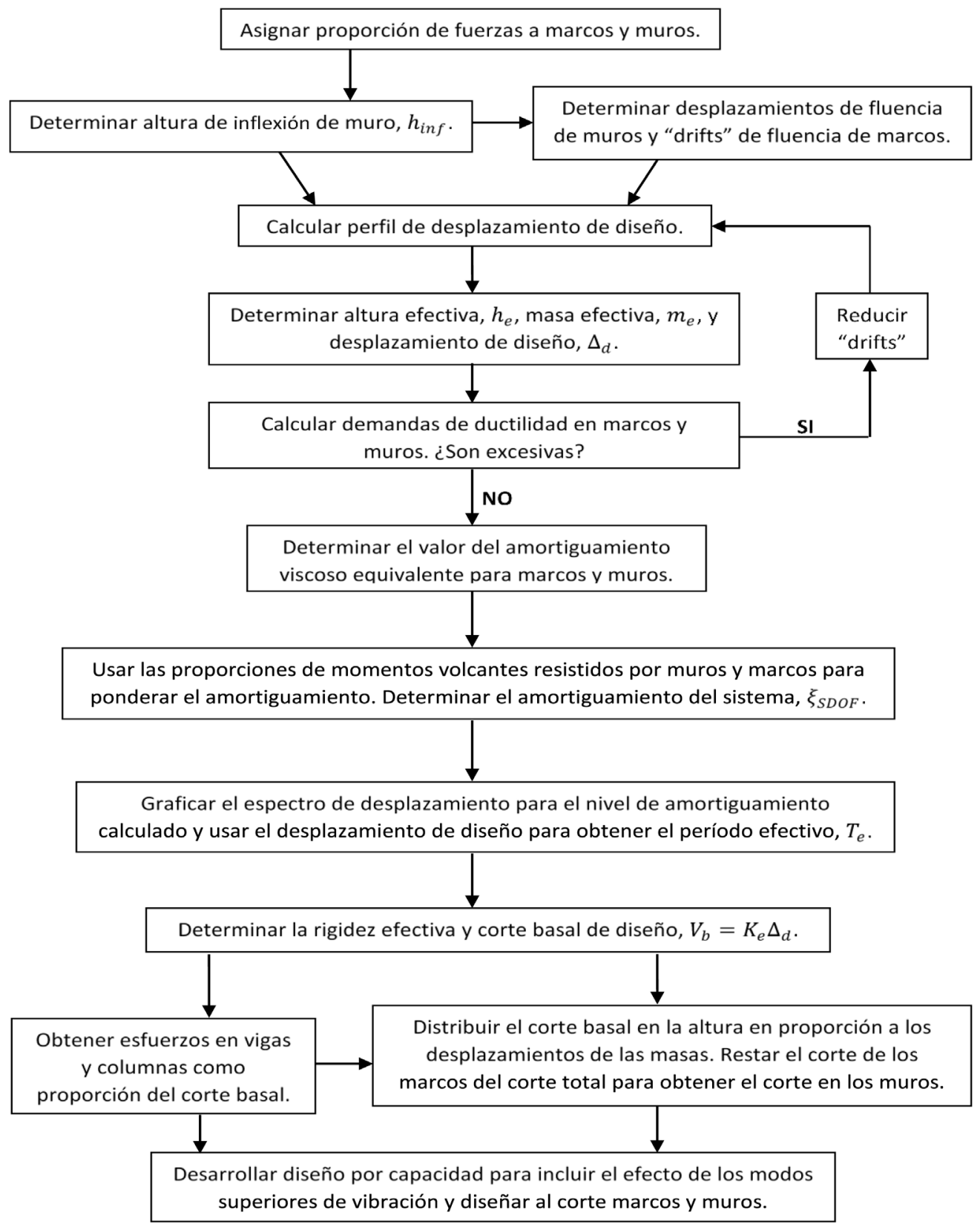

Figura 4: Diagrama de flujo para análisis y diseño (Morales, 2013) 
piso $i$-ésimo y de la altura al piso $i$-ésimo.

$$
h_{e}=\frac{\sum_{i=1}^{N} m_{i} \Delta_{i} h_{i}}{\sum_{i=1}^{N} m_{i} \Delta_{i}}
$$

Para determinar la masa efectiva $m_{e}$, se considera que la respuesta máxima de la estructura se da en el primer modo de vibrar o modo fundamental. Con esta consideración la masa efectiva se calcula como muestra la ecuación (3):

$$
m_{e}=\frac{\sum_{i=1}^{N} m_{i} \Delta_{i}}{\Delta_{d}}
$$

El único parámetro restante para definir completamente la Estructura Sustituta, es el amortiguamiento viscoso equivalente $\xi_{S D O F}$. Este último es función de la ductilidad de la estructura y también del período efectivo $T_{e}$ de la Estructura Sustituta (Grant et al., 2005; Blandon y Priestley, 2005), aunque cuando $T_{e}$ es mayor que $1 \mathrm{~s}$ su influencia puede despreciarse.

$$
\xi_{S D O F}=\frac{M_{w} \xi_{w}+M_{f} \xi_{f}}{M_{w}+M_{f}}
$$

Donde $M_{f}$ es el momento resistente de los marcos, $M_{w}$ es el momento resistente de los muros y los amortiguamientos $\xi_{w}$ y $\xi_{f}$ están dados por las ecuaciones (5) y (6) (Sullivan et al., 2006), estas últimas incluyen el amortiguamiento elástico e histerético.

$$
\begin{aligned}
& \xi_{w} \approx 0.05+\frac{95}{1.3 \pi}\left(1-\frac{1}{\mu_{w}^{0.5}}-0.1 r \mu_{w}\right) \\
& \xi_{f} \approx 0.05+\frac{120}{1.3 \pi}\left(1-\frac{1}{\mu_{f}^{0.5}}-0.1 r \mu_{f}\right)
\end{aligned}
$$

Donde $\mu_{w}$ es la demanda de ductilidad sobre los muros, $\mu_{f}$ la demanda de ductilidad sobre los marcos y $r$ es el coeficiente de rigidez post-elástico, típicamente 0.05 para estructuras de hormigón armado (ver Figura 3b). Con la Estructura Sustituta completamente definida es posible comenzar el análisis y diseño, el procedimiento recomendado por Sullivan et al. (2006) para la aplicación del método DDBD a sistemas mixtos o duales fue adaptado de Morales (2013) a los objetivos de este trabajo y se muestra en el diagrama de flujo de la Figura 4.

\section{Aplicación a sistema mixto de hormigón armado \\ Estructura analizada}

Tanto las dimensiones de los elementos estructurales como los materiales propuestos son necesarios para que el edificio presentando cumpla las disposiciones normativas vigentes en Chile; particularmente la norma NCh433 (2009) y el DS61 (2011). Por otro lado, la estructura se considera emplazada en zona sísmica 3 con un suelo tipo D, una combinación usual en el diseño de edificios chilenos en zona costera. La Figura 5 muestra la estructura en estudio, corresponde a un edificio de 12 pisos, con una altura total de $43.2 \mathrm{~m}$ y plantas rectangulares de $32.5 \mathrm{~m}$ por $24 \mathrm{~m}$, altura de entrepiso constante e igual a $3.6 \mathrm{~m}$. En la Tabla 1 se resumen las dimensiones de los elementos estructurales (muros, columnas y vigas) considerados para el análisis.

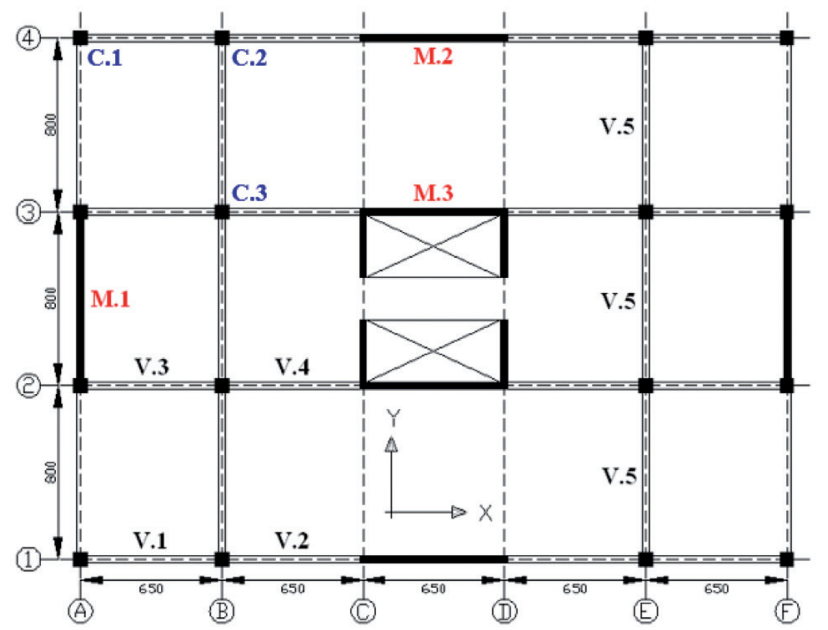

Figura 5: Planta tipo del edificio en estudio (medidas en $\mathrm{cm}$ )

Tabla 1: Dimensiones de elementos estructurales

\begin{tabular}{|c|c|c|c|c|c|}
\hline \multirow{2}{*}{$\begin{array}{c}\text { Espesor } \\
\text { muros }\end{array}$} & \multicolumn{2}{|c|}{ Columnas } & \multicolumn{2}{c|}{ Vigas } & Espesor \\
\cline { 2 - 6 } & C.1 y C.2 & C. 3 & V.1 a V.4 & V.5 & losas \\
\hline $30 \mathrm{~cm}$ & $60 \times 60 \mathrm{~cm}^{2}$ & $70 \times 70 \mathrm{~cm}^{2}$ & $30 \times 65 \mathrm{~cm}^{2}$ & $35 \times 75 \mathrm{~cm}^{2}$ & $15 \mathrm{~cm}$ \\
\hline
\end{tabular}

Se usó un hormigón calidad G25 con una resistencia específica de $25 \mathrm{MPa}$ y módulo de elasticidad de 23.5 GPa. La calidad del refuerzo es A630-420H, con 420 MPa y 630 MPa como tensión de fluencia y última, respectivamente; el módulo de elasticidad considerado para el refuerzo fue de $200 \mathrm{GPa}$. La Tabla 2 muestra los valores de los períodos asociados a las mayores masas traslacionales en cada dirección de análisis con el porcentaje de masa equivalente correspondiente. 
Tabla 2: Período y masa equivalente

\begin{tabular}{|c|c|c|c|}
\hline Dirección & Período, $\mathrm{s}$ & Modo de vibrar & $\begin{array}{c}\text { Masa } \\
\text { equivalente }\end{array}$ \\
\hline $\mathrm{X}$ & 1.03 & 2 & $66 \%$ \\
\hline $\mathrm{Y}$ & 1.24 & 1 & $68 \%$ \\
\hline
\end{tabular}

En cuanto a los desplazamientos laterales de entrepiso (o drift), la Figura 6 muestra que en ambas direcciones de análisis estos son menores al límite impuesto por la normativa vigente.

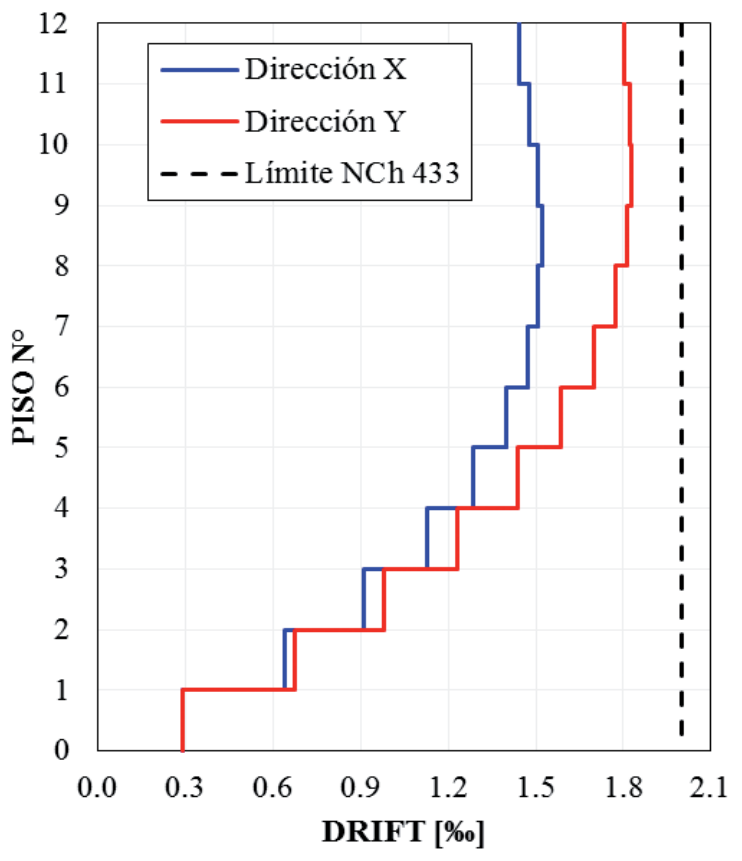

Figura 6: Deformación lateral de entrepiso

\section{Aplicación del método DDBD}

En esta sección se muestran los resultados obtenidos luego de aplicar íntegramente el diagrama de flujo mostrado en la Figura 4, al análisis y diseño de la estructura descrita en la sección previa (ver Figura 5). El diagrama de flujo propuesto sigue una secuencia lógica, que permite determinar los valores de los parámetros utilizados en la Estructura Sustituta, en la medida que son obtenidos los resultados necesarios para su definición, tal como se expone a continuación.

\section{Proporción de fuerzas para marcos y muros}

Basado en el número de marcos y muros en cada una de las direcciones analizadas y en las recomendaciones contenidas en la literatura (Sullivan et al., 2006), se asignó un $30 \%$ y un $25 \%$ del corte basal total a los marcos en las direcciones X e Y, respectivamente. La Figura 7 ilustra cualitativamente esta situación.

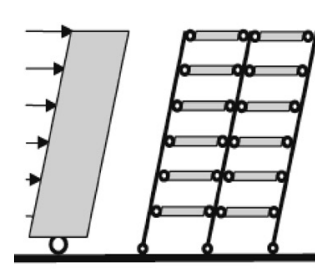

BEAM-SWAY MECHANISM

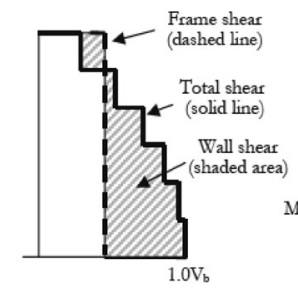

SHEARS

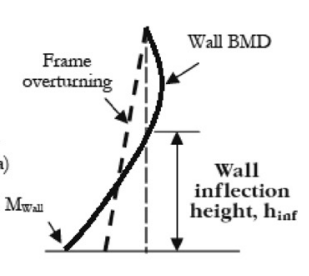

MOMENTS
Figura 7: Proporción de fuerzas en muros y marcos (Sullivan et al., 2006)

De acuerdo a la Figura 7, el corte total $V_{i, T}$ en cada piso de la estructura puede relacionarse con el corte basal $V_{b}$, como muestra la ecuación (7).

$$
\frac{V_{i, w}}{V_{b}}=\frac{V_{i, T}}{V_{b}}-\frac{V_{i, f}}{V_{b}}
$$

Donde $V_{i, w}$ es el corte en los muros y $V_{i, f}$ es el corte en los marcos, ambos en el piso $i$-ésimo. Nótese que la proporción de fuerzas en marcos y muros, asignada por el diseñador, tiene un efecto directo en la magnitud de los esfuerzos que cada elemento estructural tendrá dentro del edificio. Sin embargo, si el diseñador no está conforme con los esfuerzos resultantes, puede cambiar la proporción de esfuerzos entre marcos y muros, iterando de ser necesario, hasta lograr un diseño que se ajuste a sus requerimientos.

\section{Altura de inflexión en los muros, $h_{\text {inf }}$}

Con el objetivo de determinar la altura de inflexión del diagrama de momento en los muros (ver Figura 7), se asumió un corte basal unitario y una distribución de fuerzas en la altura del edificio consistente con el primer modo de vibrar. Con estas aproximaciones se determinó la fuerza lateral por piso $F_{i}$ usando la ecuación (8).

$$
F_{i}=\frac{m_{i} h_{i}}{\sum_{i=1}^{N} m_{i} h_{i}}
$$

En estricto rigor, el diagrama de momento de los muros debe modificarse debido a las vigas que concurren a los mismos (ver Figura 8), el valor del momento que se transfiere al eje central del muro puede estimarse con la ecuación (9) y el momento $M_{b}$ en la cara del muro y columnas con la ecuación (10). Sin embargo, en este caso, debido a que los muros tienen vigas en ambos extremos (ver Figura 5) y estas a su vez son idénticas, sus diagramas de momento no se ven adulterados. 


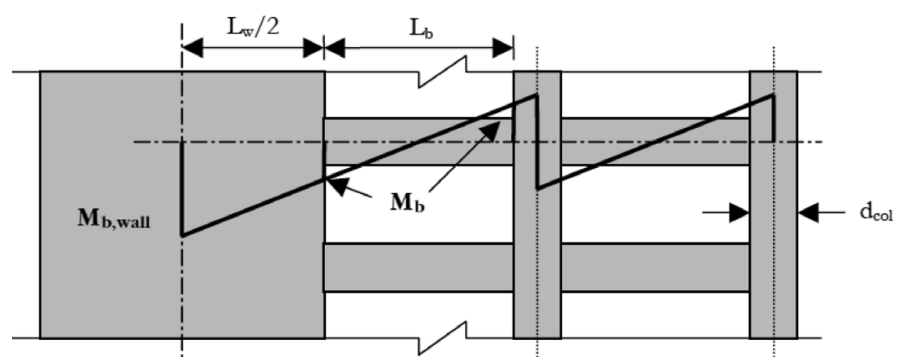

Figura 8: Momento transferido de vigas a muros (Sullivan et al., 2006)

$$
\begin{gathered}
M_{b, w}=V_{i, f}\left(1+\frac{L_{w}}{L_{b}}\right) \frac{h_{c o l}}{n_{b j}} \\
M_{b}=\frac{\sum M_{b i}}{n_{b j}}=V_{i, f} \frac{h_{c o l}}{n_{b j}}
\end{gathered}
$$

Donde $n_{b j}$ es el número de potenciales rótulas plásticas en las vigas, sin considerar la correspondiente a la unión viga muro $h_{c o l}$, es la altura de entrepiso del piso $i$-ésimo y $L_{w}$ es el largo del muro.

La Tabla 3 muestra las variables, parámetros y el resultado de los cálculos necesarios para determinar la altura de inflexión (o altura en la que el diagrama de momento cambia de signo) del diagrama de momento para los muros del edificio en la dirección X.

Tabla 3: Altura de inflexión del muro, dirección X

\begin{tabular}{|c|c|c|c|c|c|c|c|c|c|}
\hline Piso & $m_{i}$, ton & $h_{i}, \mathrm{~m}$ & $m_{i} h_{i}$ & $F_{i}$ & $V_{i, T}$ & $M_{\text {ОТМ }, i}$ & $V_{i, f}$ & $V_{i, w}$ & $M_{i, w}$ \\
\hline 12 & 595.7 & 43.2 & 25734.3 & 0.133 & 0.133 & 0.000 & 0.3 & -0.167 & 0.000 \\
\hline 11 & 704.4 & 39.6 & 27892.4 & 0.144 & 0.278 & 0.480 & 0.3 & -0.022 & -0.600 \\
\hline 10 & 704.4 & 36 & 25356.7 & 0.131 & 0.409 & 1.480 & 0.3 & 0.109 & -0.680 \\
\hline 9 & 704.4 & 32.4 & 22821.1 & 0.118 & 0.527 & 2.952 & 0.3 & 0.227 & -0.288 \\
\hline 8 & 704.4 & 28.8 & 20285.4 & 0.105 & 0.632 & 4.850 & 0.3 & 0.332 & 0.530 \\
\hline 7 & 704.4 & 25.2 & 17749.7 & 0.092 & 0.724 & 7.127 & 0.3 & 0.424 & 1.727 \\
\hline 6 & 704.4 & 21.6 & 15214.0 & 0.079 & 0.803 & 9.734 & 0.3 & 0.503 & 3.254 \\
\hline 5 & 704.4 & 18 & 12678.4 & 0.066 & 0.869 & 12.625 & 0.3 & 0.569 & 5.065 \\
\hline 4 & 704.4 & 14.4 & 10142.7 & 0.053 & 0.921 & 15.752 & 0.3 & 0.621 & 7.112 \\
\hline 3 & 704.4 & 10.8 & 7607.0 & 0.039 & 0.961 & 19.068 & 0.3 & 0.661 & 9.348 \\
\hline 2 & 704.4 & 7.2 & 5071.3 & 0.026 & 0.987 & 22.526 & 0.3 & 0.687 & 11.726 \\
\hline 1 & 704.4 & 3.6 & 2535.7 & 0.013 & 1.000 & 26.079 & 0.3 & 0.700 & 14.199 \\
\hline 0 & 0.0 & 0 & 0.0 & 0.000 & 1.000 & 29.679 & 0.3 & 0.700 & 16.719 \\
\hline Suma & $\mathbf{8 3 4 3 . 6}$ & & $\mathbf{1 9 3 0 8 8 . 8}$ & $\mathbf{1 . 0 0 0}$ & & & & & \\
\hline & & & & & & & & \multicolumn{2}{c|}{$\boldsymbol{h}_{\text {inf }}=\mathbf{3 1 . 1 3} \mathbf{m}$} \\
\hline
\end{tabular}

En la tabla $3 M_{\text {ОтМ }, i}$ es el momento volcante total del edificio, $V_{i, w}$ es el corte en los muros y finalmente $M_{i, w}$ es el momento de los muros, todos para el piso $i$-ésimo. La altura de inflexión $h_{\text {inf }}$ en este caso es $31.13 \mathrm{~m}$. Nótese que este valor corresponde a la interpolación lineal entre las alturas del octavo y noveno piso.

De manera análoga a la dirección $\mathrm{X}$, en la Tabla 4 se muestran los resultados obtenidos durante la estimación de la altura de inflexión en la dirección Y. La altura resultante $33.99 \mathrm{~m}$ que corresponde a una interpolación lineal en las alturas de los pisos noveno y décimo.

Tabla 4: Altura de inflexión del muro, dirección Y

\begin{tabular}{|c|c|c|c|c|c|c|c|c|c|}
\hline Piso & $m_{i}$, ton & $h_{i}, \mathrm{~m}$ & $m_{i} h_{i}$ & $F_{i}$ & $V_{i, T}$ & $M_{\text {ОТM,i }}$ & $V_{i, f}$ & $V_{i, w}$ & $M_{i, w}$ \\
\hline 12 & 595.7 & 43.2 & 25734.3 & 0.133 & 0.133 & 0.000 & 0.25 & -0.117 & 0.000 \\
\hline 11 & 704.4 & 39.6 & 27892.4 & 0.144 & 0.278 & 0.480 & 0.25 & 0.028 & -0.420 \\
\hline 10 & 704.4 & 36.0 & 25356.7 & 0.131 & 0.409 & 1.480 & 0.25 & 0.159 & -0.320 \\
\hline 9 & 704.4 & 32.4 & 22821.1 & 0.118 & 0.527 & 2.952 & 0.25 & 0.277 & 0.252 \\
\hline 8 & 704.4 & 28.8 & 20285.4 & 0.105 & 0.632 & 4.850 & 0.25 & 0.382 & 1.250 \\
\hline 7 & 704.4 & 25.2 & 17749.7 & 0.092 & 0.724 & 7.127 & 0.25 & 0.474 & 2.627 \\
\hline 6 & 704.4 & 21.6 & 15214.0 & 0.079 & 0.803 & 9.734 & 0.25 & 0.553 & 4.334 \\
\hline 5 & 704.4 & 18.0 & 12678.4 & 0.066 & 0.869 & 12.625 & 0.25 & 0.619 & 6.325 \\
\hline 4 & 704.4 & 14.4 & 10142.7 & 0.053 & 0.921 & 15.752 & 0.25 & 0.671 & 8.552 \\
\hline 3 & 704.4 & 10.8 & 7607.0 & 0.039 & 0.961 & 19.068 & 0.25 & 0.711 & 10.968 \\
\hline 2 & 704.4 & 7.2 & 5071.3 & 0.026 & 0.987 & 22.526 & 0.25 & 0.737 & 13.526 \\
\hline 1 & 704.4 & 3.6 & 2535.7 & 0.013 & 1.000 & 26.079 & 0.25 & 0.750 & 16.179 \\
\hline 0 & 0.0 & 0.0 & 0.0 & 0.000 & 1.000 & 29.679 & 0.25 & 0.750 & 18.879 \\
\hline Suma & $\mathbf{8 3 4 3 . 6}$ & & $\mathbf{1 9 3 0 8 8 . 8}$ & $\mathbf{1 . 0 0 0}$ & & & & & \\
\hline & & & & & & & & $\boldsymbol{h}_{\text {inf }}=\mathbf{3 3 . 9 9} \mathbf{m}$ \\
\hline
\end{tabular}

a)

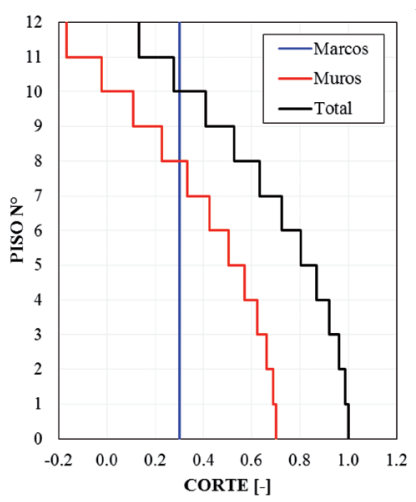

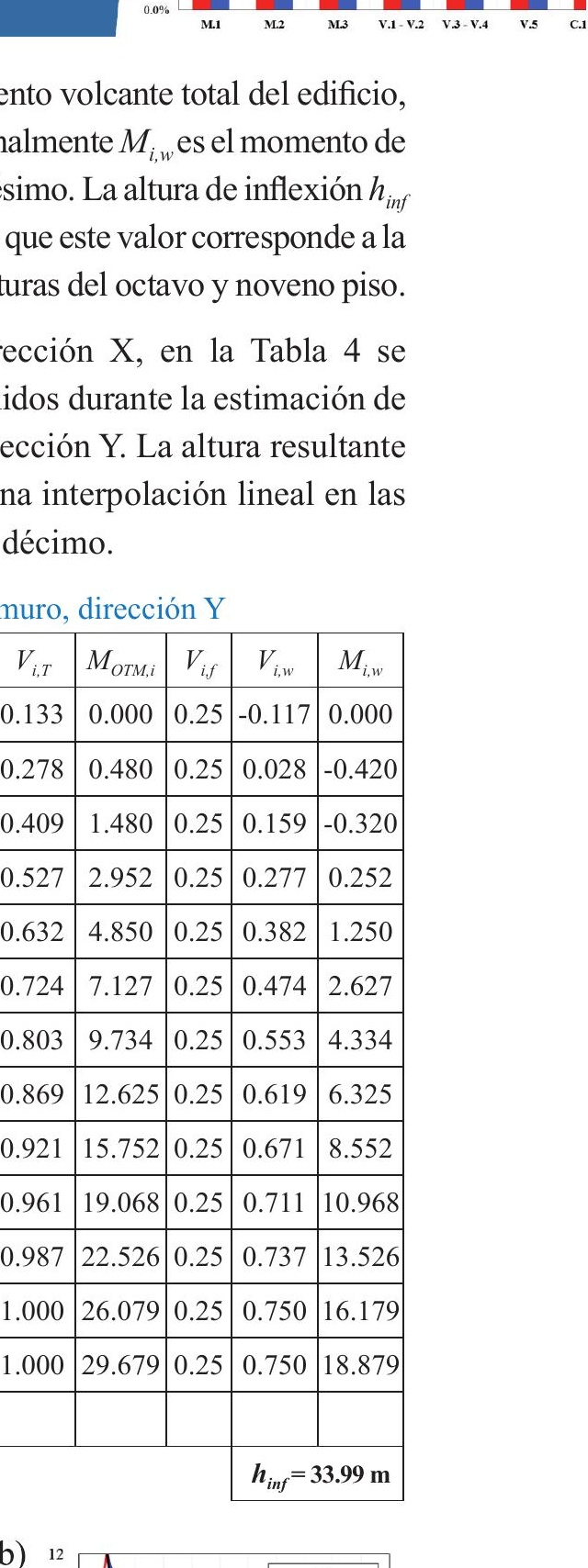

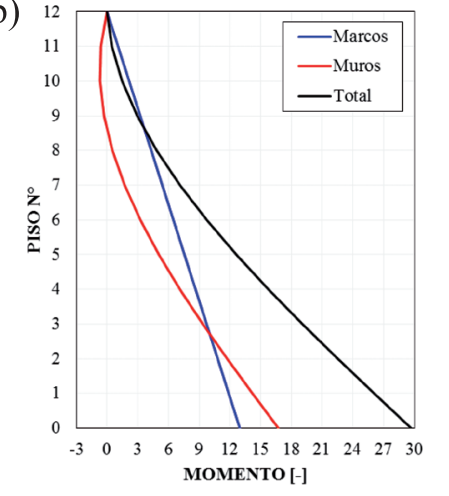

Figura 9: Proporción de esfuerzos entre muros y marcos en dirección X: (a) corte y (b) momento

Los gráficos mostrados en las Figuras 9 y 10 ilustran la distribución de esfuerzos (momentos y cortes) entre marcos y muros en las direcciones $\mathrm{X}$ e $\mathrm{Y}$ del edificio, 

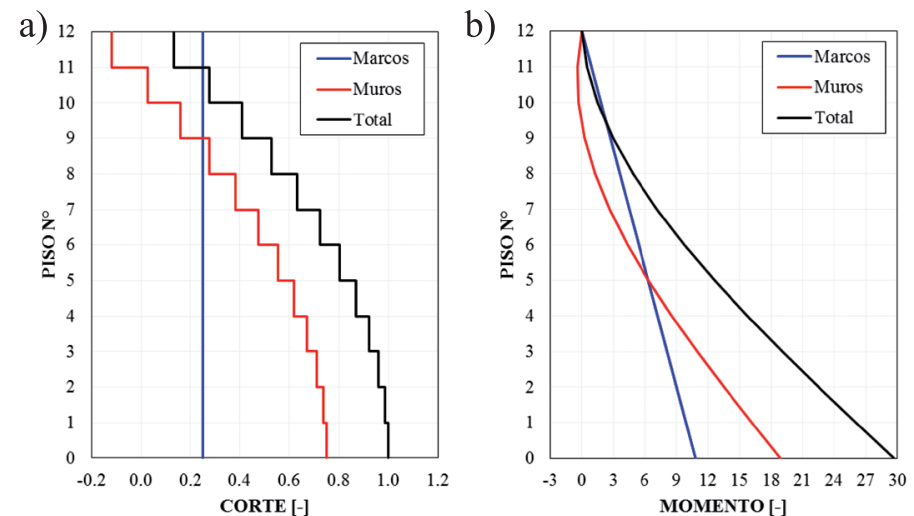

Figura 10: Proporción de esfuerzos entre muros y marcos en dirección Y: (a) corte y (b) momento

respectivamente. Nótese que es la misma información contenida en las Tablas 3 y 4.

\section{Perfil de desplazamiento de diseño}

Debido a que la respuesta en sistemas mixtos o duales (muros y marcos trabajando en conjunto) tiende a ser controlada por los muros (Paulay, 2002), la curvatura de fluencia, y por ende el desplazamiento de fluencia del muro, es fundamental para determinar el perfil de desplazamiento de diseño del edificio. Por otro lado, la importancia del desplazamiento de fluencia de los marcos radica principalmente en la absorción de energía de estos, a través de los ciclos histeréticos de las vigas (Sullivan et al., 2006).

El perfil de desplazamiento de fluencia del muro se determina con la curvatura de fluencia según la ecuación (11) (Priestley, 2003), la altura de inflexión del diagrama de momento de los muros y la altura de piso, de acuerdo a las ecuaciones (12) y (13), respectivamente.

$$
\begin{aligned}
& \phi_{y, w}=(1.5-2.0) \frac{\varepsilon_{y}}{L_{w}} \\
& \Delta_{y, i} \approx \frac{\phi_{y, w} h_{i n f} h_{i}}{2}-\frac{\phi_{y, w} h_{i n f}^{2}}{6} \quad \text { si } \quad h_{i} \geq h_{\text {inf }} \\
& \Delta_{y, i} \approx \frac{\phi_{y, w} h_{i}^{2}}{2}-\frac{\phi_{y, w} h_{i}^{3}}{6 h_{\text {inf }}} \quad \text { si } \quad h_{i}<h_{\text {inf }}
\end{aligned}
$$

Para determinar el perfil de desplazamiento de diseño se utiliza la ecuación (14) e información calculada previamente. La deformación lateral de diseño $\Delta_{i}$ del piso $i$-ésimo se obtiene como la superposición de la deformación

\section{de fluencia $\Delta_{y, i}$ más la deformación no lineal, esta última es
función del giro de diseño $\theta_{d}$.
$\Delta_{i}=\Delta_{y, i}+\left(\theta_{d}-\frac{\phi_{y, w} h_{i n f}}{2}\right) h_{i}$
El valor del giro de diseño $\theta_{d}$ es definido por el diseñador,
generalmente obedece a un cierto nivel de deformaciones
esperadas o desempeño. En este caso se tomó igual a 0.015
o $1.5 \%$, correspondiente al desplazamiento o drift de techo
esperado para la estructura, de acuerdo a lo definido en el
DS61 (2011).
Características de la Estructura Sustituta
La Tabla 5 resume las propiedades de la Estructura Sustituta
calculadas para cada dirección de análisis, usando las
ecuaciones (1), (2) y (3) expuestas previamente.
Tabla 5: Propiedades de la estructura sustituta
\begin{tabular}{|l|c|c|}
\hline Propiedad & Dirección X & Dirección Y \\
\hline Masa efectiva $m_{e}$, ton & 6127.3 & 6127.3 \\
\hline Altura efectiva $h_{e}, \mathrm{~m}$ & 30.53 & 30.72 \\
\hline Despl. de diseño $\Delta_{\mathrm{d}}, \mathrm{m}$ & 0.39 & 0.38 \\
\hline
\end{tabular} \\ de fluencia $\Delta_{y, i}$ más la deformación no lineal, esta última es
función del giro de diseño $\theta_{d}$.
$\Delta_{i}=\Delta_{y, i}+\left(\theta_{d}-\frac{\phi_{y, w} h_{i n f}}{2}\right) h_{i}$
El valor del giro de diseño $\theta_{d}$ es definido por el diseñador,
generalmente obedece a un cierto nivel de deformaciones
esperadas o desempeño. En este caso se tomó igual a 0.015
o 1.5\%, correspondiente al desplazamiento o drift de techo
esperado para la estructura, de acuerdo a lo definido en el
DS61 (2011).
Características de la Estructura Sustituta
La Tabla 5 resume las propiedades de la Estructura Sustituta
calculadas para cada dirección de análisis, usando las
ecuaciones (1), (2) y (3) expuestas previamente.
Tabla 5: Propiedades de la estructura sustituta
\begin{tabular}{|l|c|c|}
\hline Propiedad & Dirección X & Dirección Y \\
\hline Masa efectiva $m_{e}$, ton & 6127.3 & 6127.3 \\
\hline Altura efectiva $h_{e}, \mathrm{~m}$ & 30.53 & 30.72 \\
\hline Despl. de diseño $\Delta_{\mathrm{d}}, \mathrm{m}$ & 0.39 & 0.38 \\
\hline
\end{tabular}

$$
\Delta_{i}=\Delta_{y, i}+\left(\theta_{d}-\frac{\phi_{y, w} h_{i n f}}{2}\right) h_{i}
$$ \\ de fluencia $\Delta_{y, i}$ más la deformación no lineal, esta última es
función del giro de diseño $\theta_{d}$.
$\Delta_{i}=\Delta_{y, i}+\left(\theta_{d}-\frac{\phi_{y, w} h_{i n f}}{2}\right) h_{i}$
El valor del giro de diseño $\theta_{d}$ es definido por el diseñador,
generalmente obedece a un cierto nivel de deformaciones
esperadas o desempeño. En este caso se tomó igual a 0.015
o 1.5\%, correspondiente al desplazamiento o drift de techo
esperado para la estructura, de acuerdo a lo definido en el
DS61 (2011).
Características de la Estructura Sustituta
La Tabla 5 resume las propiedades de la Estructura Sustituta
calculadas para cada dirección de análisis, usando las
ecuaciones (1), (2) y (3) expuestas previamente.
Tabla 5: Propiedades de la estructura sustituta
\begin{tabular}{|l|c|c|}
\hline Propiedad & Dirección X & Dirección Y \\
\hline Masa efectiva $m_{e}$, ton & 6127.3 & 6127.3 \\
\hline Altura efectiva $h_{e}, \mathrm{~m}$ & 30.53 & 30.72 \\
\hline Despl. de diseño $\Delta_{\mathrm{d}}, \mathrm{m}$ & 0.39 & 0.38 \\
\hline
\end{tabular} \\ de fluencia $\Delta_{y, i}$ más la deformación no lineal, esta última es
función del giro de diseño $\theta_{d}$.
$\Delta_{i}=\Delta_{y, i}+\left(\theta_{d}-\frac{\phi_{y, w} h_{i n f}}{2}\right) h_{i}$
El valor del giro de diseño $\theta_{d}$ es definido por el diseñador,
generalmente obedece a un cierto nivel de deformaciones
esperadas o desempeño. En este caso se tomó igual a 0.015
o 1.5\%, correspondiente al desplazamiento o drift de techo
esperado para la estructura, de acuerdo a lo definido en el
DS61 (2011).
Características de la Estructura Sustituta
La Tabla 5 resume las propiedades de la Estructura Sustituta
calculadas para cada dirección de análisis, usando las
ecuaciones (1), (2) y (3) expuestas previamente.
Tabla 5: Propiedades de la estructura sustituta
\begin{tabular}{|l|c|c|}
\hline Propiedad & Dirección X & Dirección Y \\
\hline Masa efectiva $m_{e}$, ton & 6127.3 & 6127.3 \\
\hline Altura efectiva $h_{e}, \mathrm{~m}$ & 30.53 & 30.72 \\
\hline Despl. de diseño $\Delta_{\mathrm{d}}, \mathrm{m}$ & 0.39 & 0.38 \\
\hline
\end{tabular} \\ de fluencia $\Delta_{y, i}$ más la deformación no lineal, esta última es
función del giro de diseño $\theta_{d}$.
$\Delta_{i}=\Delta_{y, i}+\left(\theta_{d}-\frac{\phi_{y, w} h_{i n f}}{2}\right) h_{i}$
El valor del giro de diseño $\theta_{d}$ es definido por el diseñador,
generalmente obedece a un cierto nivel de deformaciones
esperadas o desempeño. En este caso se tomó igual a 0.015
o 1.5\%, correspondiente al desplazamiento o drift de techo
esperado para la estructura, de acuerdo a lo definido en el
DS61 (2011).
Características de la Estructura Sustituta
La Tabla 5 resume las propiedades de la Estructura Sustituta
calculadas para cada dirección de análisis, usando las
ecuaciones (1), (2) y (3) expuestas previamente.
Tabla 5: Propiedades de la estructura sustituta
\begin{tabular}{|l|c|c|}
\hline Propiedad & Dirección X & Dirección Y \\
\hline Masa efectiva $m_{e}$, ton & 6127.3 & 6127.3 \\
\hline Altura efectiva $h_{e}, \mathrm{~m}$ & 30.53 & 30.72 \\
\hline Despl. de diseño $\Delta_{\mathrm{d}}, \mathrm{m}$ & 0.39 & 0.38 \\
\hline
\end{tabular} \\ de fluencia $\Delta_{y, i}$ más la deformación no lineal, esta última es
función del giro de diseño $\theta_{d}$.
$\Delta_{i}=\Delta_{y, i}+\left(\theta_{d}-\frac{\phi_{y, w} h_{i n f}}{2}\right) h_{i}$
El valor del giro de diseño $\theta_{d}$ es definido por el diseñador,
generalmente obedece a un cierto nivel de deformaciones
esperadas o desempeño. En este caso se tomó igual a 0.015
o $1.5 \%$, correspondiente al desplazamiento o drift de techo
esperado para la estructura, de acuerdo a lo definido en el
DS61 (2011).
Características de la Estructura Sustituta
La Tabla 5 resume las propiedades de la Estructura Sustituta
calculadas para cada dirección de análisis, usando las
ecuaciones (1), (2) y (3) expuestas previamente.
Tabla 5: Propiedades de la estructura sustituta
\begin{tabular}{|l|c|c|}
\hline Propiedad & Dirección X & Dirección Y \\
\hline Masa efectiva $m_{e}$, ton & 6127.3 & 6127.3 \\
\hline Altura efectiva $h_{e}, \mathrm{~m}$ & 30.53 & 30.72 \\
\hline Despl. de diseño $\Delta_{\mathrm{d}}, \mathrm{m}$ & 0.39 & 0.38 \\
\hline
\end{tabular} \\ de fluencia $\Delta_{y, i}$ más la deformación no lineal, esta última es
función del giro de diseño $\theta_{d}$.
$\Delta_{i}=\Delta_{y, i}+\left(\theta_{d}-\frac{\phi_{y, w} h_{i n f}}{2}\right) h_{i}$
El valor del giro de diseño $\theta_{d}$ es definido por el diseñador,
generalmente obedece a un cierto nivel de deformaciones
esperadas o desempeño. En este caso se tomó igual a 0.015
o 1.5\%, correspondiente al desplazamiento o drift de techo
esperado para la estructura, de acuerdo a lo definido en el
DS61 (2011).
Características de la Estructura Sustituta
La Tabla 5 resume las propiedades de la Estructura Sustituta
calculadas para cada dirección de análisis, usando las
ecuaciones (1), (2) y (3) expuestas previamente.
Tabla 5: Propiedades de la estructura sustituta
\begin{tabular}{|l|c|c|}
\hline Propiedad & Dirección X & Dirección Y \\
\hline Masa efectiva $m_{e}$, ton & 6127.3 & 6127.3 \\
\hline Altura efectiva $h_{e}, \mathrm{~m}$ & 30.53 & 30.72 \\
\hline Despl. de diseño $\Delta_{\mathrm{d}}, \mathrm{m}$ & 0.39 & 0.38 \\
\hline
\end{tabular} \\ de fluencia $\Delta_{y, i}$ más la deformación no lineal, esta última es
función del giro de diseño $\theta_{d}$.
$\Delta_{i}=\Delta_{y, i}+\left(\theta_{d}-\frac{\phi_{y, w} h_{i n f}}{2}\right) h_{i}$
El valor del giro de diseño $\theta_{d}$ es definido por el diseñador,
generalmente obedece a un cierto nivel de deformaciones
esperadas o desempeño. En este caso se tomó igual a 0.015
o 1.5\%, correspondiente al desplazamiento o drift de techo
esperado para la estructura, de acuerdo a lo definido en el
DS61 (2011).
Características de la Estructura Sustituta
La Tabla 5 resume las propiedades de la Estructura Sustituta
calculadas para cada dirección de análisis, usando las
ecuaciones (1), (2) y (3) expuestas previamente.
Tabla 5: Propiedades de la estructura sustituta
\begin{tabular}{|l|c|c|}
\hline Propiedad & Dirección X & Dirección Y \\
\hline Masa efectiva $m_{e}$, ton & 6127.3 & 6127.3 \\
\hline Altura efectiva $h_{e}, \mathrm{~m}$ & 30.53 & 30.72 \\
\hline Despl. de diseño $\Delta_{\mathrm{d}}, \mathrm{m}$ & 0.39 & 0.38 \\
\hline
\end{tabular} \\ de fluencia $\Delta_{y, i}$ más la deformación no lineal, esta última es
función del giro de diseño $\theta_{d \cdot}$.
$\Delta_{i}=\Delta_{y, i}+\left(\theta_{d}-\frac{\phi_{y, w} h_{i n f}}{2}\right) h_{i}$
El valor del giro de diseño $\theta_{d}$ es definido por el diseñador,
generalmente obedece a un cierto nivel de deformaciones
esperadas o desempeño. En este caso se tomó igual a 0.015
o $1.5 \%$, correspondiente al desplazamiento o drift de techo
esperado para la estructura, de acuerdo a lo definido en el
DS61 (2011).
Características de la Estructura Sustituta
La Tabla 5 resume las propiedades de la Estructura Sustituta
calculadas para cada dirección de análisis, usando las
ecuaciones (1), (2) y (3) expuestas previamente.
Tabla 5: Propiedades de la estructura sustituta
\begin{tabular}{|c|c|c|}
\hline Propiedad & Dirección X & Dirección Y \\
\hline Masa efectiva $m_{e}$, ton & 6127.3 & 6127.3 \\
\hline Altura efectiva $h_{e}, \mathrm{~m}$ & 30.53 & 30.72 \\
\hline Despl. de diseño $\Delta_{d}, \mathrm{~m}$ & 0.39 & 0.38 \\
\hline
\end{tabular} \\ de fluencia $\Delta_{y, i}$ más la deformación no lineal, esta última es
función del giro de diseño $\theta_{d}$.
$\Delta_{i}=\Delta_{y, i}+\left(\theta_{d}-\frac{\phi_{y, w} h_{i n f}}{2}\right) h_{i}$
El valor del giro de diseño $\theta_{d}$ es definido por el diseñador,
generalmente obedece a un cierto nivel de deformaciones
esperadas o desempeño. En este caso se tomó igual a 0.015
o 1.5\%, correspondiente al desplazamiento o drift de techo
esperado para la estructura, de acuerdo a lo definido en el
DS61 (2011).
Características de la Estructura Sustituta
La Tabla 5 resume las propiedades de la Estructura Sustituta
calculadas para cada dirección de análisis, usando las
ecuaciones (1), (2) y (3) expuestas previamente.
Tabla 5: Propiedades de la estructura sustituta
\begin{tabular}{|l|c|c|}
\hline Propiedad & Dirección X & Dirección Y \\
\hline Masa efectiva $m_{e}$, ton & 6127.3 & 6127.3 \\
\hline Altura efectiva $h_{e}, \mathrm{~m}$ & 30.53 & 30.72 \\
\hline Despl. de diseño $\Delta_{\mathrm{d}}, \mathrm{m}$ & 0.39 & 0.38 \\
\hline
\end{tabular} \\ de fluencia $\Delta_{y, i}$ más la deformación no lineal, esta última es
función del giro de diseño $\theta_{d}$.
$\Delta_{i}=\Delta_{y, i}+\left(\theta_{d}-\frac{\phi_{y, w} h_{i n f}}{2}\right) h_{i}$
El valor del giro de diseño $\theta_{d}$ es definido por el diseñador,
generalmente obedece a un cierto nivel de deformaciones
esperadas o desempeño. En este caso se tomó igual a 0.015
o 1.5\%, correspondiente al desplazamiento o drift de techo
esperado para la estructura, de acuerdo a lo definido en el
DS61 (2011).
Características de la Estructura Sustituta
La Tabla 5 resume las propiedades de la Estructura Sustituta
calculadas para cada dirección de análisis, usando las
ecuaciones (1), (2) y (3) expuestas previamente.
Tabla 5: Propiedades de la estructura sustituta
\begin{tabular}{|l|c|c|}
\hline Propiedad & Dirección X & Dirección Y \\
\hline Masa efectiva $m_{e}$, ton & 6127.3 & 6127.3 \\
\hline Altura efectiva $h_{e}, \mathrm{~m}$ & 30.53 & 30.72 \\
\hline Despl. de diseño $\Delta_{\mathrm{d}}, \mathrm{m}$ & 0.39 & 0.38 \\
\hline
\end{tabular} \\ de fluencia $\Delta_{y, i}$ más la deformación no lineal, esta última es
función del giro de diseño $\theta_{d}$.
$\Delta_{i}=\Delta_{y, i}+\left(\theta_{d}-\frac{\phi_{y, w} h_{i n f}}{2}\right) h_{i}$
El valor del giro de diseño $\theta_{d}$ es definido por el diseñador,
generalmente obedece a un cierto nivel de deformaciones
esperadas o desempeño. En este caso se tomó igual a 0.015
o 1.5\%, correspondiente al desplazamiento o drift de techo
esperado para la estructura, de acuerdo a lo definido en el
DS61 (2011).
Características de la Estructura Sustituta
La Tabla 5 resume las propiedades de la Estructura Sustituta
calculadas para cada dirección de análisis, usando las
ecuaciones (1), (2) y (3) expuestas previamente.
Tabla 5: Propiedades de la estructura sustituta
\begin{tabular}{|l|c|c|}
\hline Propiedad & Dirección X & Dirección Y \\
\hline Masa efectiva $m_{e}$, ton & 6127.3 & 6127.3 \\
\hline Altura efectiva $h_{e}, \mathrm{~m}$ & 30.53 & 30.72 \\
\hline Despl. de diseño $\Delta_{\mathrm{d}}, \mathrm{m}$ & 0.39 & 0.38 \\
\hline
\end{tabular}

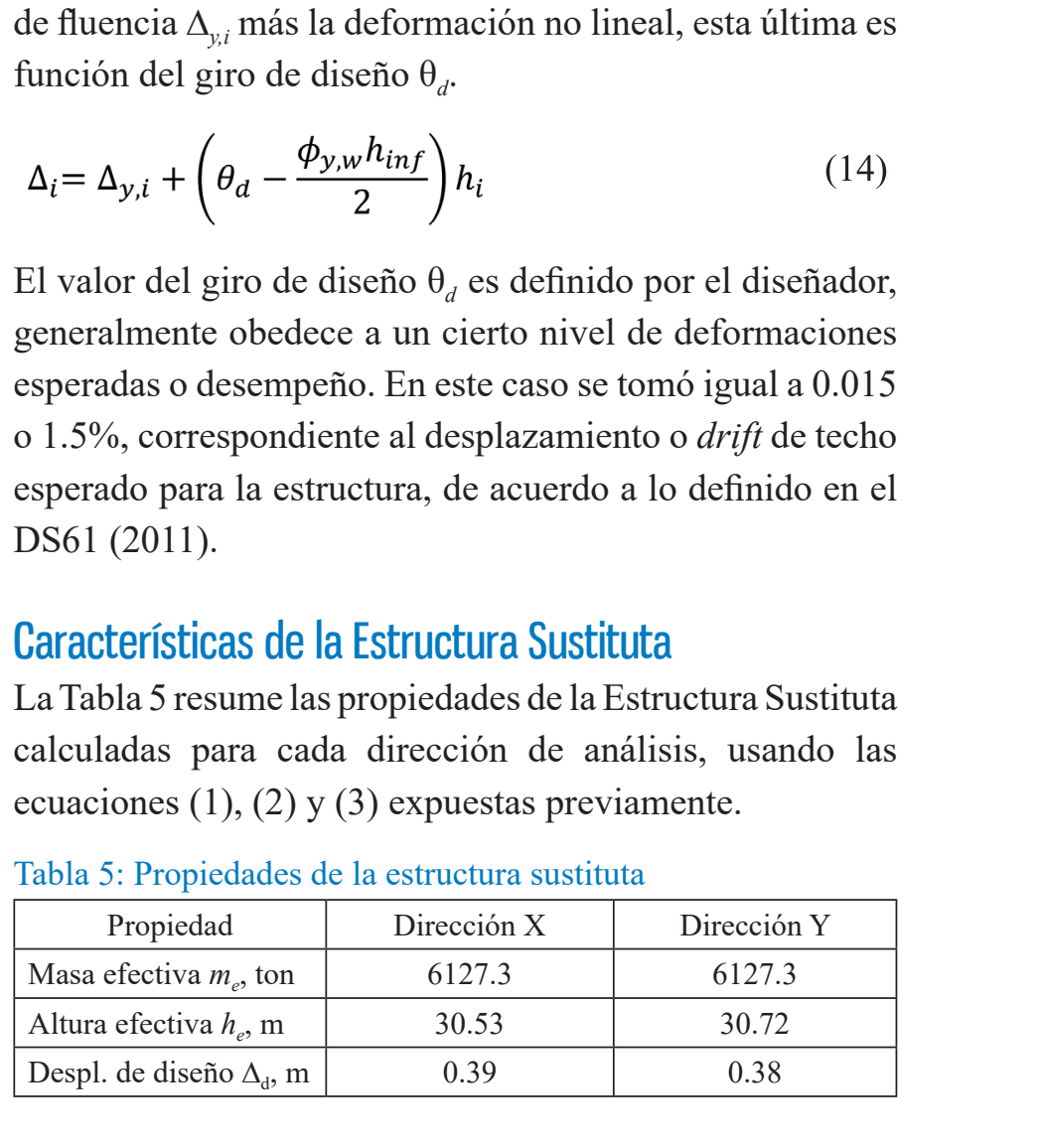

\begin{tabular}{|l|c|c|}
\hline \multicolumn{1}{|c|}{ Propiedad } & Dirección X & Dirección Y \\
\hline Masa efectiva $m_{e}$, ton & 6127.3 & 6127.3 \\
\hline Altura efectiva $h_{e}, \mathrm{~m}$ & 30.53 & 30.72 \\
\hline Despl. de diseño $\Delta_{\mathrm{d}}, \mathrm{m}$ & 0.39 & 0.38 \\
\hline
\end{tabular}

Demandas de ductilidad, amortiguamiento equivalente y período efectivo

Las demandas de ductilidad de desplazamiento sobre los muros pueden estimarse usando las propiedades de la Estructura Sustituta (ver Tabla 5) y la ecuación (15).

$$
\mu_{w}=\frac{\Delta_{d}}{\Delta_{h e, y}}
$$

Donde $\Delta_{h e, y}$ es el desplazamiento de fluencia en la altura efectiva, obtenida a partir del perfil de desplazamiento de fluencia evaluando las ecuaciones (12) o (13) en $h_{e}$, según corresponda. Análogamente, las demandas de ductilidad de desplazamiento para los marcos $\mu_{f, i}$ se obtienen de la ecuación (16), para cada piso $i$-ésimo.

$$
\mu_{f, i}=\left(\frac{\Delta_{i}-\Delta_{i-1}}{h_{i}-h_{i-1}}\right) \frac{1}{\theta_{y, f}}
$$

En la ecuación (16), $\Delta_{i}, \Delta_{i-1}, h_{i}$ y $h_{i-1}$ representan los desplazamientos de diseño y las alturas de los pisos $i$ e $i-1$, respectivamente; $\theta_{y, f}$ es el giro o drift de fluencia de los marcos y puede estimarse con la ecuación (17) propuesta por Priestley (1998). 


$$
\theta_{y, f}=\frac{0.5 l_{b} \varepsilon_{y}}{h_{b}}
$$

Donde $l_{b}$ es el promedio de las longitudes de las vigas y $h_{b}$ es el promedio de la altura de las vigas. Si las vigas tienen la misma resistencia en todos los niveles de la estructura, la demanda de ductilidad de desplazamiento en los marcos puede estimarse como el promedio de todos los niveles (Sullivan et al., 2006).

El amortiguamiento viscoso equivalente del sistema SDOF se determina con las ecuaciones (4), (5) y (6). La Tabla 6 resume los resultados obtenidos para cada dirección de análisis.

Tabla 6: Parámetros y razón de amortiguamiento SDOF

\begin{tabular}{|c|c|c|c|c|c|c|c|}
\hline Dirección & $M_{w}$ & $\mu_{w}$ & $\xi_{w} \%$ & $M_{f}$ & $\mu_{f}$ & $\xi_{f}, \%$ & $\xi_{\text {SDOF }} \%$ \\
\hline $\mathrm{X}$ & 16.72 & 2.8 & 14.1 & 12.96 & 1.37 & $9.1 \%$ & 11.9 \\
\hline $\mathrm{Y}$ & 18.88 & 2.4 & 13.1 & 10.80 & 1.33 & $8.7 \%$ & 11.5 \\
\hline
\end{tabular}

El período $T_{e}$ efectivo del sistema SDOF se obtiene directamente del espectro de desplazamiento para el nivel de amortiguamiento $\xi_{S D O F}$ correspondiente; en este trabajo se utilizó el espectro elástico contenido en el DS61 (2011), definido para $\xi=5 \%$. Por lo tanto, es necesario corregir el espectro elástico de desplazamiento llevándolo a un nivel de amortiguamiento $\xi_{S D O F}$. Para este propósito se usó el factor $\eta$ definido en el Eurocódigo 8 (CEN, 2004) y que se muestra en la ecuación (18).

$$
\eta=\sqrt{\frac{10}{5+\xi_{\text {SDOF }}}} \geq 0.55
$$

Las Figuras 11a y 11b muestran los espectros elásticos de desplazamientos para las direcciones $\mathrm{X}$ e $\mathrm{Y}$, respectivamente. Adicionalmente, las figuras también muestran los espectros para cada nivel de amortiguamiento $\xi_{S D O F}$, el desplazamiento de diseño $\Delta_{d}$ e ilustran la obtención del período efectivo $T_{e}$.

En los gráficos de las Figuras 11a y 11b se ingresa el desplazamiento de diseño en el eje de las ordenadas hasta intersectar el espectro de desplazamiento para el nivel de amortiguamiento correspondiente, en este punto se identifica el período en el eje de las abscisas. Los períodos efectivos para la Estructura Sustituta resultan $2.8 \mathrm{~s}$ y $3.0 \mathrm{~s}$ en las direcciones $\mathrm{X}$ e Y, respectivamente. a)

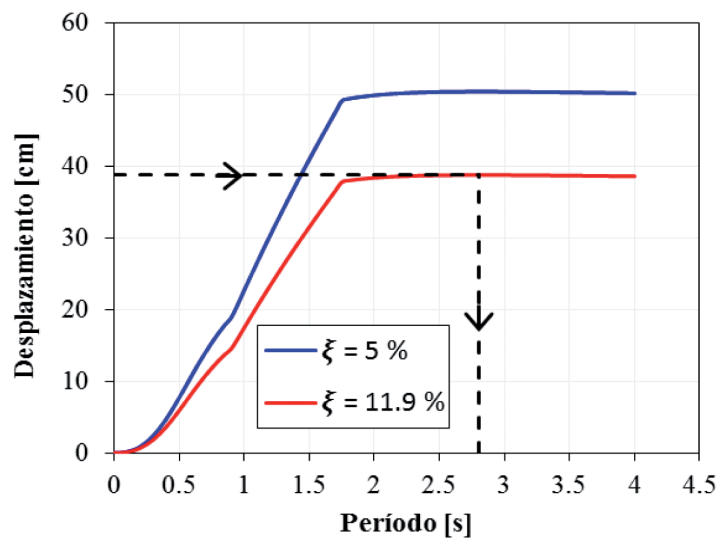

b)

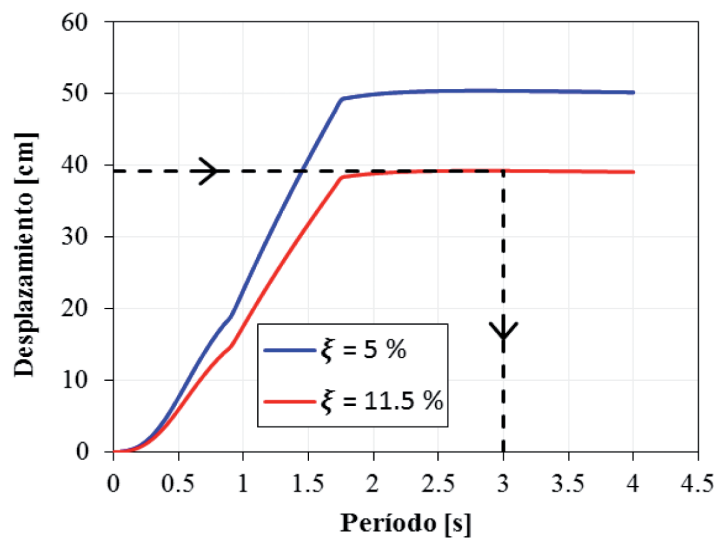

Figura 11: Espectro de desplazamiento (zona 3, suelo tipo D) y período efectivo: (a) dirección X y (b) dirección $\mathrm{Y}$

\section{Corte basal de diseño para el sistema SDOF}

Al tratarse de un sistema de un grado de libertad SDOF, caracterizado por su masa efectiva $m_{e}$, período efectivo $T_{e}$ y desplazamiento de diseño $\Delta_{d}$, resulta evidente que la rigidez efectiva $K_{e}$ y el corte basal de diseño $V_{b}$ pueden determinarse con las ecuaciones (19) y (20), respectivamente.

$$
\begin{aligned}
& K_{e}=4 \pi^{2} \frac{m_{e}}{T_{e}^{2}} \\
& V_{b}=K_{e} \Delta_{d}
\end{aligned}
$$

La Tabla 7 resume el valor de rigidez efectiva y corte basal para la estructura estudiada. Considerando que el peso total de la estructura es aproximadamente $81800 \mathrm{kN}$, los cortes basales representan el $15 \%$ y $12 \%$ del peso del edificio en las direcciones $\mathrm{X}$ e $\mathrm{Y}$, respectivamente.

Tabla 7: Rigidez efectiva y corte basal del sistema SDOF

\begin{tabular}{|c|c|c|c|c|c|c|}
\hline Dirección & $M_{e}$, ton & $T_{e}, \mathrm{~s}$ & $K_{e}, \mathrm{kN} / \mathrm{m}$ & $\Delta_{e}, \mathrm{~m}$ & $V_{b}, \mathrm{kN}$ & $V_{b} / W$ \\
\hline $\mathrm{X}$ & 6127.3 & 2.8 & 30854 & 0.39 & 12016 & 0.15 \\
\hline $\mathrm{Y}$ & 6127.3 & 3.0 & 26507 & 0.38 & 9944 & 0.12 \\
\hline
\end{tabular}


El corte de diseño para esta estructura, de acuerdo a la NCh433 (2009) es de $7880 \mathrm{kN}$ y $6615 \mathrm{kN}$ en las direcciones $\mathrm{X}$ e $\mathrm{Y}$, respectivamente. Para el diseño de los elementos estructurales del edificio, al considerar las combinaciones de carga de la NCh3171 (2017), el corte basal de diseño debe mayorarse por 1.4; en definitiva los cortes basales con los que se diseña son $11032 \mathrm{kN}$ y $9260 \mathrm{kN}$ en la direcciones $\mathrm{X}$ e $\mathrm{Y}$, respectivamente. Estos valores resultan muy cercanos a los obtenidos con el método DDBD, presentados en la Tabla 7. Una comparación detallada del diseño de la estructura en estudio, de acuerdo a la práctica y normativa chilena y al método DDBD, puede hallarse en el trabajo de Morales (2013).

\section{Diseño de elementos de hormigón armado}

En esta sección, más que diseñar los elementos de hormigón armado, se entregan directrices o lineamientos que deben seguirse en el diseño, debido a que el método DDBD considera dentro de sus hipótesis un mecanismo de colapso ideal para los edificios (ver Figura 7). En otras palabras, en el caso de muros, el comportamiento no-lineal o rótulas plásticas debidas a flexión deben estar localizadas en la base. En los marcos, sólo se permite comportamiento nolineal en la base de columnas y en vigas (en la cara de los nudos). Al tratarse de un diseño basado en un sistema SDOF, con una distribución de fuerzas laterales consistentes con el primer modo de vibrar, debe considerarse en el diseño la influencia de los modos superiores de vibrar. Algunas recomendaciones se exponen a continuación en este trabajo.

Para obtener los esfuerzos en muros y marcos, basta multiplicar los valores de momentos y cortes de las Tablas 3 y 4 (calculados para $V_{b}=1$ ) por el corte basal según la dirección de análisis que corresponda (ver Tabla 7). Los esfuerzos en los muros se distribuyen en proporción a su rigidez efectiva, o lo que es equivalente, a $L_{w}^{2}$ (Priestley et al., 2007); las cargas axiales en este caso, al ser muros desacoplados, pueden estimarse usando áreas tributarias. Para garantizar el mecanismo deseado en los muros es fundamental usar envolventes de diseño para momentos y corte, de esta manera se evita la incursión no-lineal fuera de la base de los muros y fallas frágiles; se recomienda diseño al corte por capacidad en muros. Envolventes de diseño, que incluyen la influencia de los modos superiores de vibrar, pueden hallarse en diversos códigos de diseño (Eurocode 8, 2004; NZS 3101, 2006) y en la literatura técnica (Paulay y Priestley, 1992; Priestley et al., 2007; Morales et al., 2019).

Respecto a las vigas, conocido el corte total por piso en los marcos, puede determinarse el momento de cada una con la ecuación (10) y el diseño al corte de las mismas debe hacerse por capacidad, destacando que la resistencia a flexión de las vigas del último piso debe ser la mitad que en los pisos inferiores, de esta forma el corte en los marcos es constante. Los momentos en las columnas se obtienen por equilibrio, considerando el punto de inflexión del diagrama de momento en $0.5 h_{c}$, excepto en el primer piso donde se considera $0.6 h_{c}$ (Priestley et al., 2007). El diseño al corte de las columnas debe desarrollarse por capacidad, considerando efectos de amplificación dinámica debido a la influencia de modos superiores de vibrar, típicamente un factor de amplificación 1.3 arroja resultados adecuados (Sullivan et al., 2012; Morales, 2015). Adicionalmente, es fundamental cumplir el criterio columna fuerte-viga débil.

No se combinan fuerzas sísmicas y gravitacionales, a pesar que algunos códigos lo exigen sin justificación, no se usan factores de mayoración ni de reducción de resistencia, excepto para verificar que la capacidad de los elementos es mayor que la demanda proveniente de la combinación de cargas gravitacionales (Priestley et al., 2007).

Considerando que las dimensiones de los elementos estructurales (muros, columnas y vigas) se mantuvieron constantes para el diseño de acuerdo a la normativa chilena y el método DDBD, resulta interesante comparar los diseños resultantes. La Figura 12 resume las cuantías longitudinales de refuerzo en la sección crítica de muros, columnas y vigas, para cada metodología de diseño. Nótese que la notación usada en el gráfico es la misma mostrada en la Figura 5.

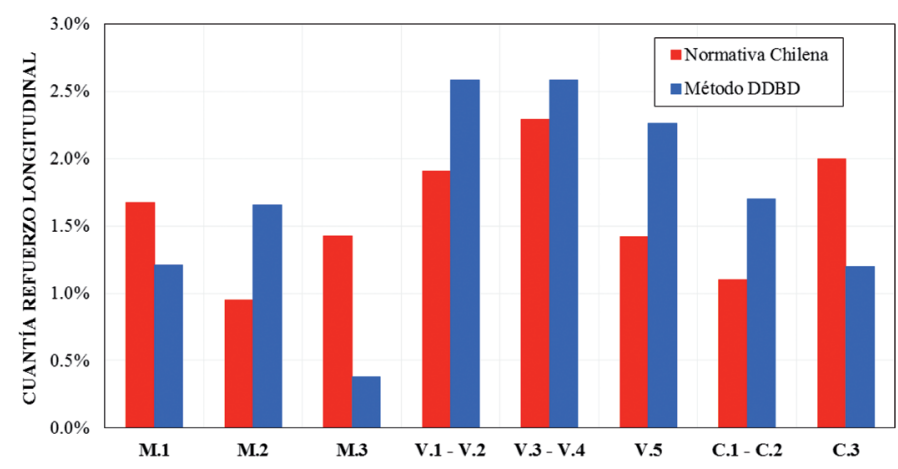

Figura 12: Cuantías longitudinales de refuerzo 
En la Figura 12, al observar las cuantías de refuerzo en los muros, se nota que entre las dos metodologías de diseño no hay una correlación, es decir, queda en evidencia que una de las principales diferencias es la manera en que cada diseño distribuye el esfuerzo total (corte basal de diseño) entre los distintos muros. Mientras la práctica chilena actual distribuye en función de la rigidez inicial elástica de los elementos (o una fracción de ella), el método DDBD utiliza una rigidez consistente con la resistencia nominal a flexión suministrada a los elementos estructurales. Queda en evidencia, además, que en general columnas y vigas requieren mayor cantidad de refuerzo en el método DDBD, lo que implica que la influencia de los marcos en la respuesta de la estructura es mayor que la considerada con el diseño usando la normativa vigente en Chile.

\section{Análisis no lineal tiempo-historia (ANLTH)} Modelo de análisis

El ANLTH se realizó con el programa RUAUMOKO 2D (Carr, 2017), representando el edificio con modelos planos en cada dirección de análisis. La ecuación de movimiento del sistema se resolvió a través del método de Newmark con aceleración constante (Newmark, 1959) bajo el supuesto de pequeños desplazamientos, es decir, se despreciaron efectos de segundo orden como el $P-\Delta$. En cuanto al amortiguamiento, debido a que el modelo clásico de Rayleigh presenta algunos problemas de sobreestimación de las fuerzas viscosas (Chrisp, 1980; Chopra y MacKenna, 2015), se utilizó un modelo que considera una relación lineal entre la razón de amortiguamiento y las frecuencias naturales elásticas del sistema. En este caso, se optó por una razón de amortiguamiento constante igual al 5\% para todo el rango de frecuencias (o todos los modos de vibrar), tal como se recomienda en algunos trabajos (Chopra, 2001; Carr, 2007).

Todos los elementos (vigas, columnas y muros) se modelaron con elementos tipo Giberson beam, en este elemento la no-linealidad se concentra en los extremos, quedando el interior del elemento con propiedades lineales elásticas; la Figura 13 muestra el elemento.

En cada resorte del elemento Giberson beam debe especificarse una longitud de rótula plástica, para calibrar la regla de histéresis, en función del diagrama momentocurvatura de las secciones. La regla de histéresis usada en vigas y columnas fue la de Takeda et al. (1970) con las modificaciones de Otani (1974). Esta curva es ampliamente usada en elementos de hormigón armado y es definida según lo muestra la Figura 14a. La curva de histéresis que se usó para representar el comportamiento de los muros es la tipo SINA tri-lineal (Saiidi y Sozen, 1979), definida en la Figura 14b.

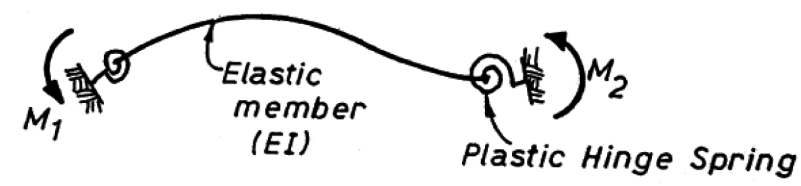

Figura 13: Elemento Giberson beam (Carr, 2017)

a)

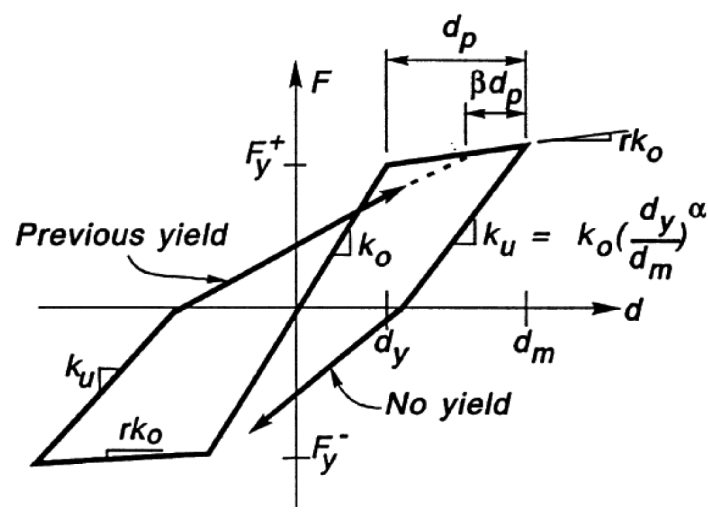

b)

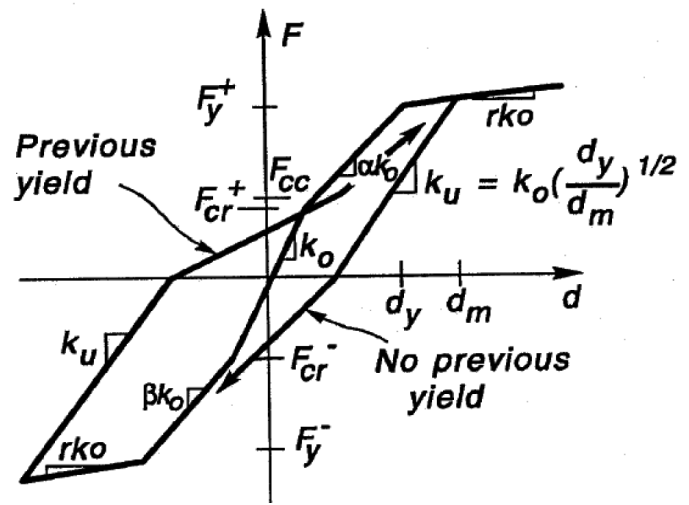

Figura 14: Reglas de histéresis: (a) Takeda modificada y (b) SINA tri-lineal (Carr, 2017)

El ANLTH se desarrolló sólo en la dirección X del edificio en estudio, esta dirección resulta de mayor interés ya que presenta uniones de vigas y muros, a diferencia de lo que ocurre en la dirección Y.

\section{Demanda: registros sísmicos}

Para los ANLTH se consideraron 3 registros sísmicos naturales, todos medidos durante el terremoto del 
Maule (2010) en zona sísmica 3 y suelos tipo D: MargaMarga componente EW (MMEW), Concepción Centro componentes EW y NS (CCEW y CCNS, respectivamente). La Figura 15 muestra sus espectros elásticos de desplazamientos (para $\xi=5 \%$ ) en superposición con el espectro elástico del DS61 (2011).

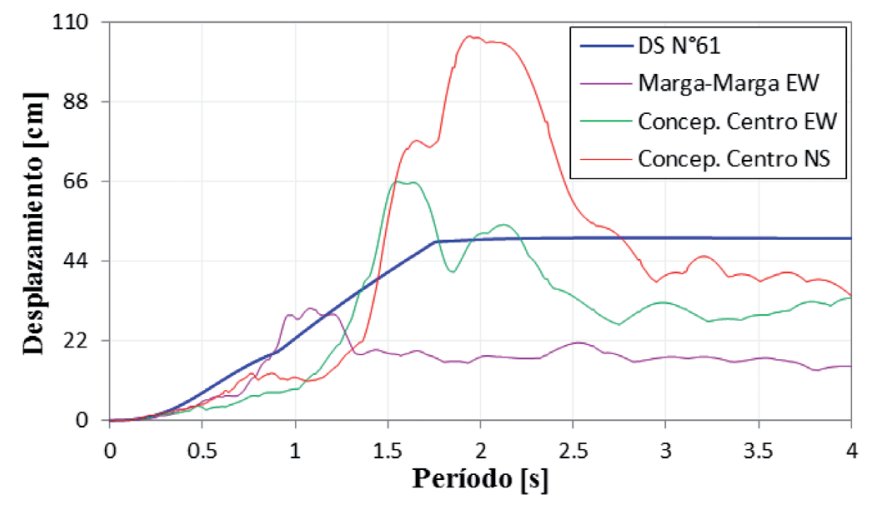

Figura 15: Espectro de desplazamiento para $\xi=5 \%$

\section{Resultados: desplazamientos laterales y drifts de entrepiso}

La Figura 16 muestra los desplazamientos laterales absolutos y relativos de entrepiso, obtenidos con los ANLTH. Las líneas punteadas azules indican los desplazamientos objetivos esperados de acuerdo al diseño con el método DDBD.

Se infiere de la Figura 16 que las mayores demandas de desplazamiento sobre la estructura en estudio ocurren bajo la acción del registro sísmico Concepción Centro componente NS (CCNS), por otro lado, las menores demandas se obtienen con el registro Marga-Marga componente EW (MMEW). En todos los casos, los desplazamientos objetivos esperados de acuerdo al método DDBD no son sobrepasados.

\section{Conclusiones}

Se expusieron las principales deficiencias del método de diseño basado en fuerzas. En paralelo se presentó el método directo basado en desplazamientos (DDBD) para sistemas mixtos de hormigón armado, mostrando su fundamento teórico y detallando paso a paso el procedimiento de análisis a través de su aplicación a un edificio de 12 pisos. El análisis no-lineal tiempo-historia (ANLTH) del edificio demostró que el método DDBD para sistemas mixtos proporciona un muy buen control de deformaciones, a)

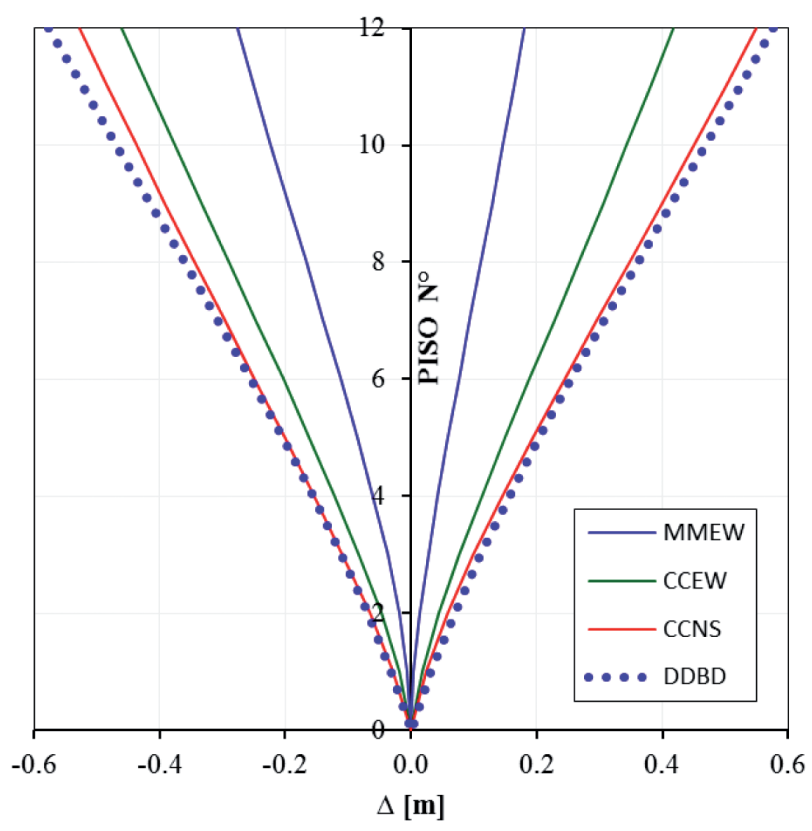

b)

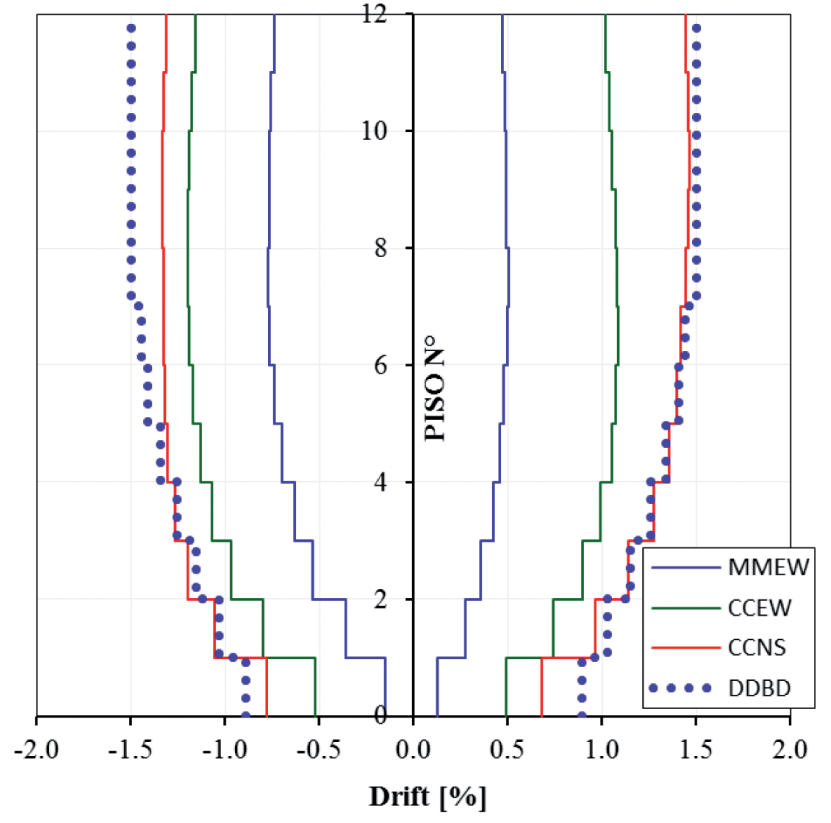

Figura 16: Desplazamientos laterales: (a) absolutos y (b) relativos de entrepiso

relativas de entrepiso y absolutas. Además, la interacción de muros y marcos es representada con éxito.

En cuanto a la limitaciones del método DDBD, las recomendaciones para el cálculo de perfiles de desplazamiento se consideran válidas para muros con relación de aspecto $\left(H_{t} / L_{w}\right)$ mayor que tres. Si el método se aplica a estructuras con muros cuya relación de aspecto es menor, el análisis debe considerar las deformaciones por corte. 
Es fundamental realizar el diseño por capacidad para muros y marcos ya que el método DDBD, al estar basado en un sistema SDOF, no considera directamente la influencia de los modos de vibrar superiores que pueden incrementar las demandas de corte en muros y columnas. En este punto existe una diferencia con el diseño de acuerdo a la práctica chilena, ya que esta última no considera el diseño al corte por capacidad en muros.

El método DDBD asume que el mecanismo de colapso del sistema mixto es con rótulas plásticas en vigas y en la base de elementos verticales (columnas y muros). Para cumplir esta hipótesis el marco debe cumplir el criterio columna fuerte-viga débil. Debido a las características de la estructura estudiada, el análisis no incluyó efectos tridimensionales; sin embargo, con algunas consideraciones particulares, el método DDBD sigue siendo aplicable.

Finalmente, se compararon las cuantías longitudinales de refuerzo en la sección crítica de muros, columnas y vigas. Considerando que los cortes basales de diseño resultaron ser similares si se consideran la normativa vigente en Chile y el método DDBD, se infiere que la principal diferencia entre ambos diseños radica en como se distribuyen los esfuerzos entre los distintos elementos estructurales dentro del edificio. En ese sentido, el método DDBD utiliza una estimación realista ya que la rigidez flexural se estima en función de la capacidad nominal a flexión suministrada a cada elemento, a diferencia de la práctica actual en Chile que considera la rigidez inicial elástica de los elementos (o una fracción de ella).

\section{Agradecimientos}

Se agradece el importante aporte de la Profesora Wendy Wiegand que, con su experiencia y sugerencias, contribuyó a mejorar la calidad de este artículo.

\section{Referencias}

Beyer, K., Simonini, S., Constantin, R. and Rutenberg, A. (2014). Seismic shear distribution among interconnected cantilever walls of different lengths. Earthquake Engineering \& Structural Dynamics 43(10), 1423-1441

Blandon, C.A. and Priestley, M.J.N. (2005). Equivalent viscous damping equations for direct displacement based design. Journal of Earthquake Engineering 9(2), 257-278
Carr, A. (2017). Ruaumoko 2D-dynamic analysis of 2-dimensional in-elastic structures. University of Canterbury, Christchurch, New Zealand

Carr, A. (2007). Ruaumoko Manual - Volume 1: Theory. Department of Civil Engineering, University of Canterbury, Christchurch, New Zealand.

Chrisp, D. (1980). Damping models for inelastic structures. Master's thesis, University of Canterbury, Christchurch, New Zealand Chopra, A.K. (2001). Dynamics of structures. Prentice-Hall, New Jersey, USA

Chopra, A.K. and McKenna, F. (2016). Modeling viscous damping in nonlinear response history analysis of buildings for earthquake excitation. Earthquake Engineering and Structural Dynamics 45(2), 193-211

DS61 (2011). Reglamento que fija el diseño sísmico de edificios y deroga Decreto No 117 de 2010. Decreto Supremo, Ministerio de Vivienda y Urbanismo, Diario Oficial de la República de Chile, $N^{0} 40.133,8-12$.

Eurocode 8 (2004). Design provisions for earthquake resistance of structures - Part 1: General rules, seismic actions and rules for buildings. European Committee for Standardization CEN, Brussels, Belgium

Grant, D.N., Blandon, C.A. and Priestley, M.J.N. (2005). Modelling inelastic response in direct-displacement based design. Research report ROSE - 2005/3, IUSS Press, Pavia, Italy.

Moehle, J.P. (1992). Displacement-based design of RC structures subjected to earthquakes. Earthquake Spectra 8(3), 403-428

Morales, A. (2013). Aplicación del método directo basado en desplazamientos a un sistema mixto de hormigón armado y comparación con práctica Chilena. Actividad de graduación master IEG, P. Universidad Católica de Chile, Santiago, Chile.

Morales, A. (2015). Efectos de la incursión no-lineal de muros en pisos superiores sobre los marcos de sistemas mixtos de hormigón armado. XI Congreso Chileno de Sismología e Ingeniería Sísmica ACHISINA, Santiago, Chile, trabajo $\mathrm{N}^{\circ} 43$

Morales, A., Ceresa, P. and Hube, M. (2019). Seismic shear and moment demands in reinforced concrete wall buildings. $7^{\text {th }}$ International Conference on Computational Methods in Structural Dynamics and Earthquake Engineering, COMPDYN 2019, M. Papadrakakis and M. Fragiadakis (eds.), Crete, Greece. ECCOMAS Proceedia, 4115-4127 
NCh433 (2009). Diseño sísmico de edificios. Norma Chilena Oficial NCh433 Of.96 Mod2009. Instituto Nacional de Normalización INN, Santiago, Chile

NCh3171 (2017). Diseño estructural - disposiciones generales y combinaciones de carga. Norma Chilena Oficial. Instituto Nacional de Normalización INN, Santiago, Chile.

Newmark, N.M. (1959). A method of computation for structural dynamics. Journal of the Engineering Mechanics Division 85(3), 67-94.

NZS 3101 (2006). The design of concrete structures. Standards New Zealand NZS, Wellington, New Zealand

Otani, S. (1974). SAKE-A computer program for inelastic response of $\mathrm{R} / \mathrm{C}$ frames to earthquakes. Civil Engineering Studies, Structural Research Series No. 413, University of Illinois at Urbana-Champaign, Illinois, USA

Panagiotou, M. and Restrepo, J.I. (2011). Displacementbased method of analysis for regular reinforced-concrete wall buildings: application to a full-scale 7-story building slice tested at UC-San Diego. Journal of Structural Engineering 137(6), $677-690$

Paulay, T. and Restrepo, J.I. (1998). Displacement and ductility compatibility in buildings with mixed structural systems. Bulletin of the New Zealand National Society for Earthquake Engineering 11, 7-12

Paulay, T. and Priestley, M.J.N. (1992). Seismic design of reinforced concrete and masonry structures. Prentice Hall

Paulay, T. (2002). A displacement-focused seismic design of mixed building systems. Earthquake Spectra 18(4), 689-718
Priestley, M.J.N. (1998). Brief comments on elastic flexibility of reinforced concrete frames and significance to seismic design. Bulletin of the New Zealand Society for Earthquake Engineering 31(4), 246-259

Priestley, M.J.N. (2003). Myths and fallacies in earthquake engineering, revisited. Rose School report, Pavia, Italy.

Priestley, M.J.N., Calvi, G.M. and Kowalsky M.J. (2007). Displacement-based seismic design of structures. IUSS Press, Pavia, Italy

Rutenberg, A. and Nsieri, E. (2006). The seismic shear demand in ductile cantilever wall systems and the EC8 provisions. Bulletin of Earthquake Engineering 4:1-21

Saiidi, M. and Sozen, M.A. (1979). Simple and complex models for nonlinear seismic response of reinforced concrete structures. Civil Engineering Studies, Structural Research Series No. 465, University of Illinois at Urbana-Champaign, Illinois, USA

Shibata, A. and Sozen, M.A. (1976). Substitute-structure method for seismic design in R/C. Journal of the Structural Division 102(1), 1-18

Sullivan, T.J., Priestley, M.J.N. and Calvi, G.M. (2006). Direct displacement-based design of frame-wall structures. Journal of Earthquake Engineering 10(1), 91-124

Sullivan, T.J., Priestley, M.J.N. and Calvi, G.M. (2012). A model code for the direct displacement-based seismic design of structures. DBD12. IUSS Press, Pavia, Italy

Takeda, T., Sozen, M.A. and Nielsen, N.M. (1970). Reinforced concrete response to simulated earthquakes. Journal of the Structural Division 96(12), 2557-2573 